Running head: SELF-REGULATION DURING COVID-19

\title{
Title: Relating psychiatric symptoms and self-regulation during the COVID-19 crisis
}

Authors: Matilde M. Vaghi ${ }^{1}$, McKenzie P. Hagen ${ }^{1,2}$, Henry M. Jones ${ }^{1,3}$, Jeanette A. Mumford ${ }^{1}$, Patrick G. Bissett ${ }^{1}$, Russell A. Poldrack ${ }^{1}$

${ }^{1}$ Department of Psychology, Stanford University, Stanford, CA, USA

${ }^{2}$ Department of Psychology, Washington State University, Washington, WA, USA

${ }^{3}$ Department of Psychology, University of Chicago, Chicago, IL, USA

\section{Corresponding author}

Correspondence should be addressed to Matilde M. Vaghi (matilde.vaghi@gmail.com)

\begin{abstract}
Disruptions of self-regulation are a hallmark of numerous psychiatric disorders. Here, we examine the relationship between transdiagnostic dimensions of psychopathology and changes in self-regulation in the early phase of the COVID-19 pandemic.

We used data-driven approach on a large number of cognitive tasks and self-reported surveys in training datasets. Then we derived measures of self-regulation and psychiatric functioning in an independent population sample $(\mathrm{N}=102)$ tested both before and after the onset of the COVID-19 pandemic, when the restrictions in place represented a threat to mental health and forced people to flexibly adjust to modifications of daily routines.

We found independent relationships between transdiagnostic dimensions of psychopathology and longitudinal alterations in specific domains of self-regulation defined using the drift diffusion model. Compared to the period preceding the onset of the pandemic, a symptom dimension related to anxiety and depression was characterized by a more cautious behavior, indexed by the need to accumulate more evidence before making a decision. Instead, socialwithdrawal related to faster non-decision processes. Self-reported measures of self-regulation predicted variance in psychiatric symptoms both concurrently and prospectively, revealing the psychological dimensions relevant for separate transdiagnostic dimensions of psychiatry, but tasks did not.

Taken together, our study shows that self-regulation can be affected depending on the interaction between external events and trait-like vulnerabilities and suggests that the study of cognition needs to take into account the dynamic nature of real-world events as well as withinsubject variability over time.
\end{abstract}




\section{Introduction}

The psychological construct of self-regulation broadly refers to a range of abilities that enable flexible and goal-directed behavior. Together with related concepts such as cognitive control and impulsivity, it has been associated to numerous real-world outcomes such as academic performance, health, and economic well-being (Moffitt et al., 2011). Environmental demands such as physiological and psychological stress are thought to impair cognitive functions implicated in self-regulation (Sandi, 2013; Shields, Sazma, \& Yonelinas, 2016). Even though it remains unclear to what degree laboratory manipulations can generalize to real-world stress, a large set of studies have identified the ways in which stress affects self-regulation (Gillan et al., 2020; Otto, Raio, Chiang, Phelps, \& Daw, 2013; Schwabe, Dalm, Schächinger, \& Oitzl, 2008; Schwabe, Dickinson, \& Wolf, 2011; Schwabe \& Wolf, 2010; Shields et al., 2016). Additionally, distortions of self-regulation are a hallmark of numerous psychiatric disorders, including schizophrenia, depression and obsessive-compulsive disorders (Insel et al., 2010). Substantial evidence demonstrates disruption of cognitive constructs relevant for selfregulation (Abramovitch, Abramowitz, \& Mittelman, 2013; Robbins, Vaghi, \& Banca, 2019; Snyder, 2013; Snyder, Kaiser, Warren, \& Heller, 2015; Snyder, Miyake, \& Hankin, 2015) as well as the associated neural circuitry (McTeague et al., 2017; McTeague, Goodkind, \& Etkin, 2016) across several psychiatric conditions.

The outbreak of the SARS-CoV-2 virus causing the COVID-19 pandemic provided an unprecedented opportunity to track the impact of an unfolding crisis on self-regulation, in an ecological fashion, rather than relying on artificial manipulations generally used in laboratory experiments (Goldfarb, 2020). In the early phases of the pandemic, individuals had to adapt quickly to a novel situation and employ a degree of cognitive and behavioral flexibility to adjust to modifications in daily routines and circumstances, due to changes in national behavioral patterns as well as shutdowns of usual day-to-day functioning. Critically, the rapidly evolving situation was also characterized by extreme uncertainty and fear of potential infection, likely to increase perceived stress and anxiety. Regardless of the nature of the disaster, traumatic, natural or environmental crises aggravate depression, posttraumatic stress disorders, as well as substance abuse (Neria, Nandi, \& Galea, 2008). In the case of the COVID-19

pandemic, containment measures implemented to reduce the spread of the virus mainly included social distance and self-isolation, which are known as risk factors for mental health issues (Hawkley \& Cacioppo, 2010). For example, recent work has shown transient volumetric brain change patterns in regions commonly associated with stress and anxiety occurring 
following the initial outbreak of the COVID-19 pandemic. Those changes were associated with the amount of time elapsed from lockdown relief (Salomon et al., 2020).

While extensive research has documented the effect of the pandemic on mental health (Brooks et al., 2020; Di Blasi et al., 2021; Ettman et al., 2020; Loosen, Skvortsova, \& Hauser, 2021; Shafran, Coughtrey, \& Whittal, 2020; Taylor et al., 2020), limited information is currently available on its impact on cognitive mechanisms supposedly relevant for flexible adaptation. Our study set out to examine the role of individual differences in psychiatric symptoms in relation to changes in self-regulation during the early stages of the COVID-19 pandemic. Understanding such consequences can shed light on the vulnerable cognitive mechanisms in the face of real-life stressors. These might exacerbate cognitive alterations for people with underlying psychiatric difficulties.

To address this question, we took advantage of an existing cohort that had been previously examined on a broad battery of self-regulation mechanisms via 37 computer based cognitive tasks as well as 22 self-reported surveys (Eisenberg et al., 2019), providing a baseline for selfregulation before the onset of the pandemic. A subset of these individuals were invited to complete the entire battery again during the unfolding of the initial phase of the pandemic $\left(5^{\text {th }}\right.$ May $2020-11^{\text {th }}$ June 2020), at which point they also provided additional information regarding psychiatric symptomatology. Additionally, on this second occasion, they also reported on their wellbeing and the subjective impact of COVID-19.

Adoption of this large battery overcomes some of the limitations of traditional approaches, which generally rely on selecting a specific task (or a small subset). However, this approach does not account for the possible heterogeneity between patients within a given diagnostic entity. It also leaves untested the hypothesis that deficits observed across different tasks might be due to the same underlying dysfunctional mechanism. Here, we used an extensive multidimensional battery of tasks and self-report surveys that aimed at dissecting and quantifying several constructs associated with self-regulation, rather than focusing on a specific task. In order to identify comprehensive cognitive factors, each capturing specific processes of relevance for successful self-regulation, we used Exploratory Factor Analysis (EFA) on training datasets to derive latent orthogonal dimensions of self-regulation. These have been shown to possess stability over time (Enkavi et al., 2019), overcoming some of the challenges of obtaining robust individual differences from cognitive paradigms (Enkavi et al., 2019; 
Hedge, Powell, \& Sumner, 2018; Saunders, Milyavskaya, Etz, Randles, \& Inzlicht, 2018). Similarly, a dimensional analysis was conducted on psychiatric symptoms questionnaires to uncover transdiagnostic dimensions of psychiatric symptoms (Gillan, Kosinski, Whelan, Phelps, \& Daw, 2016; Rouault, Seow, Gillan, \& Fleming, 2018).

Using scores derived from a dimensional analysis of psychiatric symptoms, we show that core dimensions of psychopathology were related to a differential cognitive response in face of the emerging COVID-19 pandemic. We show that in spite of a statistical relationship between psychiatric symptoms and cognitive tasks, the latter fail to predict substantial variance in psychiatric symptoms, challenging the possibility of using cognitive tasks to predict mental health outcomes. In contrast, the predictive success of self-reported measures of self-regulation revealed the psychological dimensions relevant for separate transdiagnostic dimensions of psychiatry. Overall, these results show that people with high psychiatric traits were characterized by changes in self-regulation cognitive functions during the emergence of the COVID-19 pandemic.

\section{Results}

The results presented derive from our two-step analytical approach (Material and Methods). Briefly, we used data from previously published studies as training datasets to generate datadriven factor structures (Figure 1). Then, factor solutions obtained on the training datasets were used to predict the factor scores of the independent pool of subjects $(\mathrm{N}=102)$ tested twice, in a longitudinal fashion, before (i.e., 2016) and after (i.e., 2020) the onset of the pandemic. This approach avoided biased estimation and allowed the use of factor scores of the testing datasets, which were brought forward for further longitudinal analyses. For longitudinal and crosssectional analyses, significance values were FDR corrected over the number of dependent variables tested within each set of models. 


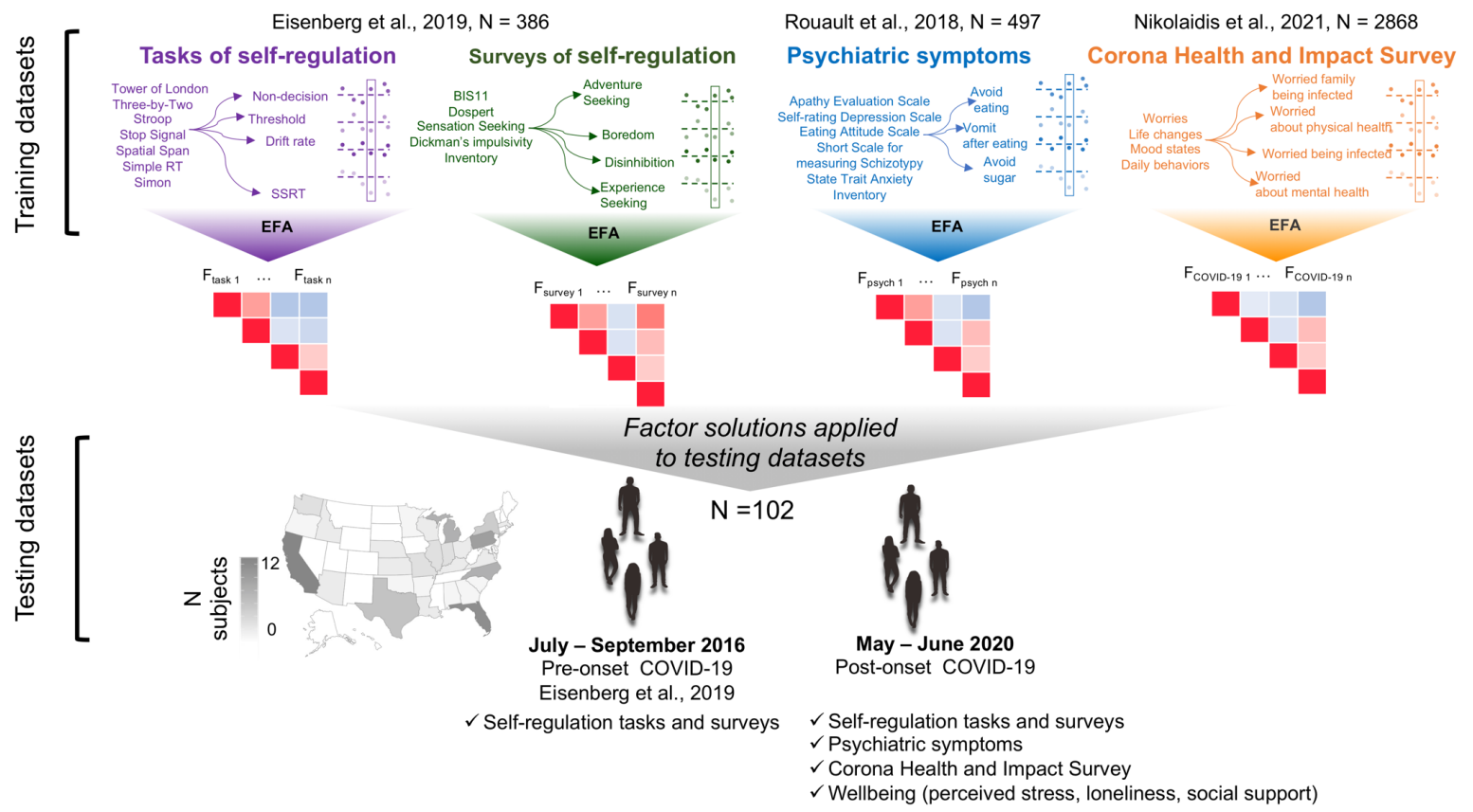

Figure 1. Study design and experimental procedure. We used data from published studies as training datasets. The training datasets included measures of self-regulation (Eisenberg et al., 2019), psychiatric symptoms (Rouault et al., 2018), and impact of the COVID-19 pandemic (Nikolaidis et al., 2021) which were investigated in the current study. We used Exploratory Factor Analysis (EFA) for each set of variables, and we applied the obtained factor solutions to our independent testing datasets. Testing datasets included 102 participants who completed tasks and surveys of self-regulation twice; before (July-September 2016; Eisenberg et al., 2019) and after (May-June 2020) the onset of the COVID-19 pandemic. Data collection after the onset of COVID-19 additionally included a large battery of questionnaires investigating psychiatric symptoms as well as the impact of COVID-19, which was assessed via the Corona Health and Impact Survey (Nikolaidis et al., 2021). Finally, measures of wellbeing (i.e., perceived stress, loneliness, social support) were collected after the onset of COVID19. However, no training dataset was available for this set of measure hence a different analysis pipeline was used (see Material and Methods). Amazon Mechanical Turk was used for data collection. Location of participants in our testing datasets is illustrated on the map.

Exploratory Factor Analysis on training datasets. To identify a latent structure pointing to dissociable factors, we used EFA on each of our training datasets (Figure 1 and Material and Methods). In the case of self-regulation, 61 variables from surveys or 113 variables from tasks reflected means of specific item sets, comparisons between task conditions, or model parameters thought to capture psychological constructs (Figure 1). Similarly, EFA was applied to each of the training datasets pertaining to psychiatric symptoms and to the Corona Health and Impact Survey (CRISIS). For each EFA, overall model fit was satisfactory (RMSEA < .08) (Browne \& Cudeck, 1992) (Supplementary Table 2) and the moderate correlations of the factor scores (Pearson's correlation $<.5$, (Cohen, 1988)) within each training set suggested that they reflected largely independent constructs (Supplementary Figure 5).

A parsimonious latent structure of 4 and 8 factors was identified for tasks and surveys of selfregulation, respectively, based on the Bayesian Information Criterion. Similarly, a 10 factor 
solution was obtained from the CRISIS survey. Finally, 3 psychiatric dimensions were obtained from the set of questionnaires investigating psychiatric symptoms. Interpretation of the obtained factor solutions was based on the strongest individual loadings (Figure 2).

A

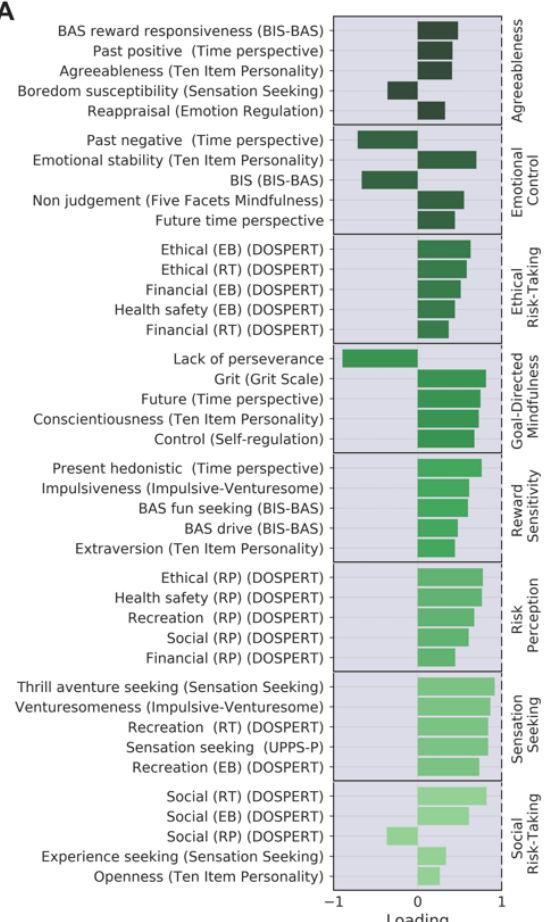

B

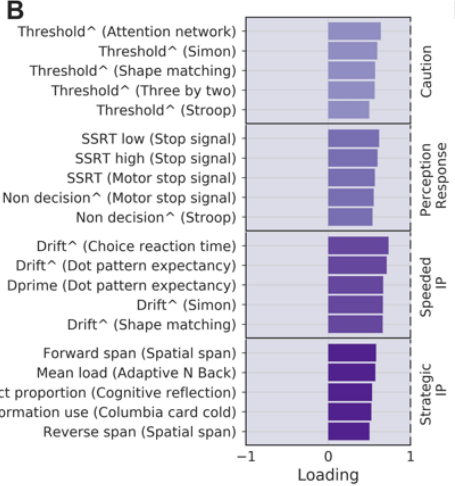

C

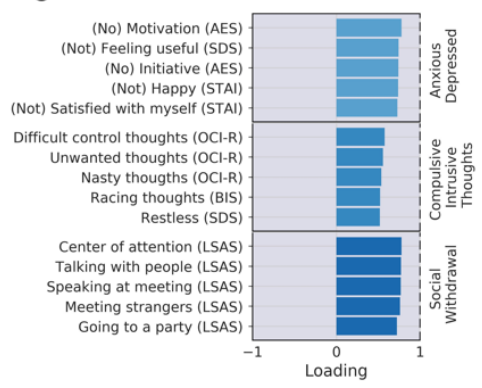

D

Wed about becoming infected Worried family/friends infected Worried about mental health Reading about COVID-19 Quality family relationships Quality friends relationships CVID-19, positive changes
Hopeful CoviD-19 end Changes in contacts with people Concerned about living situation COVID-19, economic difficulty Generally worried Time videogames
Negative thoughts Generally worried Relaxed vs. anxious
Enjoy usual activities Negative thoughts Negative thoughts
Reading about COVID-19 Time on social medial Time of tv media Enjoy usual activities Fidgety / restless
Fanjoy usual activites Fatigued or tired Fatigued or tire
Irritable / angere Able to concentrate / focus Negative thoughts Time outdoors Time spent outside Exercise
COVID-19, positive changes
Time videgames Sleep hours (weekdays) Sleep hours (wekdays) Time videogames Fatigued or tired Enjoy usual activities Bed time (weekends) Bed time (weekdays) Time videogames Lonely
Time of tv media

in social contacts. Stressed stay at home restriction Stressed changes in family contacts Difficulty in following social distan pirculy cancelation or mportant events

Figure 2. Summary of Exploratory Factor Analysis conducted on the training datasets for (A) self-regulation surveys, (B) self-regulation tasks, (C) psychiatric symptoms, (D) Corona Health and Impact survey. For each factor, the 5 items loadings more strongly are shown. The complete matrix of loadings is displayed in the online Jupyter Notebook. The height of the bar reflects the loading. Color codes indicate the subset of variables on which EFA was performed. ${ }^{\wedge}$ indicates a parameter from the Drift Diffusion Modelling. BAS, Behavioral Activation System subscale; BIS, Behavioral Inhbition System subscale; EB, expected benefits subscale; RT, risk taking subscale; RP, risk perception subscale; AES, Apathy Evaluation Scale; SDS, Self-rating Depression Scale; STAI, State Trait Anxiety Inventory; OCI-R, Obsessive Compulsive Inventory Revised; LSAS, Leibowitz Social Anxiety Scale.

Factors for the survey model reflected a combination of closely related variables, deriving from different surveys aimed at measuring overlapping constructs. For example, variables that strongly loaded on the Sensation Seeking factor derived from the Sensation Seeking Scale, the UPPS-P Impulsive Behavior Scale, and the Domain Specific Risk taking scale. In contrast, an heterogenous set of variables determined the nature of a few factors such as in the case of the Emotional Control factor incorporating measures related to emotional stability, future time perspective, eating behavior, and behavioral inhibition. Similarly, the GoalDirected/Mindfulness factor relates to perseverance, grit, conscientiousness, self-control, and 
mindfulness (Figure 2 A). For EFA on self-regulation tasks, Strategic Information Processing (IP) captured high order strategies as variables loading on that factor related to working memory, risk taking, and model-based decision making. In contrast, Speeded IP, Caution, and Perception/Response factors related to speeded decision-making tasks and captured separate parameters estimated using the Drift Diffusion Model (DDM), namely drift rate, threshold, and non-decision time, respectively (Figure $2 \mathrm{~B}$ ).

In agreement with previous work (Gillan et al., 2016; Rouault et al., 2018), the EFA solution for psychiatric questionnaires led to the identification of factors reflecting Anxious-Depression (AD), Compulsive behavior and Intrusive Thoughts (CIT), and Social Withdrawal (SW) phenotype based on the strongest individual item loadings (Figure $2 \mathrm{C}$ ).

The EFA solution on the CRISIS questionnaire isolated 10 factors generally indexing mood (i.e., COVID-19 Worries, General Anxiety, Negative Mood), life-changes (i.e., Changes relationship, Economic concern, Stress life changes), and daily behavior (i.e., Media usage, Physical exercise, Sleep hours, Sleep time) related to the period following the onset of the pandemic (Figure 2 D).

Effect of pandemic outbreak on task-based self-regulation measures. Firstly, we tested the hypothesis that individual differences in psychiatric symptoms related to changes of selfregulation in response to the emergence of COVID-19. To this aim, we used factor scores of self-regulation as dependent variables in the context of linear mixed models, which included transdiagnostic psychiatric dimensions as regressors of interest, while systematically controlling for the effect of age, gender, and IQ (Supplementary Table 3 and Material and Methods).

Longitudinal changes in self-regulation were related to individual differences in transdiagnostic dimensions of psychiatry symptoms. We found that the Anxious-Depression psychiatric factor related to longitudinal changes on the Caution self-regulation task factor ( $\beta$ $\left.[95 \% \mathrm{CI}]=.23[.06, .40] ; P_{\mathrm{unc}}=.01, P_{\mathrm{FDR}}=.04\right)($ Figure 3$)$. In contrast, the Social-Withdrawal psychiatric factor was associated with within-person changes on the Perception/Response selfregulation task factor $\left(\beta[95 \% \mathrm{CI}]=-.30[-.52,-.07] ; P_{\mathrm{unc}}=.01, P_{\mathrm{FDR}}=.04\right)$. We ascertained that these results remained significant even after the exclusion of potential influential cases as 
described in the Methods section (Caution: $\beta[95 \% \mathrm{CI}]_{A D^{*} \text { time }}=.21[.05, .35] ; P_{\mathrm{unc}}=.01, P_{\mathrm{FDR}}$ $=.02$; Perception/Response: $\left.\beta[95 \% \mathrm{CI}]_{S W^{*} \text { time }}=-.31[-.50,-.12] ; P_{\mathrm{unc}}<.001, P_{\mathrm{FDR}}<.001\right)$.

When conditioning on baseline, results confirmed that the Anxious-Depression factor related to longitudinal changes on the Caution factor $\left(\beta[95 \% \mathrm{CI}]=.26[.10, .43] ; P_{\mathrm{unc}}<.001, P_{\mathrm{FDR}}<\right.$ .001). Similarly, there was an effect of the Social-Withdrawal psychiatric factor on longitudinal changes on the Perception/Response factor $\left(\beta[95 \% \mathrm{CI}]=-.26[-.47,-.05] ; P_{\mathrm{unc}}=.02, P_{\mathrm{FDR}}=\right.$ .04). Hence, higher scores on the Anxious-Depression phenotype related to a larger increase in within-subject change over time in cautious responding, where a higher threshold (i.e. more cautious responding) was observed during the pandemic (compared to pre-pandemic). There was also indication that a Social-Withdrawal dimension corresponded to faster stimulus encoding and motor processes during the pandemic. Apart from an effect of these two psychiatric factors, all the other regressors did not have a significant effect on changes in selfregulation, as also shown via equivalence testing (Supplementary Figure 6).

As expected, there were main effects of IQ and age. Higher IQ was associated with better performance on the Strategic IP $\left(\beta[95 \% \mathrm{CI}]=.56[.43, .69] ; P_{\mathrm{unc}}<.001, P_{\mathrm{FDR}}<.001\right)$, and with faster decision time (Speeded IP) $\left(\beta[95 \% \mathrm{CI}]=.33[.19, .48] ; P_{\mathrm{unc}}<.001, P_{\mathrm{FDR}}<.001\right)$. Older age was associated with worse performance on the Strategic IP $(\beta[95 \% \mathrm{CI}]=-.24[-.37$, $\left.-.10] ; P_{\mathrm{unc}}=.001, P_{\mathrm{FDR}}<.001\right)$ and increased Caution $\left(\beta[95 \% \mathrm{CI}]=.24[.06, .42] ; P_{\mathrm{unc}}=.01\right.$, $\left.P_{\text {FDR }}<.02\right)$. 


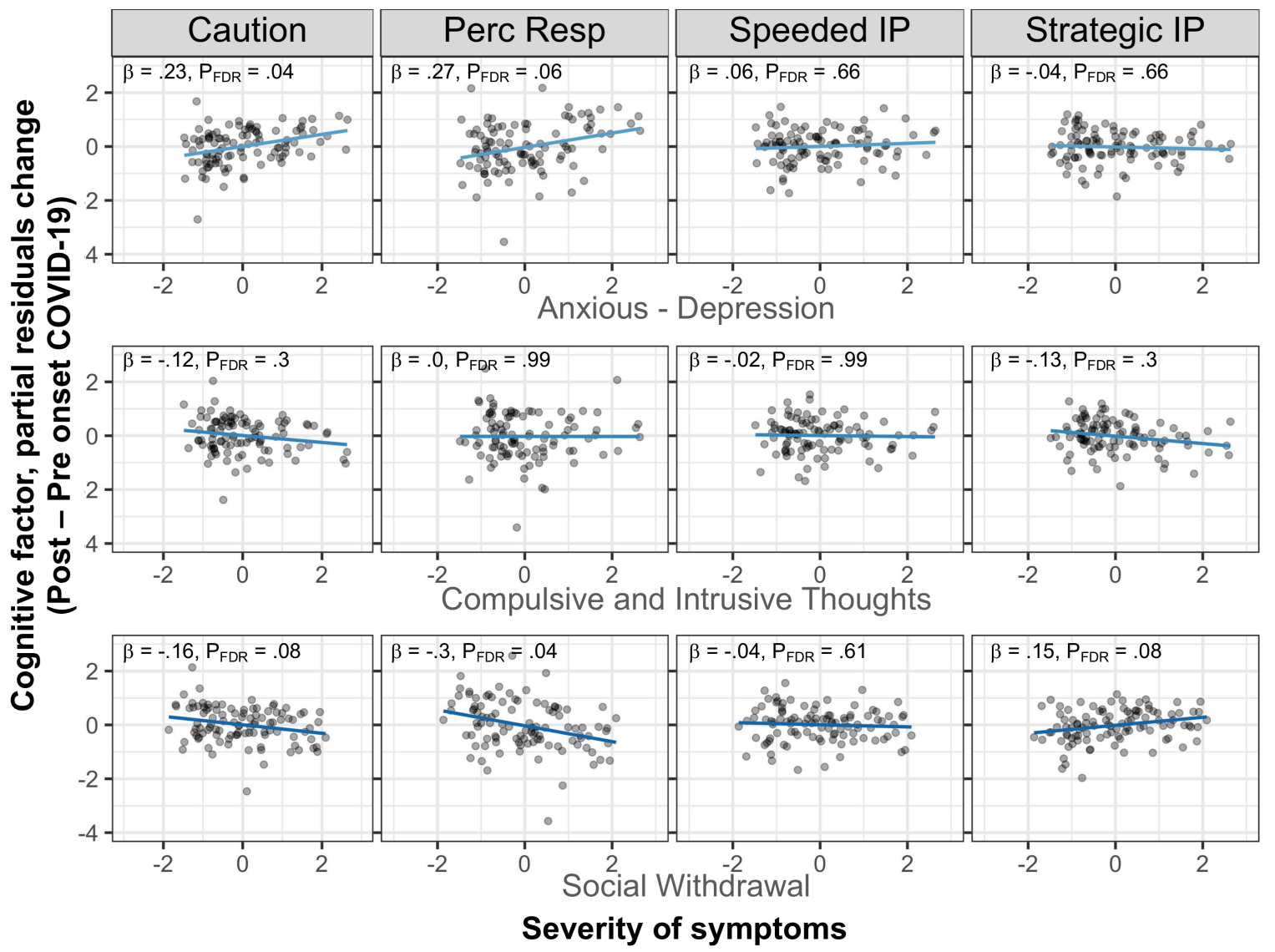

Figure 3. Relationship between psychiatric dimensions and within-subject self-regulation changes. The plots represent within-subject change in cognitive factor from before to after the onset of the pandemic (y axis) in relation to severity of different symptoms dimensions ( $x$ axis). The first, second, third, and fourth column represents within-subject change for the Caution, Perception Response, Speeded IP, Strategic IP factor, respectively. Severity of Anxious-Depression symptoms related to within-subject change in the Caution factor from before to after the onset of the pandemic. Higher values on the Caution factor index the need to accumulate more evidence until a response is executed. Severity of Social-Withdrawal symptoms related to a decrease on the Perception/Response factor after the onset of the pandemic, indexing faster perceptual and motor execution processes. As our outcome measures did not contain any missing data for any subjects, a two stage model can be used for visualization purposes (Verbeke \& Molenberghs, 2000). Firstly, we computed the paired difference for the dependent variable of interest. Then, we fit a linear model to the paired difference. Hence, the partial residuals, controlling for the effect of variables in the model, besides each of the predictor (i.e., AD) were plotted. effect_plot from jtools package in $R$ (Long, 2021) was used for this visualization. The linear relationship between the change score and the psychiatry symptoms displayed here is conceptually identical to the interaction effect of the model described in the main text. All the psychiatric dimensions were entered in the same model, which also controlled for the influence of age, gender, and IQ as explained in the Methods section. P-values reported on the figure refer to the main analysis described in the main text and reported in Supplementary Table 3. P-values for each effect of interest (e.g., interaction effect, AD $x$ Time prepost on Caution) are FDR-corrected for multiple comparisons over the number of dependent variables tested $(N=4)$. We ascertained that FDR-corrected $P$ values remained significant even after the exclusion of potential influential cases as described in the Methods section. All the individual data points are shown in the plots. 
Effect of pandemic outbreak on survey-based self-regulation measures. We used a separate set of models and adopted an approach that mirrored the one used for cognitive factors of selfregulation to test whether pre to post pandemic changes in survey-based self-regulation were moderated by individual differences. As expected given that these measures of self-regulation are thought to index largely stable traits (and consistent with their relatively high retest reliability; Enkavi et al., 2019), the sudden onset of the pandemic did not cause a change on those measures (Supplementary Table 4). Equivalence testing (Material and Methods) confirmed that the effects of the interactions were smaller than the smallest effect of interest (Supplementary Figure 7). In contrast, robust main effects of the transdiagnostic psychiatric symptoms were identified.

Impoverished emotional control could be observed across psychiatric dimensions. Accordingly, higher values on the Anxious-Depression $\left(\beta[95 \% \mathrm{CI}]=-.43[-.56,-.30] ; P_{\text {unc }}<\right.$ $\left..001, P_{\mathrm{FDR}}<.001\right)$, Compulsive $\left(\beta[95 \% \mathrm{CI}]=-.24[-.36,-.13] ; P_{\mathrm{unc}}<.001, P_{\mathrm{FDR}}<.001\right)$, and Social-Withdrawal $\left(\beta[95 \% \mathrm{CI}]=-.41[-.53,-.29] ; P_{\mathrm{unc}}<.001, P_{\mathrm{FDR}}<.001\right)$ psychiatric factor related to lower emotional control. However, selective profiles of self-regulation were also identified for each psychiatric dimension. In particular, the Anxious-Depression factor was significantly associated with lower Goal Directed-Mindfulness $(\beta[95 \% \mathrm{CI}]=-.76[-.93,-.58$; $\left.P_{\mathrm{unc}}<.001, P_{\mathrm{FDR}}<.001\right)$, Agreeableness $\left(\beta[95 \% \mathrm{CI}]=-.50[-.71,-.30] ; P_{\mathrm{unc}}<.001, P_{\mathrm{FDR}}<\right.$ $.001)$, and Risk Perception $\left(\beta[95 \% \mathrm{CI}]=-.34[-.56,-.12] ; P_{\mathrm{unc}}<.001, P_{\mathrm{FDR}}<.001\right)$. In contrast, the Compulsive behavior and Intrusive Thoughts factor was significantly associated with increased Ethical Risk-Taking $\left(\beta[95 \% \mathrm{CI}]=.29[.10, .47] ; P_{\mathrm{unc}}<.001, P_{\mathrm{FDR}}<.001\right)$. Sensation Seeking, Reward Sensitivity and Social Risk-Taking exhibited the reverse relationship with symptom clusters: they were increased in subjects with higher scores on the Compulsive behavior and Intrusive Thoughts factor and decreased in subjects with higher scores on the Social-Withdrawal factor (all $P_{\mathrm{FDR}}<.001$ ). Female gender was related to lower scores on the Emotional Control, Sensation Seeking, and Ethical Risk Taking factors. 
Trajectories of wellbeing related to the pandemic onset. To quantify the dynamics of wellbeing changes as COVID-19 reverberated across the U.S., we asked participants to selfreport their current stress, loneliness, and perceived social support during the emerging phase of the pandemic $\left(5^{\text {th }}\right.$ May $2020-11^{\text {th }}$ June 2020). We also asked the same questions in relation to the period preceding the onset of COVID-19; note that this assumes that memory for previous mental states is unaffected by current mental states. We modelled longitudinal changes in stress, loneliness and perceived social support as a function of demographic characteristics, psychiatric symptoms, and mindset. The non-significant interactions between our variables and time (all $P_{F D R}>.09$, Supplementary Table 5 and Material and Methods) suggested that none of them were associated with longitudinal changes on perceived stress, loneliness, and social support. Equivalence testing (Material and Methods) confirmed that the effects of the interactions were smaller than the smallest effect of interest (Supplementary Figure 8).

Our results also indicated that there was not an effect of the pandemic's onset on wellbeing. In fact, there was not a main effect of time on perceived stress, loneliness, nor social support in the period following the onset of COVID-19, compared to judgments regarding the period preceding the pandemic (all $P_{F D R}>.9$, Figure $\left.4 \mathrm{~A}, \mathrm{C}, \mathrm{E}\right)$.

However these models, which included all three psychiatric factors scores and controlled for age, gender, and mindset attitudes, showed that higher levels of Anxious-Depression ( $\beta$ [95\% $\left.\mathrm{CI}]=.52[.38, .65] ; P_{\mathrm{unc}}<.001, P_{\mathrm{FDR}}<.001\right)$, Compulsive behavior and Intrusive Thoughts $(\beta$ $\left.[95 \% \mathrm{CI}]=.26[.14, .38], P_{\mathrm{unc}}<.001, P_{\mathrm{FDR}}<.001\right)$, and Social-Withdrawal $(\beta[95 \% \mathrm{CI}]=.2$ $\left.[.07, .33], P_{\mathrm{unc}}<.001, P_{\mathrm{FDR}}=.001\right)$ corresponded to increased perceived stress (averaged across both time points) (Figure 4 B). Additionally, an Anxious-Depression symptom dimension was associated with higher loneliness $\left(\beta[95 \% \mathrm{CI}]=.30[.11, .48] ; P_{\mathrm{unc}}<.001=P_{\mathrm{FDR}}<.001\right)$ and diminished perceived social support $\left(\beta[95 \% \mathrm{CI}]=-.52[-.72,-.32] ; P_{\mathrm{unc}}<.001, P_{\mathrm{FDR}}<.001\right)$ (Figure 4 D, F). 
A
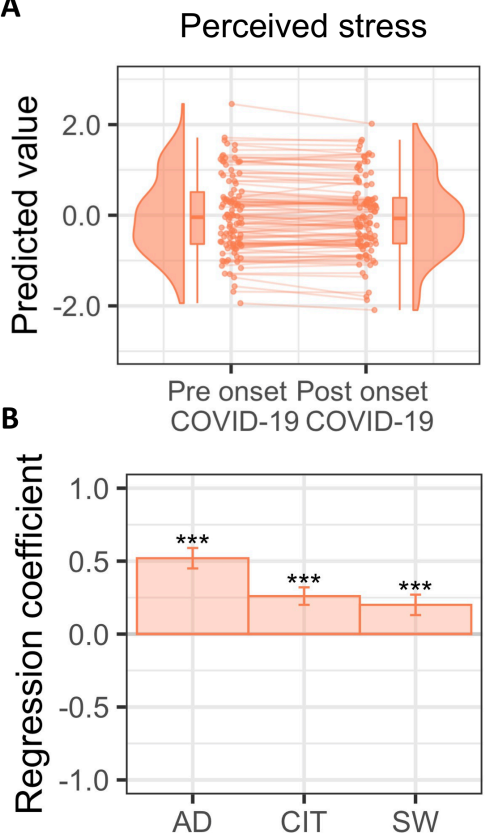

C

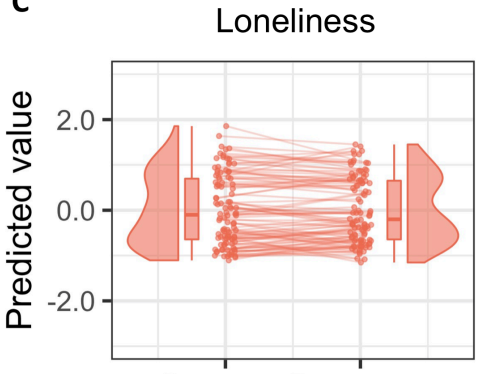

Pre onset Post onset COVID-19 COVID-19

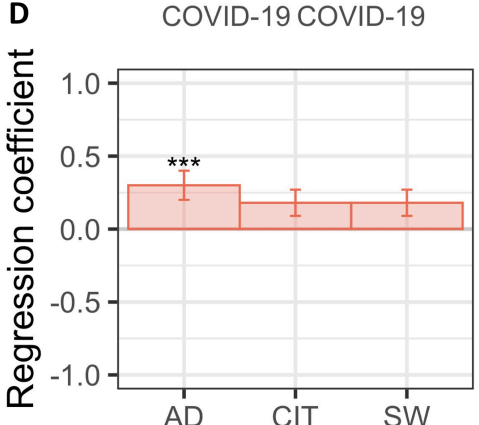

$\mathbf{E}$

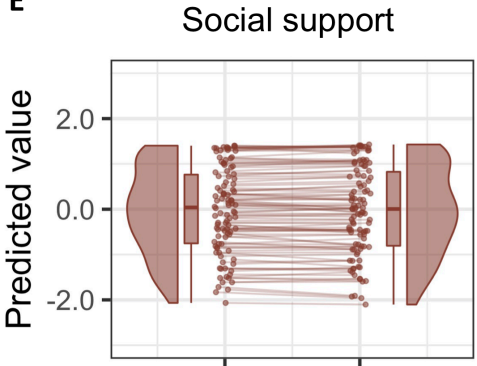

Pre onset Post onset COVID-19 COVID-19

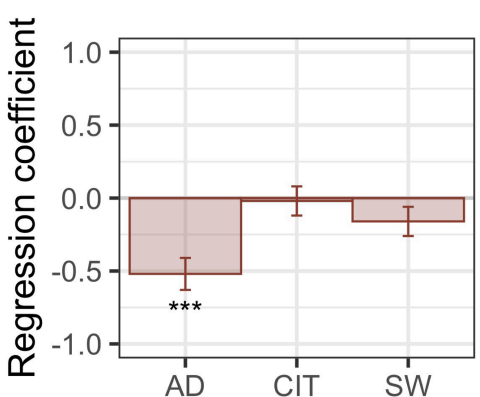

Figure 4. Trajectories of wellbeing in relation to the pandemic onset. A series of longitudinal models was conducted to examine psychological and psychosocial changes in correspondence with the onset of the pandemic. In the top row, predicted values from the respective longitudinal model are shown for each of the dependent variables. Predicted, rather than raw values are shown, to account for the covariates included in the models. The predict function in $R$ was used to obtain the predicted value based on the linear model implemented. (A) perceived stress, $(C)$ loneliness, and (E) social support did not vary as a function of the pandemic onset. In the bottom row, association between (B) perceived stress, (D) loneliness, and $(F)$ social support and each of the psychiatric dimensions is displayed. Higher levels of psychopathology were related to increased perceived stress. Additionally, an AD psychiatric symptom dimension related to increased loneliness and reduced perceived social support. For each dependent variable, all the psychiatric dimensions were entered in the same model, which also controlled for the influence of age, gender, IQ as well as mindset attitudes as explained in the Methods section. Hence, the regression coefficients reflect adjusted values. The $y$ axis indicates the change in the dependent variable for each change of $1 S D$ of symptom scores. Error bars denote $S E$. ** $P_{F D R}<.01$, *** $P_{F D R}<.001 . P_{-}$ values for each effect of interest (e.g., main effect of AD phenotype on perceived stressed) are FDR-corrected for multiple comparisons over the number of dependent variables tested $(N=3)$. AD, Anxious-Depression; CIT, Compulsive behavior and Intrusive Thoughts; SW, Social Withdrawal. See also Supplementary Table 5.

Subjective impact of the pandemic onset. Finally, we aimed at evaluating the subjective impact of the pandemic onset in the context of a cross-sectional analysis using factors derived from the CRISIS questionnaire (Nikolaidis et al., 2021). Namely, each factor score was the dependent variable of a general linear model which included covariates of interest (i.e., demographic characteristics, psychiatric symptoms, and mindset) (Supplementary Table 6). Overall, higher scores on the psychiatric dimensions were associated with several factors from the CRISIS questionnaires, suggesting a negative impact of the pandemic for people with higher psychiatric traits.

More specifically, an Anxious-Depression phenotype was characterized by a worsening of relationships with family and friends $\left(\beta[95 \% \mathrm{CI}]=-.29[-.46,-.12] ; \mathrm{P}_{\text {unc }}=<.001, P_{\mathrm{FDR}}=<\right.$ 
.001). Subjects with high compulsivity traits experienced high COVID-19 related worries (e.g., worries of becoming infected) as well as high stress related to life changes induced by the pandemic (Supplementary Table 6). High Compulsivity was also linked to high economic difficulty, high media usage, and high physical exercise (Supplementary Table 6). Both high Social-Withdrawal and high Compulsivity related to higher values on the general anxiety factor (Supplementary Table 6).

Finally, high negative mood states were found in association with an Anxious-Depression ( $\beta$ $\left.[95 \% \mathrm{CI}]=.31[.22, .41] ; P_{\mathrm{unc}}<.001, P_{\mathrm{FDR}}<.001\right)$, Compulsive behavior and Intrusive Thoughts $\left(\beta[95 \% \mathrm{CI}]=.49[.4, .57] ; P_{\mathrm{unc}}<.001, P_{\mathrm{FDR}}<.001\right)$, and the Social Withdrawal $(\beta$ $\left.[95 \% \mathrm{CI}]=.24[.15, .33] ; P_{\mathrm{unc}}<.001, P_{\mathrm{FDR}}=.001\right)$ psychiatric factor.

Mindset attitude was also associated with the subjective impact of the pandemic. We found that a catastrophic mindset attitude towards the pandemic related to increased COVID-19 worries $\left(\beta[95 \% \mathrm{CI}]=.21[.07, .35] ; P_{\text {unc }}<.001, P_{\mathrm{FDR}}<.001\right)$ as well as reduced sleep hours per night $\left(\beta[95 \% \mathrm{CI}]=-.30[-.44,-.16] ; P_{u n c}=<.001, P_{\mathrm{FDR}}=<.001\right)$. A more positive mindset towards stress related to an improvement of relationships with family and friends during the emergence of the pandemic $\left(\beta[95 \% \mathrm{CI}]=.20[.07, .31] ; P_{u n c}=.001, P_{\mathrm{FDR}}<.001\right)$.

Prediction of psychiatric symptoms. We next sought to assess whether measures of selfregulation can successfully predict psychiatric symptoms during the COVID-19 pandemic. To conduct a preliminary evaluation in this direction, we used factors of self-regulation derived from tasks or surveys to predict transdiagnostic psychiatric dimensions. We used transdiagnostic measures of psychopathology which in other contexts have demonstrated superior value compared to the individual variables from questionnaires of psychopathology (Gillan et al., 2016; Rouault et al., 2018). However, the use of the latter did not change the overall interpretation (Supplementary Table 7-10).

As psychiatric symptoms were assessed after the onset of the pandemic but self-regulation was measured before and after, we could test both the prospective and cross-sectional predictive value of cognitive and personality factors for transdiagnostic dimensions of psychiatry. Namely, to test the prospective predictive value of self-regulation for psychiatric symptoms, we used factor scores related to data collected before the onset of the pandemic as predictive 
features. In contrast, factor scores of self-regulation derived from data collected after the onset of the pandemic were used for cross-sectional predictions.

For each analysis, we created two separate predictive feature matrices including either the 8 survey factor scores or the 4 task factor scores. In sample as well as out-of-sample prediction were assessed to predict psychiatric dimensions of interest. We used L2-regularized linear regression using scikit learn, using an internal crossvalidation loop to select the best hyperparameter. Predictive performance was quantified using $\mathrm{R}^{2}$ (computed using the sum of squares formulation) and mean absolute error (MAE) (note that negative $\mathrm{R}^{2}$ values in this formulation are reflective of predictive model fits that are worse than the sample mean).

Cognitive factors had no predictive ability either prospectively (average cross-validated, $\mathrm{R}^{2}=$ $-.07, \min :=-.07, \max =-.07 ; \mathrm{MAE}=.8, \min =.73, \max =.84$ ) or cross-sectionally (average cross-validated, $\mathrm{R}^{2}=-.06$, min: -.07 , $\max :-.04 ; \mathrm{MAE}=.79, \min =.71, \max =.83$ ). Insample predictive analyses failed to reveal significant association as well (randomization test: $P>.05$ ) (Supplementary Figure 9). Results remained qualitatively unchanged when using the individual cognitive variables to predict psychiatric symptoms.

In contrast to tasks, survey responses were significantly predictive of all transdiagnostic psychiatric dimensions (randomization test: $P<.05$ ) either when considering their prospective (average cross-validated, $\mathrm{R}^{2}=.43$, $\min : .39$, $\max : .48$; $\mathrm{MAE}=.55, \min =.52, \max =.58$ ) as well as their cross-sectional (average cross-validated, $\mathrm{R}^{2}=.54$, min: .49 , max: .6 ; $\mathrm{MAE}=.45$, $\min =.43, \max =.49)$ predictive power (Figure $6 \mathrm{~A}$ ). We visualized the standardized $\beta$ coefficients of the predictive models to create a fingerprint representing the contribution of various self-regulation constructs to the final predictive model for a particular psychiatric dimension. Low correlation between the features included in the model allowed interpretation of the resulting fingerprints (Figure $6 \mathrm{~B}, \mathrm{C}$ ). It is evident that Emotional Control (referring to measures such as emotional stability, behavioral inhibition, and emotional eating) is a relevant dimension for all the psychiatric dimensions. Additionally, the fingerprints point to the contribution of different self-regulation constructs for specific psychiatric dimensions. For instance, while the AD dimension related to a combination of Agreeableness and GoalDirected/Mindfulness, the CIT dimension related to a combination of Reward Sensitivity, Sensation Seeking and Social Risk-Taking. The overall fingerprints (i.e., the contribution of 
each self-regulation construct to each psychiatric dimensions) obtained from prospective (Figure $6 \mathrm{~B}$ ), and cross-sectional predictions (Figure $6 \mathrm{C}$ ) were comparable.

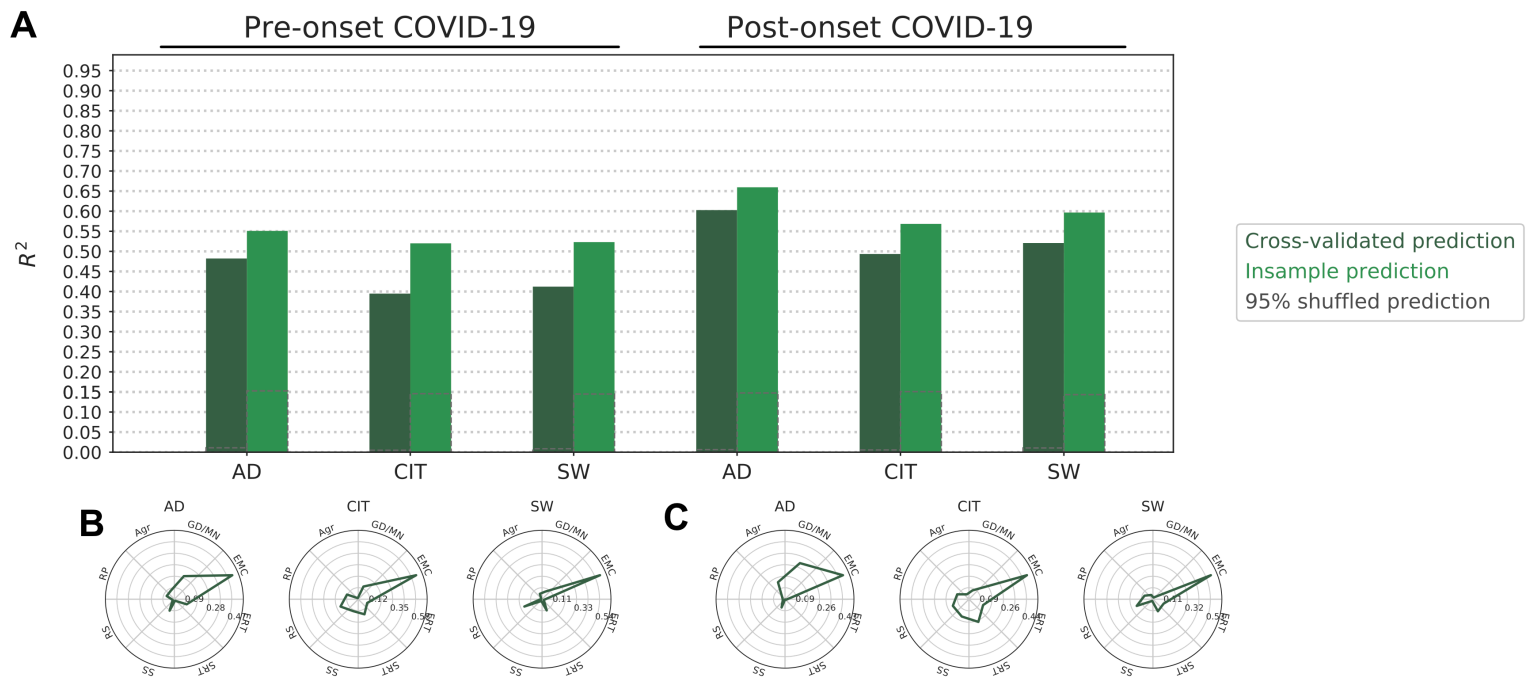

Figure 6. Prediction of psychiatric symptoms dimension using survey factor-scores. (A) Predictions where selfregulation survey-factors scores of the period preceding (pre, prospective) or following (post, cross-sectional) the onset of COVID-19 were used to predict psychiatric symptoms assessed during the initial phase of the COVID19 pandemic. In the bottom row, fingerprints using factor scores of the period preceding $(B)$ or following $(C)$ the onset of the COVID-10 pandemic are displayed. Dark and light bars indicate $R^{2}$ cross-validated and insample prediction respectively. Dashed gray boxes indicate $95 \%$ of null distribution, estimated from 2500 shuffles of the target outcome. Fingerprints displayed as polar plots indicate the standardized $\beta$ for each factor. The $y$-axes are scaled for each fingerprint to highlight the distribution of associations - no inference can be drawn comparing individual factor magnitudes across outcomes. EMC, Emotional Control; GD/MND, Goal-Directed/Mindfulness; Agr, Agreeableness; RP, Risk Perception; RS, Reward Sensitivity; SS, Sensation Seeking; SRT, Social-Risk Taking; ERT, Ethical Risk-Taking; AD, Anxious-Depression; CIT, Compulsive behavior and Intrusive Thoughts ; SW, Social Withdrawal.

Prediction of change in health risk behavior. That survey factor scores could predict different psychiatric dimensions well aligns with previous work. Eisenberg and colleagues (2019) established that survey-derived factors of self-regulation relate not only to mental health broadly defined, but also to other real-world outcomes such as smoking and drug use. Here, we asked participants to answer questions related to their health risk behavior during the emerging phase of the pandemic ( $5^{\text {th }}$ May $2020-11^{\text {th }}$ June 2020). As the same questions were asked to the same participants in 2016 we could test the hypothesis that self-regulation factors referring to the period before the onset of the pandemic could predict changes in health risk behavior. We reasoned that these might have been potentially affected by change in routines and lifestyle due to shelter in place restrictions. We implemented a prediction analysis as the one described above. In this case, our dependent variables were represented by derived measures of change in outcome behavior, obtained as described in the Supplementary Methods. 
Surveys, but not tasks factor scores, exhibited above chance prediction (randomization test: $P$ $<.05$ ) for a few measures (e.g., daily smoking; mental health) (Supplementary Figure 11)

\section{Discussion}

Here, we sought to delineate self-regulation responses in a period that required large-scale behavioral changes. We show that in the initial phase of the COVID-19 pandemic, changes in self-regulation could be observed in relation on trait-like psychiatric symptoms. In this longitudinal study, we administered a large number of cognitive tasks and personality surveys and adopted a data-driven approach to derive orthogonal dimensions of self-regulation and transdiagnostic factors for psychiatric symptoms. To the best of our knowledge, this study represents the most comprehensive assessment of self-regulation abilities during the emergence of the COVID-19 pandemic to date.

Our quantitative approach revealed that an Anxious-Depression psychiatric dimension interacted with the onset of the pandemic and related to changes in the Caution cognitive factor, which captures the threshold parameter from the diffusion drift modelling (DDM) of speeded decision-making tasks. Hence, in those with an Anxious-Depression phenotype, behavior changed in the period after the onset of the pandemic compared to a period preceding the onset of the pandemic and was characterized by accumulating more evidence before making a decision. During decision making tasks, humans can strategically prioritize accuracy or speed, resulting in high or low decision thresholds (Ratcliff \& Rouder, 1998). Accordingly, the threshold parameter can capture the well-known speed-accuracy trade-off in speeded tasks (Wickelgren, 1977). In this context, participants were not explicitly instructed to emphasize speed or accuracy. However, those with an increased values on the Anxious-Depression psychiatric dimension tended towards a more cautious response mode during COVID-19, compared to a period preceding the onset of the pandemic. DDM has been previously applied in affective psychopathology research (Dillon et al., 2015; Lawlor et al., 2020; Pe, Vandekerckhove, \& Kuppens, 2013; Price, Brown, \& Siegle, 2019; Tipples, 2015; White, Ratcliff, \& Vasey, 2016; White, Ratcliff, Vasey, \& McKoon, 2010, 2009), with findings of both increased threshold (Lawlor et al., 2020) and reduced drift rate (Dillon et al., 2015; Lawlor et al., 2020) in patients with depression. That an AD psychiatric symptom dimension was associated with changes in decision threshold is consistent with some of these results where clinical depression relates to higher decision threshold (Lawlor et al., 2020). The examination of a range of cognitive tasks allows generalization of our findings. The Caution factor 
encapsulates threshold parameters from multiple tasks (e.g., Attention Network Task, Simon, Shape matching, Three by two, Stroop) and points to a potentially more cautious mode that can explain behavior seen across different tasks in depression and anxiety.

Additionally, we found that higher Social-Withdrawal was associated with faster stimulus encoding and motor processes in correspondence with the onset of the pandemic. Results accrued in the literature suggest enhanced perceptual processes in social anxiety disorder (McTeague, Shumen, Wieser, Lang, \& Keil, 2011; Mühlberger et al., 2009; Rossignol, Philippot, Bissot, Rigoulot, \& Campanella, 2012). Our results align with these findings and support the hypothesis of an amplification of early sensory attention and the idea of a general hyper-vigilance in phobic patients (Eysenck, 2014), even though previous research mostly related to tasks deploying social stimuli. Overall, our results suggest that situational demands and an increasingly stressful situation could have impacted cognitive functioning, depending on psychiatric dimensions, exacerbating a relationship which could not otherwise be identified before the stresses of the COVID-19 pandemic.

That these processes were impacted under a challenging environmental situation is suggestive of a potentially vulnerable cognitive system in susceptible individuals (Kendler, Karkowski, \& Prescott, 1999). In contrast to our predictions, we found that orthogonal psychiatric dimensions are characterized by impairments in different self-regulation domains. Hence, rather than sharing impairments in common dimensions of self-regulation, specificity can be identified for different psychiatric features. Critically, only the AD and SW dimensions displayed cognitive susceptibility in a period associated with stressful life circumstances, while for example the CIT dimension was spared. This might also point to different pathogenic mechanisms for different class of symptoms. Several social and environmental factors, such as for example natural disasters or low social support, have been robustly identified as elements of risk for major depressive disorder (Lee et al., 2021; Otte et al., 2016). In contrast, no compelling evidence exist on the relationship between psycho-social risk factors and, for example, Obsessive-Compulsive Disorder (Brander, Pérez-Vigil, Larsson, \& Mataix-Cols, 2016).

However, the ability to directly link alterations of cognitive functioning to an increased stressful situation is limited in the current study by lack of evidence in relation to an increase in psychological and psychosocial distress during the outbreak of the pandemic. Retrospective reports were the only viable solution for a set of measures aimed at measuring trajectories of 
wellbeing, as they were not acquired in the first wave of data collection. Due to this methodological limitation, our results might have been driven by biases linked to retrospective reports, which are vulnerable to different distortions. For example, they are influenced by current mood (Parkinson, Briner, Reynolds, \& Totterdell, 1995) and, especially in the case of negative mood states, tend to be exaggerated in retrospective ratings (Sato \& Kawahara, 2011). Nevertheless, several other studies which used different approaches to investigate the trajectory of psychological distress in the period corresponding to the emergence of the pandemic were unable to detect significant changes in psychological and psychosocial function in correspondence of the time period sampled in this study. In a nationwide sample of American adults, no significant mean changes in loneliness were found between January and April 2020 (Luchetti et al., 2020). Similarly, during the seven weeks of strict lockdown in the UK, longitudinal assessments revealed that loneliness levels remained relatively stable $(\mathrm{Bu}$, Steptoe, \& Fancourt, 2020). Google Trends showed that Google searches for loneliness increased in the month leading up to lockdowns in Western Europe but remained high only for the following fortnight, before returning to usual levels (Brodeur, Clark, Fleche, \& Powdthavee, 2020). More generally, longitudinal studies indicated that mental health in UK and USA sample has deteriorated (Daly, Sutin, \& Robinson, 2021; Pierce et al., 2020), but only for a limited period of time. Trajectories over time revealed that although psychological distress rose in the initial stages of the pandemic in the USA (April 2020), they were similar to those measured pre-pandemic by June (Daly \& Robinson, 2021). A similar result was also confirmed by an independent study where the proportion of US individuals reporting serious psychological distress in April 2020 did not significantly differ from that of July 2020 (McGinty, Presskreischer, Anderson, Han, \& Barry, 2020). In USA, a considerable increase in mental health related Google searches was identified in the period immediately preceding the government's disposition (i.e., shelter in place, week March 16 2020), but this quickly stabilized in less than 4 days (Jacobson et al., 2020). Given these multiple tiers of evidence, it is possible that by the time of our data collection (May-June 2020) distress already recovered towards baseline after an initial peak of mental discomfort. A possible untested competing hypothesis is that emerging cognitive difficulties were triggered by increased uncertainty, which is often ill-tolerated in anxiety disorders and depression (Carleton et al., 2012).

Beside changes over time dependent on individual differences in psychiatric dimensions, our results highlighted that older age is associated with an increase in response caution, which is in line with canonical findings of slower decisions in elder people, through an increase in 
response caution and longer non decision time (Ratcliff, Thapar, \& McKoon, 2010). We also identified an association such that higher estimated IQ and younger age related to better Strategic IP, as it has been shown for a host of cognitive tasks measuring high order functions captured by this factor (Arffa, 2007).

Our prediction analysis showed that self-regulation cognitive constructs lack predictive power for psychiatric symptoms. In contrast, surveys of self-regulation predicted psychiatric symptoms moderately well. Previous work has shown the merits of a dimensional view of psychiatry, whereby transdiagnostic psychiatric dimensions capture information over and above the individual constituent scales (Gillan et al., 2016; Rouault et al., 2018). However, in this case, prediction power of cognitive measures was not ameliorated by a dimensional approach and indeed predictive performance of tasks was not significantly different when using transdiagnostic measures for psychiatric symptoms or the traditional individual scores.

Even though cognitive tasks have shown successful predictive performance in the case of political attitudes (Zmigrod, Eisenberg, Bissett, Robbins, \& Poldrack, 2021), lack of predictive power from cognitive tasks is not surprising. Our results mirror and replicate some of previous published work where self-regulation factor scores derived from surveys but not tasks predicted real-world outcomes, including mental health (Eisenberg et al., 2019). Similarly, in a large sample of adolescents, self-reported measures of compulsivity were predictive of longitudinal developmental trajectory of a cognitive measure indexing model-based decision making. In contrast, model-based learning was not predictive of the longitudinal trajectory of symptoms (Vaghi et al., 2020). Formal analytical work has further clarified why tasks might be unsuitable to capture individual differences, as, by construction, they are characterized by low between subject variability (Enkavi et al., 2019; Hedge et al., 2018). The predictive power of tasks might also have been affected by some limitations such as a relatively small sample size as well as the convenient sample recruited via MTurk. However, it is also evident that these factors were not undermining the ability of survey-derived measures to predict psychiatric symptoms.

These results challenge the possibility of relying solely on existing cognitive measures to yield robust predictions for psychiatric symptoms that can be used by clinicians. One likely hypothesis is that psychiatric diseases emerge from multiple causal factors that vary across several units of analysis (i.e., molecular, social, cognitive) (Paulus \& Thompson, 2019). For example reflecting on the ability of cognitive neuroscience in predicting real-world behavior, 
it has been suggested that, on analogy with genetic data where each genetic variant can account for small amount of variance, each of our (neuro)cognitive measures will have small predictive power (Poldrack et al., 2018). Therefore, it might not be possible to assume the superiority of one level as the obvious and unique candidate to explain psychiatric conditions (Kendler, 2012). One implication is that several levels of analysis need to be embraced to reach robust predictions.

Analogous to previous interpretations, successful performance of surveys might be explained by methodological similarities between the tools used to establish the presence of psychiatric symptoms and those to evaluate self-regulation via surveys as both rely on self-report assessment. Additionally, deciding whether a specific instrument is included among those evaluating self-regulation or psychiatric symptoms can be an arbitrary process. For example, in the original study by (Eisenberg et al., 2019) the Barratt Impulsiveness Scale was part of the battery of surveys aimed at investigating constructs of relevance to self-regulation. However, the same questionnaire was used to derive transdiagnostic dimensions of psychiatric symptoms (Gillan et al., 2016; Rouault et al., 2018). Here we avoided circularity by including the Barratt Impulsiveness Scale only in the set of measures to quantify transdiagnostic dimensions of psychiatry. However, it is clear that the boundaries between the two categories are labile.

Our results suggest that self-regulation measures obtained from surveys can be successfully leveraged to predict psychiatric symptoms. Machine learning approaches have already shown the potential for predicting response to specific antidepressant medication simply relying on self-reported symptoms obtained from questionnaires (Chekroud et al., 2016). Here, we showed that transdiagnostic psychiatric dimensions exhibit both uniformity and variability. For example, although emotional control is of relevance across all psychiatric factors, an AD dimension was associated with enhanced agreeableness. In turn, a dimension related to compulsivity was related to sensation seeking and reward sensitivity. This bears on the need to fractionate effectively the components relevant for each psychiatric dimension, in order to understanding its underpinning. Hence, we showed that specific self-reported measures of selfregulation, which have been associated to vulnerability and expression of psychiatric conditions (Ersche, Turton, Pradhan, Bullmore, \& Robbins, 2010), might represent an actionable target for prediction. 
Here, we used an extensive and multidimensional battery aimed at investigating selfregulation, allowing the precise dissection of orthogonal cognitive constructs relevant to successful self-regulation. Critically, a dimensional analysis uncovered a relationship between specific psychiatric phenotypes and parameters linked to decision formation, which were significantly affected concomitantly to naturally occurring stressor. Hence, we showed that cognitive functioning can change over time, possibly depending on the interaction between external events and trait-like vulnerabilities, suggesting that study of cognition needs to take into account the dynamic nature of real-world events as well as within subject variability over time (Poldrack, 2017; Poldrack et al., 2015). Finally, our results challenge the possibility of using cognitive tasks to reach robust prediction and offer insight on different self-regulation constructs which might support the development of intervention based on multiple domains of relevance for specific psychiatric dimensions.

Data availability. The data underlying the analyses of this work, as well as cleaning procedures, analysis code is available at MatildeVaghi/self_regulation_COVID-19. The study pre-registration is available at https://osf.io/ney9v.

\section{Material and Methods}

Data collection. Subjects were recruited through Amazon Mechanical Turk participant tool (MTurk). Testing was administered using the Experiment Factory Platform (Sochat et al., 2016a, 2016b), which enables collection of behavioral measures on MTurk in multiple sessions, as necessitated by our long behavioral battery. Participants were required to finish the entire battery within one week from when they started, but no other restriction was placed on their time. We aimed at identifying longitudinal changes in self-regulation putatively related to challenging real-life events connected to the emergence of the pandemic. Therefore, our participants were recruited from an existing pool of subjects $(\mathrm{N}=522)$ who completed the extensive battery of cognitive tasks and surveys on self-regulation used in this study before the onset of the COVID-19 pandemic (i.e., July-September 2016) (Eisenberg et al., 2019). To this end, we contacted 273 of the participants from the original pool who responded to recent requests of follow-up assessments (Zmigrod et al., 2021), showing appetite for being tested again. Our data collection commenced on $5^{\text {th }}$ May 2020 and ended on $11^{\text {th }}$ June 2020 when the shelter in place order was lifted in all US states (Wikipedia Entry). At the time of data collection, the pandemic was widespread and within this period US states enacted strict regulations to mitigate the spread of the virus, including limitations on social contacts as well 
as travelling. Upon the start of data collection, all the eligible participants were contacted and made aware of the possibility of participating in our follow-up study. Participants expressing their interest in taking part were offered the possibility of being recruited into the study. The majority of the participants who started the study (136 out of 145, 93.8\%) completed the battery suggesting that our measures to keep attrition manageable (Supplementary Material) were effective. The study was approved by the Stanford Institutional Review Board (Protocol number: 55844). All participants taking part in the study confirmed their agreement filling an online informed consent form at the beginning of the study. The data analysis plan was preregistered on the Open Science Framework (https://osf.io/ney9v, with deviations as outlined below).

Measures collected. Our battery for self-regulation mirrored the one used by (Eisenberg et al., 2019) and included 37 behavioral tasks and 22 self-report surveys. Derived variables reflected self-regulation measures such as temporal discounting and impulsivity as well as more generic cognitive domains such as working memory, cognitive flexibility, information processing as further described in the Supplementary Material. Supplementary Table 11 and Supplementary Table 12 give an overview of tasks and surveys of self-regulation as well as the corresponding derived variables. A full description of self-regulation measures is reported in (Eisenberg et al., 2019).

Additionally, we incorporated standard self-report questionnaires specifically investigating a range of psychiatric symptoms. The set of measures aimed at investigating psychiatric symptoms comprised surveys measuring symptoms of depression (Self-Rating Depression Scale, SDS) (Zung, 1965), schizotypy (Short Scales for Measuring Schizotypy, SSS) (Mason, Linney, \& Claridge, 2005), obsessive-compulsive disorder (Obsessive Compulsive Inventory Revised, OCI-R) (Foa et al., 2002), social-anxiety (Leibowitz Social Anxiety Scale, LSAS) (Liebowitz, 1987), generalised anxiety (State Trait Anxiety Inventory, STAI) (Spielberger et al., 1983), apathy (Apathy Evaluation Scale, AES) (Marin, Biedrzycki, \& Firinciogullari, 1991), eating disorder (Eating Attitude Test, EAT-26) (Garner, Olmsted, Bohr, \& Garfinkel, 1982), impulsivity (Barratt Impulsiveness Scale, BIS-11) (Patton, Stanford, \& Barratt, 1995), and alcohol misuse (Alcohol Use Disorder Identification Test, AUDIT) (Saunders, Aasland, Babor, Fuente, \& Grant, 1993). The selection of these surveys was based on previous studies which used these measures to derive parsimonious latent psychiatric dimensions (Gillan et al., 2016; Rouault et al., 2018). These have been characterized in relation to cognitive constructs, 
demonstrating their ability to be meaningfully linked for example to metacognition or goaldirected ability measured via well-controlled cognitive tasks (Gillan et al., 2016; Rouault et al., 2018).

In order to estimate wellbeing changes related to the emerging pandemic we also included selfreport questionnaires measuring loneliness (Short Scale for Measuring Loneliness) (Hughes, Waite, Hawkley, \& Cacioppo, 2004), perceived stress (Perceived Stress Scale) (Cohen, Kamarck, \& Mermelstein, 1983), and perceived social support (Multidimensional Scale of Perceived Social Support) (Zimet, Dahlem, Zimet, \& Farley, 1988). These measures were rated twice, with reference to a period before and after the outbreak of the SARS-CoV-2 virus. Values for each variable (i.e., loneliness, perceived stress, perceived social support) were obtained by summing or averaging the items of the respective questionnaires according to individual survey scoring procedures.

We also used the Corona Health and Impact Survey (CRISIS) (Nikolaidis et al., 2021) which measured "Covid worries" (e.g., how worried have been during the past 2 weeks about infection) "life changes" (e.g., subjective impacts of structural changes such as changes in social contacts), "mood states" (including ten items from the circumplex model of affect) and "daily behaviors" (e.g., frequency of exercise, sleep duration or media use).

Finally, we measured mindset towards the global/societal impact caused by the outbreak of COVID-19 (Zion et al., in prep) and mindset towards stress (Crum, Salovey, \& Achor, 2013) to investigate those as moderators when evaluating the subjective impact of COVID-19.

Training datasets. For measures of self-regulation, our training dataset was composed of data from subjects who completed the battery of tasks and surveys only before the onset of the pandemic $(\mathrm{N}=386)$ (Eisenberg et al., 2019). To obtain a factorial solution for transdiagnostic psychiatric dimensions, we took advantage of publicly available data $(\mathrm{N}=497)$ collected by independent researchers using the same psychiatric questionnaires we included in our study (Rouault et al., 2018). We used a large pool of available data $(\mathrm{N}=2868)$ (Nikolaidis et al., 2021) to derive a factorial solution of the Corona Health and Impact Survey (CRISIS) aimed at investigating several aspects related to the emergence of the pandemic such as worries related to COVID-19 or the subjective impact of life changes associated to it. 
Testing datasets. Data from 102 participants passed quality check criteria which were defined by (Eisenberg et al., 2019) and extended to further screen our participants (Supplementary Material). Hence, our longitudinal analyses were based on data collected on 102 subjects who provided data on self-regulation pre (i.e., 2016) and post (i.e., 2020) the onset of the COVID19 pandemic. Demographic data of subjects included in the training and testing datasets are presented in Supplementary Table 1. The training dataset was representative of the testing datasets in terms of gender, education, relationship status, divorce count as well as proportion of Hispanic/Latino included. Only a minority of subjects reported psychiatric or neurological disorders.

Deviations from pre-registration. Our pre-registration described the use of an empirical normal quantile transformation (QT) to allow variables to comply to a normal distribution. However, after implementing it, we recognized that this led to significant overfitting. Hence, we used a Power Transform (PT), a parametric version of a transformation to Gaussian. We used the Yeo-Johnson transform that works with positive and negative values (Yeo \& Johnson, 2000) as implemented in sklearn. Our PT was fit to the training dataset. The estimate of the optimal parameter was then used to transform variables in the testing datasets.

For psychiatric symptoms, we used a factor analytic approach which was different from the one specified in our pre-registration. As our sample size was expected to be low, providing a relatively low subject-to-variable ratio for a de novo factor analysis for psychiatric symptoms, we originally specified the possibility of combining the training and the testing datasets of psychiatric measures to derive underlying latent structure. Instead, to be consistent with the approach adopted for self-regulation measures, we used EFA on an independent training dataset. The obtained factor solution was used to generate factor structures and fitting models for our testing dataset (see below).

As we wanted to use a two stage model (Verbeke \& Molenberghs, 2000) for visualization purposes and for equivalence testing, our linear mixed models for longitudinal analyses were implemented exactly as we specified in our pre-registration but the regressors included in the models (i.e., age, gender, and IQ) referred to values obtained during the first wave of data collection (i.e., 2016). 
Finally, we tested the predictive power of self-regulation for psychiatric symptoms using data collected after the onset of the pandemic as originally specified. Additionally, we specified another model where data collected before the onset of the pandemic were used to predict psychiatric symptoms. This allowed to investigate the prospective predictive power of selfregulation for psychiatric dimensions.

Selection of self-regulation variables. Procedures for the selection of self-regulation variables and cleaning procedure for both the training and testing datasets are specified in the Supplementary Materials.

Exploratory factor analysis on the training datasets. Recent work conducted on the set of self-regulation variables included in the current study highlighted their relative poor test-retest reliability, especially in the case of tasks (compared to surveys) (Eisenberg et al., 2019; Enkavi et al., 2019). It also suggested that the challenge of obtaining robust individual differences measures can be addressed via factor scores obtained from EFA. The latter proved high stability over time which, for tasks, exceeded the reliability of the constituent variables (fourmonth mean test-retest reliability across factors from tasks: $\mathrm{M}=.82$; surveys: $\mathrm{M}=.86 ; \mathrm{N}=$ 150) (Enkavi et al., 2019). Accordingly, to base our analysis of longitudinal change on robust and reliable measures we relied on factor scores computed as follows. We applied EFA on our training datasets to generate data-driven factor structures to be applied on our testing datasets, avoiding biased estimation in subsequent analyses. Hence, for our longitudinal analyses, factor scores were computed at both testing time points making use of the weight matrix derived from EFA on the training dataset. Therefore, the same linear combination of variables was used to create factors scores for our testing datasets, represented by those participants who completed the battery twice, at different timepoints. Similarly to previous results obtained by Enkavi et al., 2019 factors scores computed at both time points using the same linear combination of constituent variables correlated highly with each other for four task factors $(\mathrm{M}=.70$; min $=$ 0.5 , Perception/Response, $\max =0.8$, Strategic IP $)$ and 8 survey factors $(\mathrm{M}=.83 ; \min =0.76$, Risk Perception, $\max =.91$, Emotional Control).

On all the training datasets, we used maximum likelihood estimation to perform EFA, followed by oblimin rotation to rotate the factors without enforcing orthogonality. Factor scores were estimated using the tenBerge method (ten Berge, Krijnen, Wansbeek, \& Shapiro, 1999). In line with previous investigations, EFA was applied to variables for the self-regulation measures 
(Eisenberg et al., 2019) and at the item-level for psychopathological measures (Gillan et al., 2016; Rouault et al., 2018) and the CRISIS questionnaire (Nikolaidis et al., 2021). All analyses were implemented using the $f a$ function from the psych package in R (Revelle, 2017). In order to determine the number of factors to extract we relied on methods used for each set of variables by previous investigators. For the measures pertaining to self-regulation and in the case of the CRISIS questionnaire, we used the Bayesian Information Criteria (BIC) which selects the number of factors to extract taking into account both model complexity and the ability to capture the data. We extracted 3 factors to obtain transdiagnostic dimensions of psychiatric symptoms as previous studies found that a model with three underlying factors (labelled anxious-depression, compulsive behavior and intrusive thought, and social withdrawal) provided the best account of the covariance for the dataset used here according to the Cattell's criterion (Rouault et al., 2018). Finally, we used predict from the psych package in $\mathrm{R}$ to estimate factor scores on our testing datasets, based on the EFA solution on the training ones.

Similarly to previous results obtained on a larger sample $(\mathrm{N}=522)$ (Eisenberg et al., 2019), which included part of the data used here as a training dataset $(\mathrm{N}=386)$, we observed a low correlation between variables derived from tasks and surveys of self-regulation (Supplementary Figure 1 A). Additionally, neither measurement set could predict variables from the other set (Supplementary Figure 1 B). Therefore, based on previous and current findings, surveys and tasks variables were treated independently for separate EFAs. A parsimonious latent structure of 4 and 8 factors was identified for tasks and surveys, respectively (Supplementary Figure 2). The number of factors identified diverged slightly from the original solution (Eisenberg et al., 2019), due to our reduced sample as well as a slightly different pre-processing pipeline which resulted in fewer selected variables. For example, previous results already showed that temporal discounting variables clustered on their own (Eisenberg et al., 2019). However, our pre-processing pipeline led to removal of those variables as they remained skewed after our PT and outlier removal (see Data Cleaning and Imputation in Supplementary Material). Therefore, as expected, the Discounting factor was not identified in our solution.

Interpretation of the obtained factor solutions for each training dataset was based on the strongest individual loadings. A summary of the highest factor loading is presented in Figure 2 and the loadings for each variables on each factor are displayed in the online Jupyter Notebook. In the case of self-regulation interpretation was also informed by the correlation 
between the variables loadings from the factor solution obtained in the larger sample of 522 subjects (Eisenberg et al., 2019), relating to data partially overlapping to those included in our testing dataset $(\mathrm{N}=386)$. Both in the case of self-regulation factors derived from tasks (Supplementary Figure 3) and surveys (Supplementary Figure 4), there was high concordance between individual variables loading on each factor. The only exception was represented by the Goal-Directedness and Mindfulness factors. They were independent in the original solution obtained in the bigger sample but lumped in our training dataset.

EFA solution for questionnaires of self-reported psychiatric symptoms led to the identification of the Anxious-Depression (AD), Compulsive behavior and Intrusive Thoughts (CIT), and Social Withdrawal (SW) dimensions, based on the strongest individual item loadings and in agreement with previous work (Gillan et al., 2016; Rouault et al., 2018). While the items from the scale aimed at measuring social-anxiety mostly loaded on the SW factor, a more heterogeneous factor structure was observed for the $\mathrm{AD}$ and $\mathrm{CIT}$ dimensions. Items from scales measuring apathy (Marin et al., 1991), depression (Zung, 1965) and generalised anxiety (Spielberger et al., 1983) related to an AD dimension. Instead CIT captured items from the Obsessive Compulsive Inventory Revised (OCI-R) (Foa et al., 2002), the Barratt Impulsiveness Scale (BIS-11) (Patton et al., 1995), and the Eating Attitude Test (EAT-26) (Garner et al., 1982), which are employed to measure out of control behaviors, traditionally characterizing disorders of compulsivity.

10 factors were identified by EFA on the CRISIS questionnaire (Nikolaidis et al., 2021). Questions on daily behaviors clustered in separate factors related to Media usage, Physical exercise, Sleep Hours, Sleep time. Questions related to life changes were separated into a factor capturing the Stress induced by life changes due to the pandemic, Changes in relationship and Economic concern. Finally a set of factors related to the emotional responses to the pandemic captured General anxiety, Negative Mood, and COVID-19 worries (Figure 2). These factor scores were used in the context of linear models aimed at investigating the role of demographic characteristics (i.e., age and gender), psychiatric symptoms, and mindset attitudes towards aspects related to the COVID-19 pandemic. Ime4 (Bates, Mächler, Bolker, \& Walker, 2015) packages in R was used and significance values were FDR corrected over the number of the dependent variables tested $(\mathrm{N}=10)$. 
Longitudinal analysis. We employed linear mixed models to examine longitudinal changes of self-regulation. Factors scores estimated on our testing datasets from the EFA solution on the training ones represented our dependent variables. We used lme4 (Bates et al., 2015) and lmerTest (Kuznetsova, Brockhoff, \& Christensen, 2017) packages in R. In all these model time was coded as -.5 (pre-covid) / .5 (post-covid), so that the main effects for between-subjects covariates reflect the average time effect. Further, between-subject variables were mean centered and scaled by the standard deviation, so parameters estimates for these variables reflect changes in standard deviation units and the main effect of time and intercept refer to the average value of the between-subject variables. All statistical tests were two-sided. Significance values were FDR corrected over the number of dependent variables tested within each set of models (factors from self-regulation tasks $\mathrm{N}=4$; factors from self-regulation surveys $\mathrm{N}=8$ ).

Our linear mixed models used factor scores on each of the task $(\mathrm{N}=4)$ and survey $(\mathrm{N}=8)$ selfregulation factors as dependent variables. For each factor, each subject had a value that related to data collected before or after the onset of the pandemic. By including the interaction with Time prepost covid the models tested if each of the psychiatric factor related to the amount of longitudinal changes in self-regulation, while controlling for age, IQ, and gender (coded as male: 0; female: 1). In the syntax of the lmer function in $\mathrm{R}$, the regressions were:

$$
\begin{aligned}
& \text { Self-regulation }{ }_{\mathrm{i}} \sim \\
& \left(\text { Age }+ \text { Gender }+I Q+\text { Psych }_{A D}+\text { Psych }_{C I T}+\text { Psych }_{S W}\right) * \text { Time }_{\text {pre/post covid }}+\left(1 \mid \text { Subj }_{)}\right.
\end{aligned}
$$

All models successfully converged and QQ plots were inspected for each of them. To test the robustness of our findings and in order to ascertain that results were not driven by influential observations, we used the influence.ME package in R (Nieuwenhuis, Grotenhuis, \& Pelzer, 2012), providing tests for detecting whether single cases affect the level of significance of an estimate in generalized mixed effects models. Accordingly, each of our model was estimated and influence was used subsequently to obtain information on how removing observations iteratively changed the parameter estimates. Then, we used cook.distance to calculate standardized measures of influence. An observation with a Cook's Distance larger than three times the mean Cook's Distance was regarded as an influential case, in line with common recommendations. All the results deemed significant in our original models and presented in the manuscript were unaffected by the exclusion of influential cases. 
When the results of the interactions were statistically significant, we also evaluated changes in self-regulation using an analysis of covariance conditioning on baseline to confirm that our results were not due to the specific analytical approach adopted. In this set of analyses, we used the self-regulation factor score following the onset of COVID-19 as dependent variable with the baseline measurement (i.e., self-regulation before the onset of COVID-19) as covariate together with Age, Gender, IQ and each of the psychiatric factors (Vickers \& Altman, 2001).

In order to be able to declare absence of meaningful effects of the interactions included in our models we applied equivalence testing (Lakens, Scheel, \& Isager, 2018; Walker \& Nowacki, 2011). Our outcome measures did not contain any missing data for any subjects, hence a two stage model can be used to produce the results of the mixed models (Verbeke \& Molenberghs, 2000). To improve interpretability of the equivalence test measure, we used this two stage approach by computing a paired difference for the dependent variable of interest of each model, and calculating its partial correlation with the regressors of interest. The interpretation of these partial correlations and their inferences match that of the interaction terms in the mixed model. Hence, we calculated the $90 \%$ CI using a standard Fisher's Z transformation based CI on the estimated partial correlations. If the $90 \% \mathrm{CI}$ was included within the boundaries for the medium cut off (i.e., -0.3, 0.3) (Field, 2013), the effect was deemed smaller than the smallest effect of interest, hence equivalent to a null result (Supplementary Figure 6-8).

In a separate set of models, the dependent variables were represented by the self-reported scores of perceived stress, loneliness, and reduced social support, with reference to period preceding or following the onset of the pandemic. The models were equivalent to the ones specified for self-regulation but mindset towards stress and on whether the pandemic was subjectively perceived as a catastrophe were included to ask if they affected longitudinal changes on wellbeing measures. Significance values were FDR corrected over the number of dependent variables tested $(\mathrm{N}=3)$.

$$
\begin{gathered}
\text { Wellbeing }_{i} \sim \\
\left(\text { Mindset stress }+ \text { Mindset pandemic }+ \text { Psych }_{A D}+\text { Psych }_{C I T}+\text { Psych }_{S W}+\text { Age }+ \text { Gender }\right) * \\
\text { Time pre/post covid }+(1 \mid \text { Subj })
\end{gathered}
$$

Prediction analyses. As we identified a relationship between transdiagnostic dimensions of psychopathology and measures of self-regulation, we sought to understand if factor scores from tasks or surveys could be used as features to predict psychiatric symptoms. Separate analyses 
were conducted to evaluate the perspective or cross-sectional power of self-regulation by using task and survey factor scores referring to the period preceding or following the onset of COVID-19, respectively. In the primary prediction analyses, transdiagnostic factors of psychopathology were predicted. Complementary analyses were conducted by using the individual variables obtained from each separate questionnaire investigating psychiatric symptoms as targets of the prediction analysis. Prior to running the prediction analysis, a linear regression was used to regress age, gender and IQ out of each of predicted variables, being either a transdiagnostic factor or an individual variable of psychopathology. We used a ridge regression, availing of scikit-learn with built-in cross-validation capabilities to select the best hyper-parameter. Ridge regression was preferred over lasso due to its desirable regularization properties. In fact sparse feature selection is not necessary for interpretability with so few predictors. Additionally, interpretability of feature weights was improved due to the low correlation between the features included in the model. We used both insample and crossvalidated prediction, using the same fitting models. For insample predictions, the models were fitted to the whole dataset and tested on the same dataset. In contrast, cross-validation was performed using a balanced 10-fold procedure, fitting each model with 91 or 92 participants and testing on the 11 or 10 left out participants. The insample and cross-validated predictions were correlated with the actual target variables (i.e., transdiagnostic factor scores or individual variables from psychiatric questionnaires) to obtain $\mathrm{R}^{2}$. Mean Absolute Error (MAE) was computed analogously. Cross-validated and insample predictions are shown in Supplementary Tables 9 - 10. We also created an empirical null distribution of prediction success by shuffling the target outcomes and repeating the prediction 2500 times. 95\% prediction success is shown in all prediction plots and is used as a significance cut off $(\mathrm{P}<.05)$.

The same procedure was adopted to test if self-regulation could predict changes in health risk behavior. In this additional prediction analysis, tasks and survey factor scores from the period preceding the onset of COVID-19 were used as features to predict change in health risk behavior from the from the period preceding the onset of COVID-19 to the one following it. A description of how change in health risk behavior was computed is provided in the Supplementary Methods. 
Running head: SELF-REGULATION DURING COVID-19

Acknowledgements. We thank Vanessa Sochat for developing the Experiment Factory infrastructure and Ross Otto for his assistance while collecting data. We also thank Romy Lorenz for helpful discussions. M.M.V is supported by a Human Frontier Science Program Fellowship (LT000751/2019-L). 


\section{References}

Abramovitch, A., Abramowitz, J. S., \& Mittelman, A. (2013). The neuropsychology of adult obsessive-compulsive disorder: A meta-analysis. Clinical psychology review, 33(8), $1163-1171$.

Arffa, S. (2007). The relationship of intelligence to executive function and non-executive function measures in a sample of average, above average, and gifted youth. Archives of clinical neuropsychology: the official journal of the national academy of neuropsychologists, 22(8), 969-978.

Bates, D., Mächler, M., Bolker, B., \& Walker, S. (2015). Fitting Linear Mixed-Effects Models Using lme4. Journal of statistical software, 67(1), 1-48.

ten Berge, J. M. F., Krijnen, W. P., Wansbeek, T., \& Shapiro, A. (1999). Some new results on correlation-preserving factor scores prediction methods. Linear algebra and its applications, 289(1), 311-318.

Brander, G., Pérez-Vigil, A., Larsson, H., \& Mataix-Cols, D. (2016). Systematic review of environmental risk factors for Obsessive-Compulsive Disorder: A proposed roadmap from association to causation. Neuroscience and biobehavioral reviews, 65, 36-62.

Brodeur, A., Clark, A. E., Fleche, S., \& Powdthavee, N. (2020). Assessing the impact of the coronavirus lockdown on unhappiness, loneliness, and boredom using Google Trends. ArXiv:2004.12129.

Brooks, S. K., Webster, R. K., Smith, L. E., Woodland, L., Wessely, S., Greenberg, N., et al. (2020). The psychological impact of quarantine and how to reduce it: rapid review of the evidence. The lancet, 395(10227), 912-920.

Browne, M. W., \& Cudeck, R. (1992). Alternative Ways of Assessing Model Fit. Sociological methods \& research, 21(2), 230-258. SAGE Publications Inc.

Bu, F., Steptoe, A., \& Fancourt, D. (2020). Loneliness during a strict lockdown: Trajectories and predictors during the COVID-19 pandemic in 38,217 United Kingdom adults. Social science \& medicine, 265, 113521.

Carleton, R. N., Mulvogue, M. K., Thibodeau, M. A., McCabe, R. E., Antony, M. M., \& Asmundson, G. J. G. (2012). Increasingly certain about uncertainty: Intolerance of uncertainty across anxiety and depression. Journal of anxiety disorders, 26(3), 468479.

Chekroud, A. M., Zotti, R. J., Shehzad, Z., Gueorguieva, R., Johnson, M. K., Trivedi, M. H., et al. (2016). Cross-trial prediction of treatment outcome in depression: a machine learning approach. The lancet psychiatry, 3(3), 243-250.

Cohen, J. (1988). Statistical Power Analysis for the Behavioral Sciences (2nd ed.). New York: Routledge.

Cohen, S., Kamarck, T., \& Mermelstein, R. (1983). A global measure of perceived stress. Journal of health and social behavior, 24(4), 385-396. US: American Sociological Assn.

Crum, A. J., Salovey, P., \& Achor, S. (2013). Rethinking stress: the role of mindsets in determining the stress response. Journal of personality and social psychology, 104(4), 716-733.

Daly, M., \& Robinson, E. (2021). Psychological distress and adaptation to the COVID-19 crisis in the United States. Journal of psychiatric research, 136, 603-609.

Daly, M., Sutin, A. R., \& Robinson, E. (2021). Depression reported by US adults in $2017-$ 2018 and March and April 2020. Journal of affective disorders, 278, 131-135.

Di Blasi, M., Gullo, S., Mancinelli, E., Freda, M. F., Esposito, G., Gelo, O. C. G., et al. (2021). Psychological distress associated with the COVID-19 lockdown: A two-wave network analysis. Journal of affective disorders, 284, 18-26. 
Dillon, D. G., Wiecki, T., Pechtel, P., Webb, C., Goer, F., Murray, L., et al. (2015). A computational analysis of flanker interference in depression. Psychological medicine, 45(11), 2333-2344. Cambridge University Press.

Eisenberg, I. W., Bissett, P. G., Enkavi, A. Z., Li, J., MacKinnon, D. P., Marsch, L. A., et al. (2019). Uncovering the structure of self-regulation through data-driven ontology discovery. Nature communications, 10(1), 2319.

Enkavi, A. Z., Eisenberg, I. W., Bissett, P. G., Mazza, G. L., MacKinnon, D. P., Marsch, L. A., et al. (2019). Large-scale analysis of test-retest reliabilities of self-regulation measures. Proceedings of the national academy of sciences, 116(12), 5472-5477.

Ersche, K. D., Turton, A. J., Pradhan, S., Bullmore, E. T., \& Robbins, T. W. (2010). Drug addiction endophenotypes: impulsive versus sensation-seeking personality traits. Biological psychiatry, 68(8), 770-773.

Ettman, C. K., Abdalla, S. M., Cohen, G. H., Sampson, L., Vivier, P. M., \& Galea, S. (2020). Prevalence of Depression Symptoms in US Adults Before and During the COVID-19 Pandemic. JAMA network open, 3(9), e2019686.

Eysenck, M. (2014). Anxiety and Cognition: A Unified Theory. London: Psychology Press.

Field, A. (2013). Discovering Statistics Using IBM SPSS Statistics. SAGE.

Foa, E. B., Huppert, J. D., Leiberg, S., Langner, R., Kichic, R., Hajcak, G., et al. (2002). The obsessive-compulsive inventory: development and validation of a short version. Psychological assessment, 14(4), 485-496.

Garner, D. M., Olmsted, M. P., Bohr, Y., \& Garfinkel, P. E. (1982). The eating attitudes test: psychometric features and clinical correlates. Psychological medicine, 12(4), 871878.

Gillan, C. M., Kosinski, M., Whelan, R., Phelps, E. A., \& Daw, N. D. (2016). Characterizing a psychiatric symptom dimension related to deficits in goal-directed control. ELife, 5, e11305.

Gillan, C. M., Vaghi, M. M., Hezemans, F. H., van Ghesel Grothe, S., Dafflon, J., Brühl, A. B., et al. (2020). Experimentally induced and real-world anxiety have no demonstrable effect on goal-directed behaviour. Psychological medicine, 1-12.

Goldfarb, E. V. (2020). Participant stress in the COVID-19 era and beyond. Nature reviews neuroscience, 21(12), 663-664. Nature Publishing Group.

Hawkley, L. C., \& Cacioppo, J. T. (2010). Loneliness Matters: A Theoretical and Empirical Review of Consequences and Mechanisms. Annals of behavioral medicine : a publication of the society of behavioral medicine, 40(2).

Hedge, C., Powell, G., \& Sumner, P. (2018). The reliability paradox: Why robust cognitive tasks do not produce reliable individual differences. Behavior research methods, 50(3), 1166-1186.

Hughes, M. E., Waite, L. J., Hawkley, L. C., \& Cacioppo, J. T. (2004). A Short Scale for Measuring Loneliness in Large Surveys: Results From Two Population-Based Studies. Research on aging, 26(6), 655-672.

Insel, T., Cuthbert, B., Garvey, M., Heinssen, R., Pine, D. S., Quinn, K., et al. (2010). Research Domain Criteria (RDoC): toward a new classification framework for research on mental disorders. American journal of psychiatry, 167(7), 748-751.

Jacobson, N. C., Lekkas, D., Price, G., Heinz, M. V., Song, M., O’Malley, A. J., et al. (2020). Flattening the Mental Health Curve: COVID-19 Stay-at-Home Orders Are Associated With Alterations in Mental Health Search Behavior in the United States. JMIR mental health, 7(6).

Kendler, K. S. (2012). Levels of explanation in psychiatric and substance use disorders: implications for the development of an etiologically based nosology. Molecular psychiatry, 17(1), 11-21. 
Kendler, K. S., Karkowski, L. M., \& Prescott, C. A. (1999). Causal Relationship Between Stressful Life Events and the Onset of Major Depression. American journal of psychiatry, 156(6), 837-841. American Psychiatric Publishing.

Kuznetsova, A., Brockhoff, P. B., \& Christensen, R. H. B. (2017). lmerTest Package: Tests in Linear Mixed Effects Models. Journal of statistical software, 82(1), 1-26.

Lakens, D., Scheel, A. M., \& Isager, P. M. (2018). Equivalence Testing for Psychological Research: A Tutorial. Advances in methods and practices in psychological science, 1(2), 259-269. SAGE Publications Inc.

Lawlor, V. M., Webb, C. A., Wiecki, T. V., Frank, M. J., Trivedi, M., Pizzagalli, D. A., et al. (2020). Dissecting the impact of depression on decision-making. Psychological medicine, 50(10), 1613-1622.

Lee, S. L., Pearce, E., Ajnakina, O., Johnson, S., Lewis, Glyn, Mann, F., et al. (2021). The association between loneliness and depressive symptoms among adults aged 50 years and older: a 12-year population-based cohort study. The lancet psychiatry, 8(1), 4857. Elsevier.

Liebowitz, M. R. (1987). Social phobia. Modern problems of pharmacopsychiatry, 22, 141173.

Long, J. A. (2021, March 12). Analysis and Presentation of Social Scientific Data [R package jtools version 2.1.3]. Comprehensive R Archive Network (CRAN).

Loosen, A. M., Skvortsova, V., \& Hauser, T. U. (2021). Obsessive-compulsive symptoms and information seeking during the Covid-19 pandemic. Translational psychiatry, 11(1), 1-10. Nature Publishing Group.

Luchetti, M., Lee, J. H., Aschwanden, D., Sesker, A., Strickhouser, J. E., Terracciano, A., et al. (2020). The trajectory of loneliness in response to COVID-19. The american psychologist, 75(7), 897-908.

Marin, R. S., Biedrzycki, R. C., \& Firinciogullari, S. (1991). Reliability and validity of the Apathy Evaluation Scale. Psychiatry research, 38(2), 143-162.

Mason, O., Linney, Y., \& Claridge, G. (2005). Short scales for measuring schizotypy. Schizophrenia research, 78(2-3), 293-296.

McGinty, E. E., Presskreischer, R., Anderson, K. E., Han, H., \& Barry, C. L. (2020). Psychological Distress and COVID-19-Related Stressors Reported in a Longitudinal Cohort of US Adults in April and July 2020. JAMA, 324(24), 2555.

McTeague, L. M., Goodkind, M. S., \& Etkin, A. (2016). Transdiagnostic impairment of cognitive control in mental illness. Journal of psychiatric research, 83, 37-46.

McTeague, L. M., Huemer, J., Carreon, D. M., Jiang, Y., Eickhoff, S. B., \& Etkin, A. (2017). Identification of Common Neural Circuit Disruptions in Cognitive Control Across Psychiatric Disorders. American journal of psychiatry, 174(7), 676-685.

McTeague, L. M., Shumen, J. R., Wieser, M. J., Lang, P. J., \& Keil, A. (2011). Social vision: sustained perceptual enhancement of affective facial cues in social anxiety. NeuroImage, 54(2), 1615-1624.

Moffitt, T. E., Arseneault, L., Belsky, D., Dickson, N., Hancox, R. J., Harrington, H., et al. (2011). A gradient of childhood self-control predicts health, wealth, and public safety. Proceedings of the national academy of sciences, 108(7), 2693-2698. National Academy of Sciences.

Mühlberger, A., Wieser, M. J., Herrmann, M. J., Weyers, P., Tröger, C., \& Pauli, P. (2009). Early cortical processing of natural and artificial emotional faces differs between lower and higher socially anxious persons. Journal of neural transmission, 116(6), 735-746. 
Neria, Y., Nandi, A., \& Galea, S. (2008). Post-traumatic stress disorder following disasters: a systematic review. Psychological medicine, 38(4), 467-480. Cambridge University Press.

Nieuwenhuis, R., Grotenhuis, M. te, \& Pelzer, B. (2012). influence.ME: Tools for Detecting Influential Data in Mixed Effects Models. The r journal, 4(2), 38-47.

Nikolaidis, A., Paksarian, D., Alexander, L., Derosa, J., Dunn, J., Nielson, D. M., et al. (2021). The Coronavirus Health and Impact Survey (CRISIS) reveals reproducible correlates of pandemic-related mood states across the Atlantic. Scientific reports, 11(1), 8139. Nature Publishing Group.

Otte, C., Gold, S. M., Penninx, B. W., Pariante, C. M., Etkin, A., Fava, M., et al. (2016). Major depressive disorder. Nature reviews disease primers, 2, 16065.

Otto, A. R., Raio, C. M., Chiang, A., Phelps, E. A., \& Daw, N. D. (2013). Working-memory capacity protects model-based learning from stress. Proceedings of the national academy of sciences of the united states of america, 110(52), 20941-20946.

Parkinson, B., Briner, R. B., Reynolds, S., \& Totterdell, P. (1995). Time Frames for Mood: Relations between Momentary and Generalized Ratings of Affect. Personality and social psychology bulletin, 21(4), 331-339. SAGE Publications Inc.

Patton, J. H., Stanford, M. S., \& Barratt, E. S. (1995). Factor structure of the barratt impulsiveness scale. Journal of clinical psychology, 51(6), 768-774.

Paulus, M. P., \& Thompson, W. K. (2019). The Challenges and Opportunities of Small Effects: The New Normal in Academic Psychiatry. JAMA psychiatry, 76(4), 353-354.

Pe, M. L., Vandekerckhove, J., \& Kuppens, P. (2013). A diffusion model account of the relationship between the emotional flanker task and rumination and depression. Emotion (washington, d.c.), 13(4), 739-747.

Pierce, M., Hope, H., Ford, T., Hatch, S., Hotopf, M., John, A., et al. (2020). Mental health before and during the COVID-19 pandemic: a longitudinal probability sample survey of the UK population. The lancet psychiatry, 7(10), 883-892.

Poldrack, R. A. (2017). Precision Neuroscience: Dense Sampling of Individual Brains. Neuron, 95(4), 727-729.

Poldrack, R. A., Laumann, T. O., Koyejo, O., Gregory, B., Hover, A., Chen, M.-Y., et al. (2015). Long-term neural and physiological phenotyping of a single human. Nature communications, 6 .

Poldrack, R. A., Monahan, J., Imrey, P. B., Reyna, V., Raichle, M., Faigman, D., et al. (2018). Predicting violent behavior: What can neuroscience add? Trends in cognitive sciences, 22(2), 111-123.

Price, R. B., Brown, V., \& Siegle, G. J. (2019). Computational Modeling Applied to the DotProbe Task Yields Improved Reliability and Mechanistic Insights. Biological psychiatry, Cortical Mechanisms in Schizophrenia and Autism, 85(7), 606-612.

Ratcliff, R., \& Rouder, J. N. (1998). Modeling Response Times for Two-Choice Decisions. Psychological science, 9(5), 347-356. SAGE Publications Inc.

Ratcliff, R., Thapar, A., \& McKoon, G. (2010). Individual differences, aging, and IQ in twochoice tasks. Cognitive psychology, 60(3), 127-157.

Revelle, W. R. (2017). psych: Procedures for Personality and Psychological Research.

Robbins, T. W., Vaghi, M. M., \& Banca, P. (2019). Obsessive-Compulsive Disorder: Puzzles and Prospects. Neuron, 102(1), 27-47.

Rossignol, M., Philippot, P., Bissot, C., Rigoulot, S., \& Campanella, S. (2012).

Electrophysiological correlates of enhanced perceptual processes and attentional capture by emotional faces in social anxiety. Brain research, 1460, 50-62.

Rouault, M., Seow, T., Gillan, C. M., \& Fleming, S. M. (2018). Psychiatric Symptom Dimensions Are Associated With Dissociable Shifts in Metacognition but Not Task 
Performance. Biological psychiatry, Translating Biology to Treatment in Schizophrenia, 84(6), 443-451.

Salomon, T., Cohen, A., Barazany, D., Ben-Zvi, G., Botvinik-Nezer, R., Gera, R., et al. (2020). Brain volumetric changes in the general population following the COVID-19 outbreak and lockdown. BioRxiv, 2020.09.08.285007. Cold Spring Harbor Laboratory.

Sandi, C. (2013). Stress and cognition. WIREs cognitive science, 4(3), 245-261.

Sato, H., \& Kawahara, J. (2011). Selective bias in retrospective self-reports of negative mood states. Anxiety, stress, and coping, 24(4), 359-367.

Saunders, B., Milyavskaya, M., Etz, A., Randles, D., \& Inzlicht, M. (2018). Reported Selfcontrol is not Meaningfully Associated with Inhibition-related Executive Function: A Bayesian Analysis. (S. Vazire \& S. Vazire, Eds.)Collabra: psychology, 4(1).

Saunders, J. B., Aasland, O. G., Babor, T. F., Fuente, J. R. D. L., \& Grant, M. (1993). Development of the Alcohol Use Disorders Identification Test (AUDIT): WHO Collaborative Project on Early Detection of Persons with Harmful Alcohol Consumption-II. Addiction, 88(6), 791-804.

Schwabe, L., Dalm, S., Schächinger, H., \& Oitzl, M. S. (2008). Chronic stress modulates the use of spatial and stimulus-response learning strategies in mice and man. Neurobiology of learning and memory, 90(3), 495-503.

Schwabe, L., Dickinson, A., \& Wolf, O. T. (2011). Stress, habits, and drug addiction: A psychoneuroendocrinological perspective. Experimental and clinical psychopharmacology, 19(1), 53-63.

Schwabe, L., \& Wolf, O. T. (2010). Socially evaluated cold pressor stress after instrumental learning favors habits over goal-directed action. Psychoneuroendocrinology, 35(7), 977-986.

Shafran, R., Coughtrey, A., \& Whittal, M. (2020). Recognising and addressing the impact of COVID-19 on obsessive-compulsive disorder. The lancet. psychiatry, 7(7), 570-572.

Shields, G. S., Sazma, M. A., \& Yonelinas, A. P. (2016). The Effects of Acute Stress on Core Executive Functions: A Meta-Analysis and Comparison with Cortisol. Neuroscience and biobehavioral reviews, 68, 651-668.

Snyder, H. R. (2013). Major depressive disorder is associated with broad impairments on neuropsychological measures of executive function: a meta-analysis and review., Major Depressive Disorder is Associated with Broad Impairments on Neuropsychological Measures of Executive Function: A Meta-Analysis and Review. Psychological bulletin, psychological bulletin, 139, 139(1, 1), 81, 81-132.

Snyder, H. R., Kaiser, R. H., Warren, S. L., \& Heller, W. (2015). Obsessive-compulsive disorder is associated with broad impairments in executive function: A meta-analysis. Clinical psychological science: a journal of the association for psychological science, 3(2), 301-330.

Snyder, H. R., Miyake, A., \& Hankin, B. L. (2015). Advancing understanding of executive function impairments and psychopathology: bridging the gap between clinical and cognitive approaches. Frontiers in psychology, 6. Retrieved May 12, 2021, from https://www.ncbi.nlm.nih.gov/pmc/articles/PMC4374537/.

Sochat, V. V., Eisenberg, I. W., Enkavi, A. Z., Li, J., Bissett, P. G., \& Poldrack, R. A. (2016a). The Experiment Factory: Standardizing Behavioral Experiments. Quantitative psychology and measurement, 610.

Sochat, V. V., Eisenberg, I. W., Enkavi, A. Z., Li, J., Bissett, P. G., \& Poldrack, R. A. (2016b). The Experiment Factory: Standardizing Behavioral Experiments. Frontiers in psychology, 7. 
Taylor, S., Landry, C. A., Paluszek, M. M., Fergus, T. A., McKay, D., \& Asmundson, G. J. G. (2020). COVID stress syndrome: Concept, structure, and correlates. Depression and anxiety, 37(8), 706-714.

Tipples, J. (2015). Rapid temporal accumulation in spider fear: Evidence from hierarchical drift diffusion modelling. Emotion (washington, d.c.), 15(6), 742-751.

Vaghi, M. M., Moutoussis, M., Váša, F., Kievit, R. A., Hauser, T. U., Vértes, P. E., et al. (2020). Compulsivity is linked to reduced adolescent development of goal-directed control and frontostriatal functional connectivity. Proceedings of the national academy of sciences of the united states of america, 117(41), 25911-25922.

Verbeke, G., \& Molenberghs, G. (2000). Linear Mixed Models for Longitudinal Data. Springer Series in Statistics. New York: Springer-Verlag.

Vickers, A. J., \& Altman, D. G. (2001). Analysing controlled trials with baseline and follow up measurements. BMJ : british medical journal, 323(7321), 1123-1124.

Walker, E., \& Nowacki, A. S. (2011). Understanding Equivalence and Noninferiority Testing. Journal of general internal medicine, 26(2), 192-196.

White, C. N., Ratcliff, R., \& Vasey, M. W. (2016). Anxiety-related threat bias in recognition memory: the moderating effect of list composition and semantic-similarity effects. Cognition \& emotion, 30(8), 1446-1460.

White, C. N., Ratcliff, R., Vasey, M. W., \& McKoon, G. (2010). Using diffusion models to understand clinical disorders. Journal of mathematical psychology, 54(1), 39-52.

White, C., Ratcliff, R., Vasey, M., \& McKoon, G. (2009). Dysphoria and memory for emotional material: A diffusion-model analysis. Cognition \& emotion, 23(1), 181205.

Wickelgren, W. A. (1977). Speed-accuracy tradeoff and information processing dynamics. Acta psychologica, 41(1), 67-85.

Yeo, I.-K., \& Johnson, R. A. (2000). A New Family of Power Transformations to Improve Normality or Symmetry. Biometrika, 87(4), 954-959. [Oxford University Press, Biometrika Trust].

Zimet, G. D., Dahlem, N. W., Zimet, S. G., \& Farley, G. K. (1988). The Multidimensional Scale of Perceived Social Support. Journal of personality assessment, 52(1), 30-41. US: Lawrence Erlbaum.

Zmigrod, L., Eisenberg, I. W., Bissett, P. G., Robbins, T. W., \& Poldrack, R. A. (2021). The cognitive and perceptual correlates of ideological attitudes: a data-driven approach. Philosophical transactions of the royal society b: biological sciences, 376(1822), 20200424. Royal Society.

Zung, W. W. (1965). A self -rating depression scale. Archives of general psychiatry, 12, 6370. 


\section{Supplementary Materials}

Some of the methods in relation to the self-regulation battery have been documented in previous work (Eisenberg et al., 2019). For convenience we have reused part of the text from that paper in this supplement to outline details on data collection and variables selection.

Mechanical Turk data collection procedure. A number of steps were taken in order to reduce attrition due to the length of our battery. Firstly, the online battery was only made available to those participants explicitly expressing their interest in our follow-up assessment. Additionally, we gave comprehensive instructions and sent follow-up emails, actively fielding questions from MTurk workers. As an incentive to complete the battery and in line with (Eisenberg et al., 2019), we created a payment schedule that paid a lower rate if the participant failed to complete the battery. Together, these steps were successful in keeping attrition low. Of the whole sample who started the study $(\mathrm{N}=145)$, only 9 participants did not complete the battery. We removed these participants as well as any who failed to pass the quality checks specified below.

Quality check for cognitive tasks. Participants on MTurk are wholly unsupervised, necessitating procedures to ensure data quality. Quality checks were broadly applied to all cognitive tasks to ensure that (1) response times were not unreasonably fast on average, (2) omitted responses were reasonably low, (3) accuracy on cognitive tasks was reasonably high and (4) responses were sufficiently distributed (i.e. the participant didn't only press a single key). The specific criteria we used differed for some tasks, but in general we required that median response times were longer than $200 \mathrm{~ms}$, no more than $25 \%$ of responses were omitted, accuracy was higher than $60 \%$ and no single response was given more than $95 \%$ of the time. These thresholds were determined by (Eisenberg et al., 2019), prior to our data collection and implemented here for the new wave of data collection. Overall, these steps were taken to ensure that participants in our dataset completed the tasks in earnest. Similar checks could not be performed on the self-report surveys as we did not collect response time measures and potentially suspect response patterns (e.g., selecting only one response for every item) may be input honestly.

These criteria were used to evaluate each participant/task pair; failure on any check led to removal of that particular task's data for that participant. In addition, we removed a participant's entire dataset if they failed on four or more individual tasks (29 out of the 136 participants were removed). As an additional quality check, we excluded 5 participants who at the second time of testing provided information on age and on at least another demographic measure that was incompatible with that provided previously. The list of demographic measures on which participants were screened included for example "highest education achieved" or the "number of divorce counts". On these variables, the information provided at the first testing session constrained possible successive ones. 
These quality checks were intended as thresholds to screen out participants who were intentionally gaming the HIT. We also used task-specific manipulation checks which evaluated particular performance criteria specific to different tasks, necessary for the interpretability of our derived dependent measures. Failing these manipulation checks led to the removal of that participant's data on the failed task, but did not count towards the four failed tasks that would lead to the entire participant being removed from our study. The tasks that used these additional manipulation checks were the stop signal tasks, probabilistic selection task, and twostep decision task.

Selection of self-regulation variables. From the 37 tasks and 22 surveys of self-regulation, we computed 204 dependent variables (DVs) identified in (Eisenberg et al., 2019). Each survey was analyzed identically canonical subscale scores were used as DVs. That is, items were appropriately scored (and reversed, if necessary) and summed or averaged in accordance with individual survey scoring procedures. The tasks were heterogeneous, preventing a completely generic analysis strategy. Nonetheless, many tasks involved speeded decisions between two alternatives, and are well characterized by reaction time and accuracy. It is well known that reaction time and accuracy are confounded by the speed-accuracy trade-off, which prompted to use the drift-diffusion model (DDM) in line with (Eisenberg et al., 2019). The basic DDM transforms accuracy and reaction time into a drift rate, threshold, and non-decision time, roughly corresponding to performance, response caution (a point along the speed-accuracy trade-off curve) and stimulus-processing/motor-planning, respectively. We fit the DDM parameters using the hierarchical DDM (HDDM). HDDM models the DDM parameters hierarchically, such that individual parameters are assumed to be drawn from a group distribution (Wiecki, Sofer, \& Frank, 2013). This procedure improves data efficiency (Ratcliff \& Childers, 2015), and it has been shown to better capture true parameters when dealing with small datasets, or datasets corrupted by trials influenced by processes other than evidence accumulation (e.g., attentional lapses). Though individual parameter estimates are no longer independent (due to the hierarchy), hierarchical models also have been shown to improve point estimates of individual parameters, and are particularly useful when one is interested in correlations between other traits and the individual parameter estimates (Katahira, 2016). The HDDM also allows DDM parameters to be modeled as a function of various conditions. For example, when modeling the stroop task, we modeled drift rate as a function of conflict condition while keeping the other parameters constant. Tasks that were not speeded choice tasks were heterogeneous and each analyzed according to its own scientific tradition. The full list of measures is available in Table S8 (surveys) and Table S9 (tasks).

Data cleaning and imputation. We implemented several steps to ensure our data met criteria for parametric analyses assuming normally distributed variables. Generally for all the self-regulation variables, we used a Yeo-Johnson power transform using sklearn, where the optimal parameter (i.e., fitted transformer) for stabilizing variance and minimizing skewness is estimated through maximum likelihood. Then, in line with criteria set by (Eisenberg et al., 2019), data with values more than 2.5 times the interquartile range above the third quartile or below the first quartile, were removed. Variables that remained excessively skewed (absolute 
skew $>1$ ) were dropped. Finally, as each data matrix had missing values due to our quality check procedure, we imputed the data matrix using R's missForest.

For measures of self-regulation (both tasks and survey), we estimated the fitted transformer on the training datasets and then applied it to the training and testing datasets. Outlier data were then removed. Any variable that remained excessively skewed (absolute skew $>1$ ) after our power transform and outlier removal was dropped (training dataset: 3 DVs; testing dataset, pre onset COVID-19: 5 DVs; post onset COVID-19: 8 DVs). To ensure we did not have redundant variables in the participant-by-measure data matrix, if any two dependent variables derived from the same task or survey measure were correlated $r>.85$, one of the variables was arbitrarily removed. Using this criteria, 17 variables were dropped from the training dataset, 15 variables were dropped from the pre onset COVID-19 dataset and 8 variables were dropped from the post onset COVID datasets. This pipeline resulted in $178 \mathrm{DVs}$ common to all three datasets. A minority of each data matrix was missing due to our quality check procedure (training dataset: $3.49 \%$; pre onset COVID-19 dataset: $2.81 \%$; post onset COVID-19 dataset: $2.0 \%$ ) but these missing values were not uniformly distributed amongst the DVs. Due to additional quality control measures (manipulation checks) some tasks (the stop signal tasks, the probabilistic selection task, two-step decision task, shift task, and delay discounting titrator) resulted in DVs with substantially more missing values (between 10-30\%). We imputed the data matrix using R's missForest package. Finally, for our data analysis, the total number of correct responses on the Raven's progressive matrices was excluded from the set of DVs as we planned to use this measure as a moderator variable in a set of analyses. Similarly, the 3 DVs derived from BIS-11 were excluded because this questionnaire was part of the set of measures included to investigate individual differences in psychiatric symptoms. This resulted in a final count of $174 \mathrm{DVs}$ for self-regulation ( $\mathrm{N}=113$ for tasks; $\mathrm{N}=61$ for surveys) which were common to the three datasets and could be used for further analysis. The exact same procedure was adopted for loneliness, perceived stress, perceived social support, mindset towards stress and mindset towards the pandemic. However, as no training dataset was available, data cleaning and imputation was directly applied to the matrix of data collected in this study. No variables needed to be dropped.

Change in health risk behavior. In a secondary prediction analysis we tested whether self-regulation factors referring to the period preceding the onset of the pandemic could predict changes in health risk behavior. Accordingly, we derived measures of health risk behavior following identical procedures devised for surveys and tasks for self-regulation. Namely, we applied EFA on our training dataset, composed of data on health risk behavior from subjects who answered those questions only before the onset of the pandemic $(\mathrm{N}=386)$ (Eisenberg et al., 2019). The list of the individual items included can be found in Supplementary Table 13 and was composed of surveys designed by others to assess particular health-related behavior and a set of items devised ad hoc. Before running EFA age and gender were regressed out of each health risk behavior variable. Overall model fit was satisfactory $\left(\mathrm{R}^{2}=.38\right.$; RMSEA $=.052$; RMSR $\left.=.048\right)$. The Bayesian Information Criteria yielded 6 factors: Binge Drinking, Daily Smoking, Drug Use, Lifetime smoking, Mental Health, Problem Drinking (See Supplementary Figure 10 for the factor scores correlation and the online Jupyter 
Notebook for the full factor loading matrix). Then, via predict from the psych package in $\mathrm{R}$, the same linear combination of variables was used to create factors scores for our testing datasets, represented by those participants who completed the battery twice, at different timepoints. Hence, for each subject, we obtained measures of health risk behavior of the period preceding and following the onset of the pandemic. Measures of change were obtained by regressing health risk behavior pre COVID-19 (e.g., Mental Health pre CoviD-19) from the health risk behavior following COVID-19 (e.g., Mental Health outcome COVID-19). Each of the obtained measures represented changes in health risk behaviors and were used as dependent variables of the prediction analysis described in the Material and Methods.

A

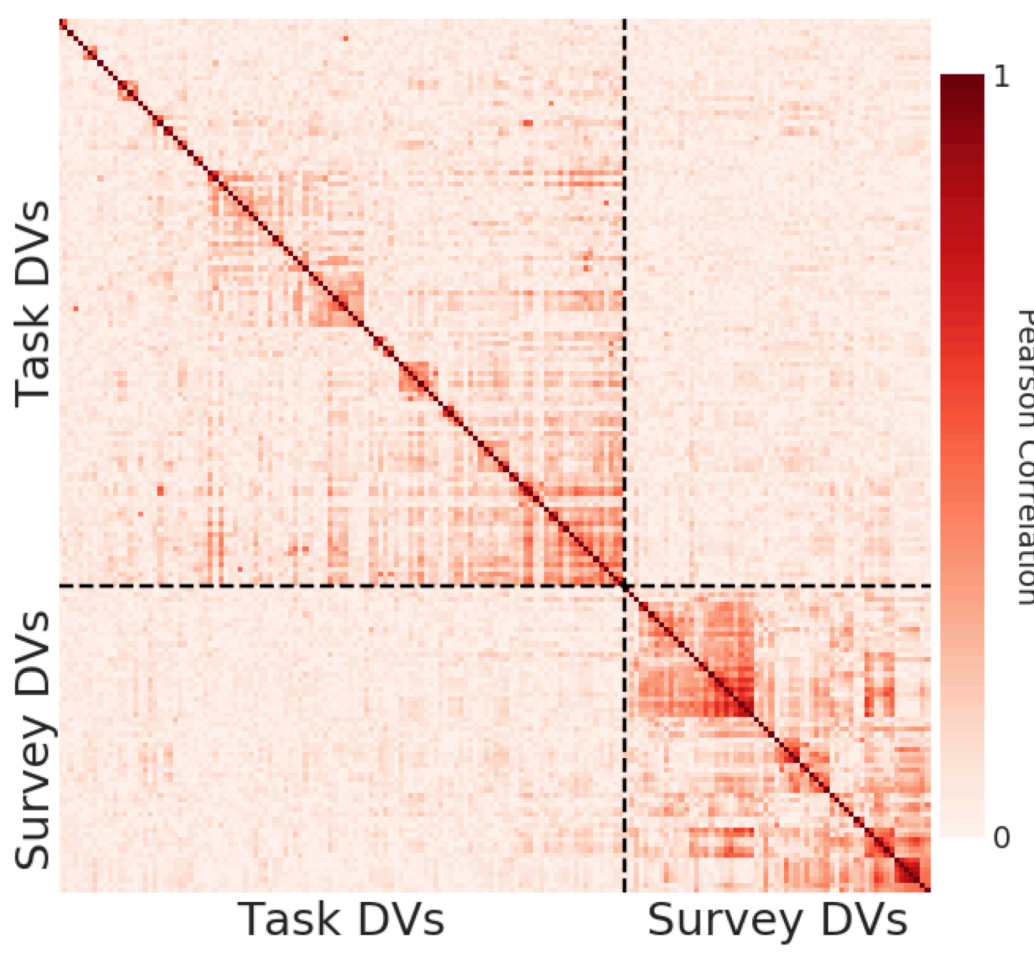

B

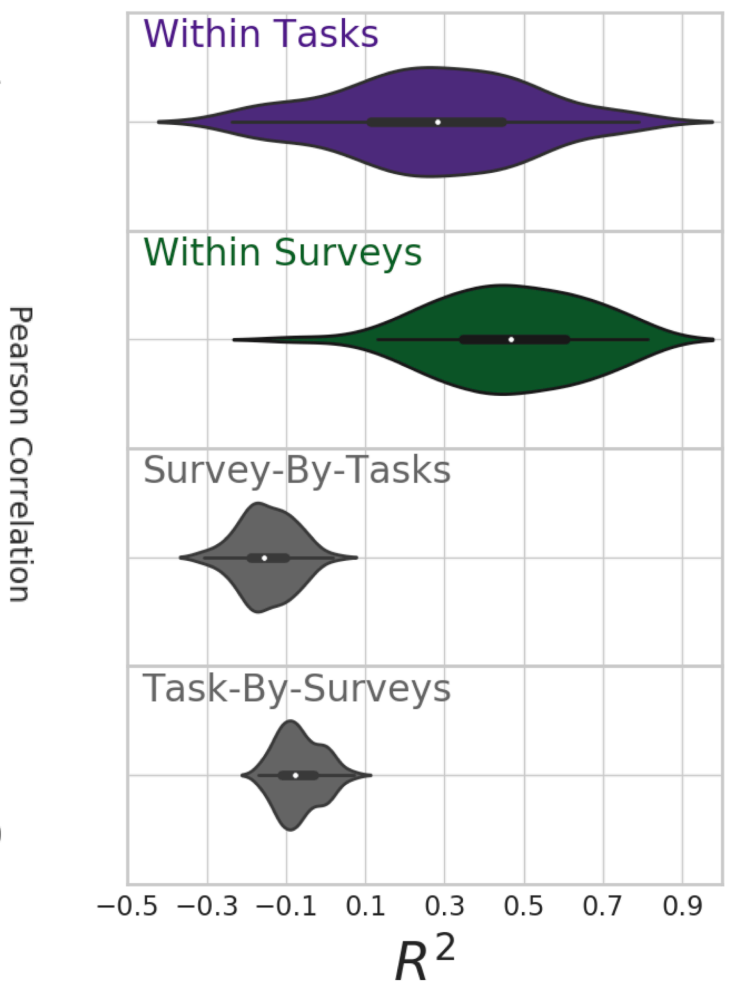

Supplementary Figure 1. Relationship between variables of self-regulation on the training dataset (N=386) (A) Pearson correlation for variables of self-regulation. Variables are organized by category (i.e., tasks, surveys) and ordered based on the respective hierarchical clustering solutions. (B) Cross-validated $R^{2}$ derived from cross-validated ridge regression of either a single task or survey variable using all survey or task variables (holding out the target).
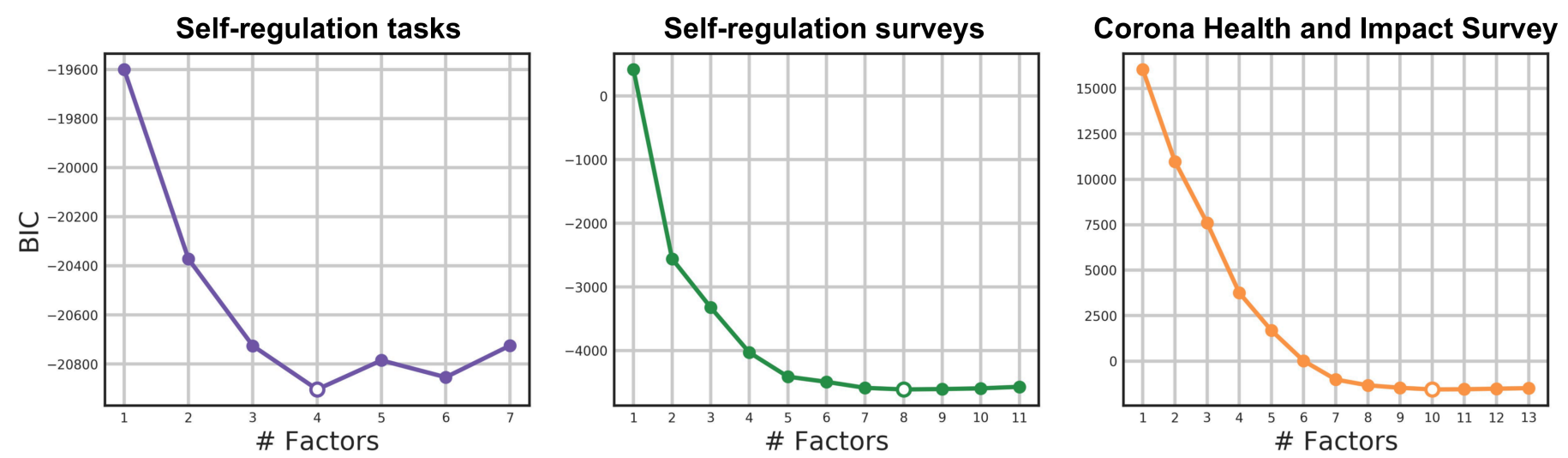

Supplementary Figure 2. Bayesian information criterion (BIC) curves for EFA conducted on the training datasets. The BIC values for a range of factors are shown for EFA on variables from the self-regulation tasks, surveys and from the Corona Health and 
Impact Survey (CRISIS). An optimal dimensionality of 4, 8, and 10 factors (empty circle in the plot) was identified for tasks, surveys, and the Corona Health and Impact Survey respectively.

\section{Loadings Correlations}

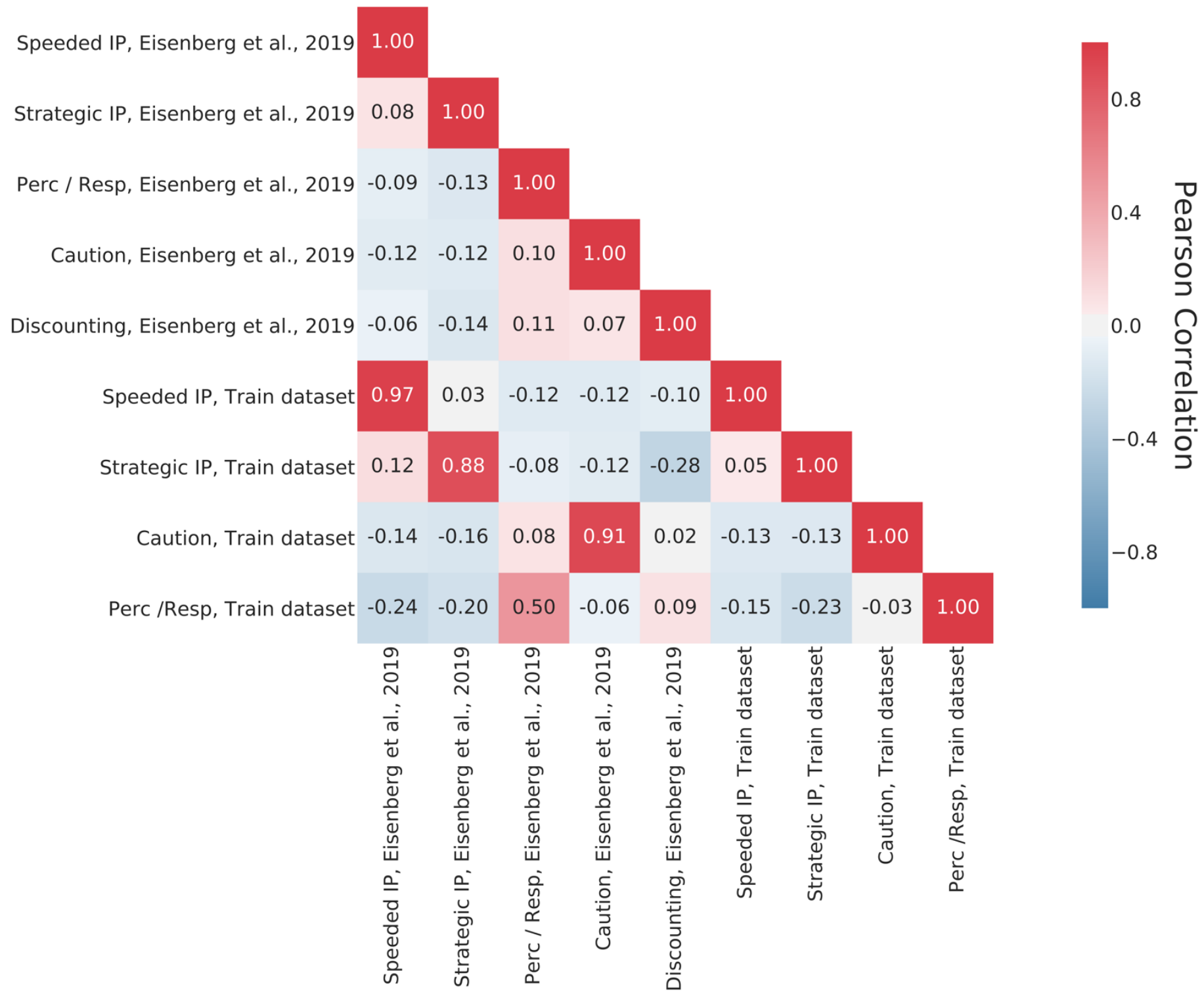

Supplementary Figure 3. The heatmap displays the correlation between the self-regulation task variables loading for each of the factors obtained from EFA on the larger sample of 522 subjects (Eisenberg et al., 2019) and that on the subset of participants of participants used as a training dataset in the current study $(N=386)$. IP, Information Processing; Perc/Resp, Perception/Response. 


\section{Loadings Correlations}

Sensation Seeking, Eisenberg et al., 2019

Emotional Control, Eisenberg et al., $20190.02 \quad 1.00$

Mindfulness, Eisenberg et al., $2019-0.100 .241 .00$

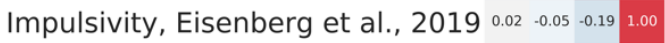

Reward Sensitivity, Eisenberg et al., $20190.010 .100 .01 \quad 0.09 \quad 1.00$

Goal-Directedness, Eisenberg et al., $2019-0.05 \quad 0.18 \quad 0.27-0.34-0.00 \quad 1.00$

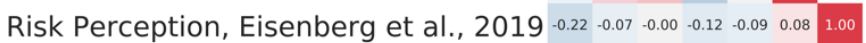

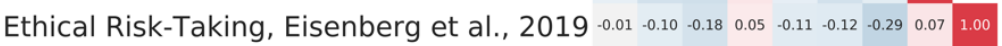

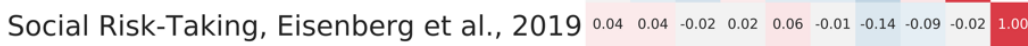

Financial Risk-Taking, Eisenberg et al., $2019 \quad \begin{array}{lllllllllllll}2 & 0.03 & 0.02 & -0.09 & 0.06 & 0.00 & -0.02 & -0.18 & 0.00 & 0.10 & 0.01 & 1.00\end{array}$

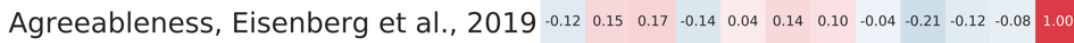

Goal-directed/Mindfulness, Train dataset $\begin{array}{ccccccccccccccccc}-0.11 & 0.20 & 0.45 & -0.37 & 0.06 & 0.46 & 0.03 & -0.24 & -0.23 & -0.01 & -0.22 & 0.03 & 1.00\end{array}$

Sensation Seeking, Train dataset $\begin{array}{llllllllllllll}0.97 & 0.03 & -0.14 & -0.00 & 0.06 & -0.13 & -0.23 & -0.08 & 0.04 & 0.05 & 0.15 & -0.16 & -0.16 & 1.00\end{array}$

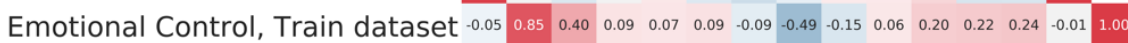

Reward Sensitivity, Train dataset $\begin{array}{llllllllllllllllllll}0.01 & 0.06 & 0.05 & 0.40 & 0.79 & -0.04 & -0.10 & 0.11 & 0.01 & -0.05 & -0.02 & -0.04 & -0.22 & 0.05 & -0.01 & 1.00\end{array}$

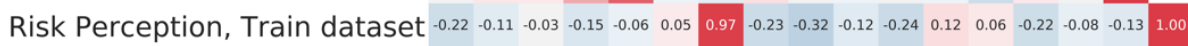

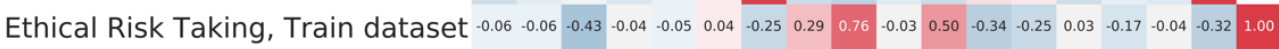

Social Risk Taking, Train dataset $\begin{array}{llllllllllllllllllllll}0.04 & 0.05 & 0.02 & -0.10 & 0.09 & 0.04 & -0.14 & -0.17 & 0.02 & 0.95 & -0.01 & -0.12 & -0.03 & 0.07 & 0.07 & 0.04 & -0.10 & -0.03 & 1.00\end{array}$

Agreeableness, Train dataset $\begin{array}{ccccccccccccccccccccc}0.14 & 0.06 & 0.08 & -0.37 & 0.28 & 0.16 & 0.05 & 0.10 & -0.30 & -0.05 & 0.04 & 0.84 & 0.16 & -0.16 & 0.08 & -0.03 & 0.07 & -0.19 & -0.08 & 1.00\end{array}$

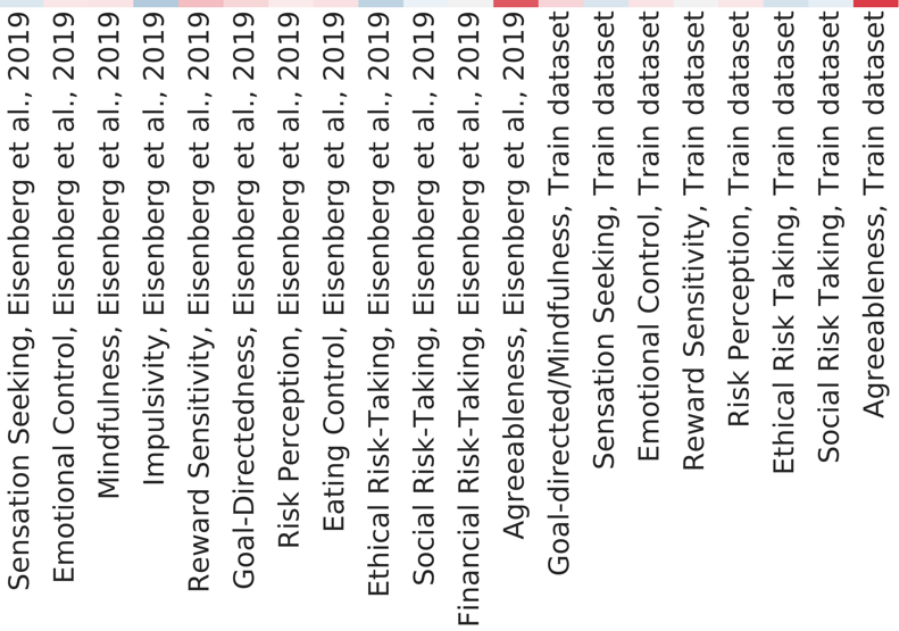

Supplementary Figure 4. The heatmap displays the correlation between the self-regulation survey variables loading for each of the factors obtained from EFA on the larger sample of 522 subjects (Eisenberg et al., 2019) and that on the subset of participants of participants used as a training dataset in the current study $(N=386)$. 
A

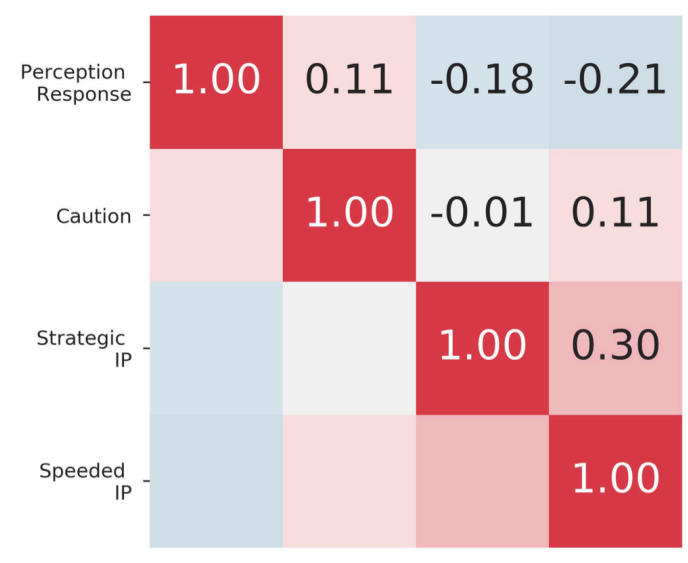

C

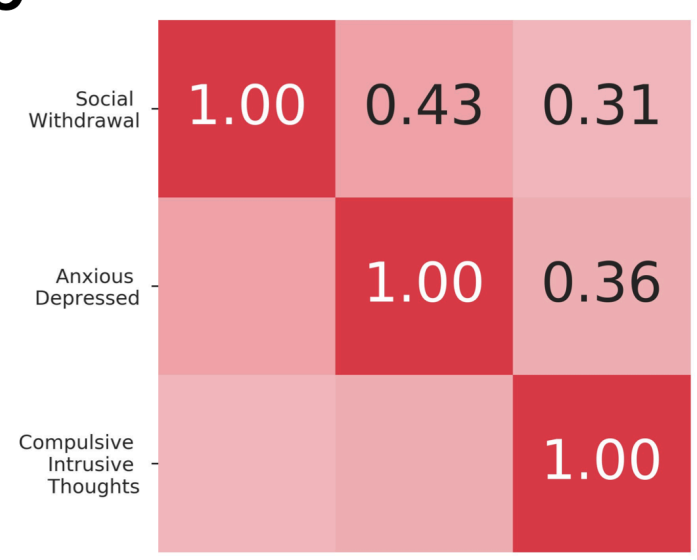

B

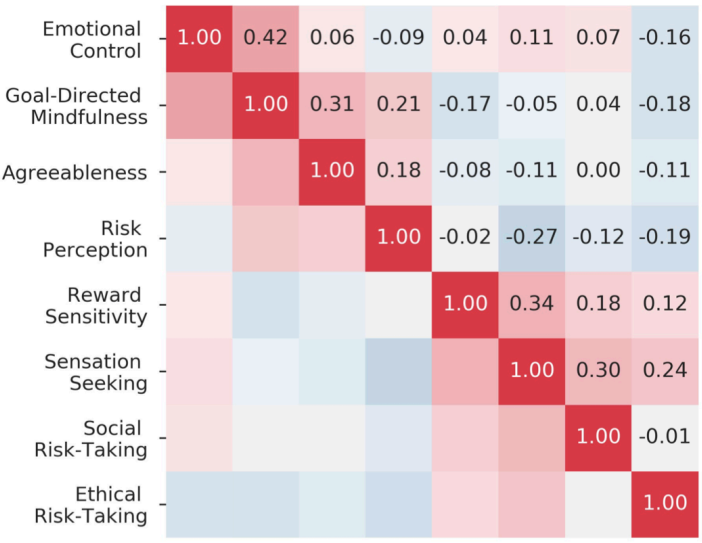

D

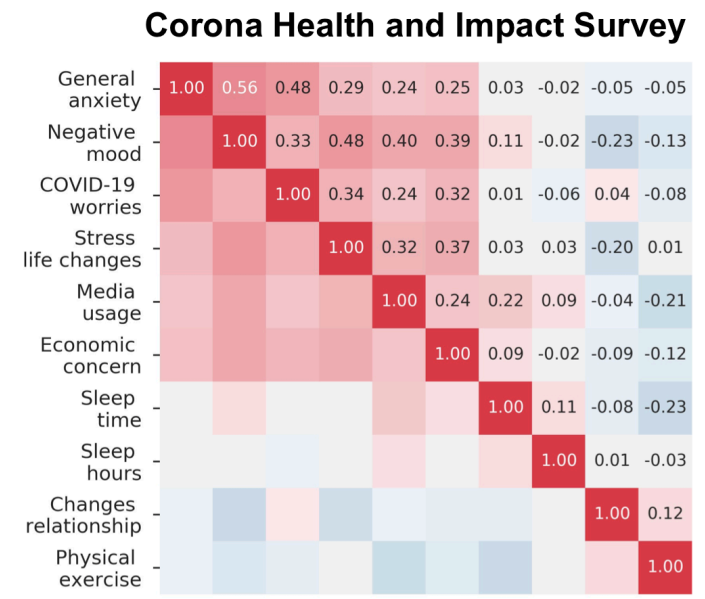

0.8

Supplementary Figure 5. Correlation of factor scores from Exploratory Factor Analysis models on the training datasets. Factor analysis on self-regulation variables from (A) tasks and (B) surveys revealed a 4 and 8 factor solution, respectively. (C) A 3 factor solution was obtained on the training dataset of psychiatric symptoms. (D) A 10 factor solution was derived from the Corona Health and Impact Survey (CRISIS). The heatmaps display the moderate correlations (r Pearson's correlation $<.05)$ between different factors, reflecting their relative independence.

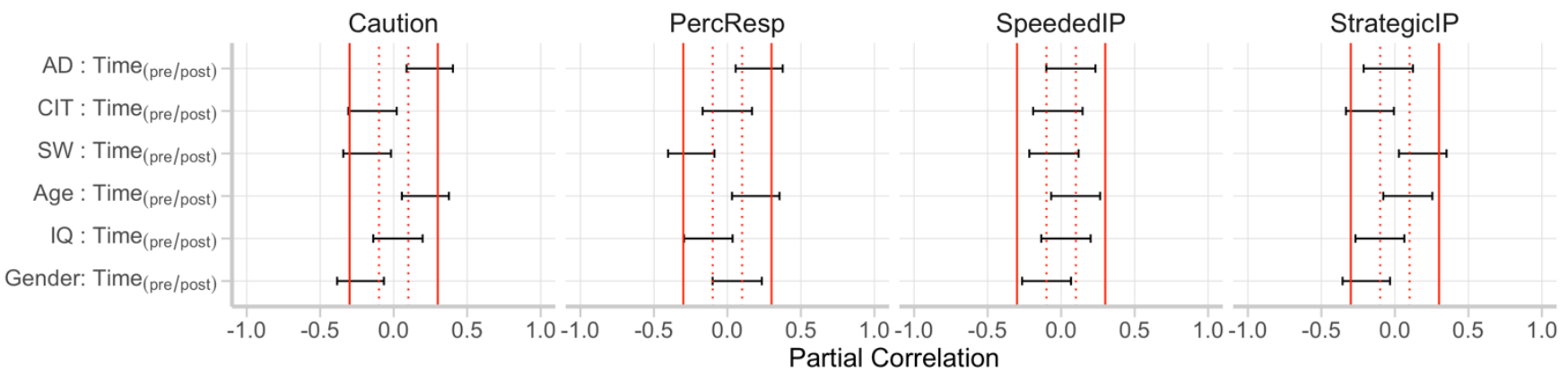

Supplementary Figure 6. Equivalence testing for models longitudinal changes in task-based self-regulation. We computed a paired difference for the dependent variable of interest (e.g., Speeded IP post onset COVID-19-Speeded IP pre onset COVID-19) of each model and calculated its partial correlation with the regressors included in the model (e.g., AD, CIT, SW, Age, IQ, Gender). The plot reflects the partial correlation obtained and the associated $90 \%$ CI, computed using a standard Fisher's Z transformation based CI. The results are effectively a test of equivalence for the interactions included in the mixed models (Material and Methods) reported in Supplementary Table 4, hence the labels on the y axis. Dotted and continuous line correspond to a small . (i.e., -0.1, 0.1) and medium (i.e., -0.3, 0.3) cut off respectively. When the $90 \%$ CI was included within the boundaries for the medium cut off (i.e., -0.3, 0.3), the effect was deemed smaller than the smallest effect of interest, hence equivalent to a null result. AD, AnxiousDepression; CIT, Compulsive behavior and Intrusive Thoughts; SW, Social Withdrawal. 


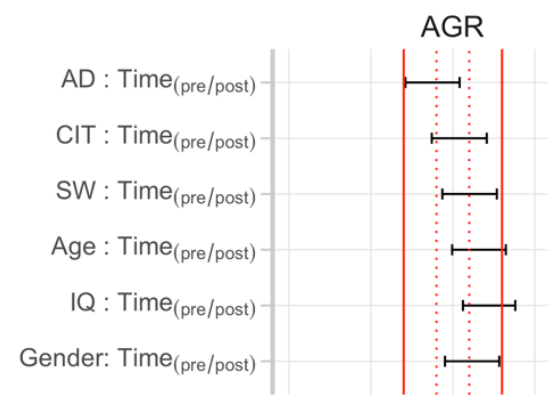

RS

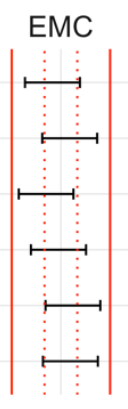

RP

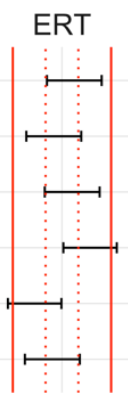

SS

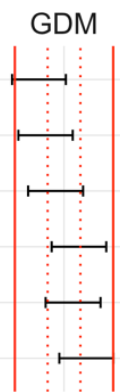

SRT

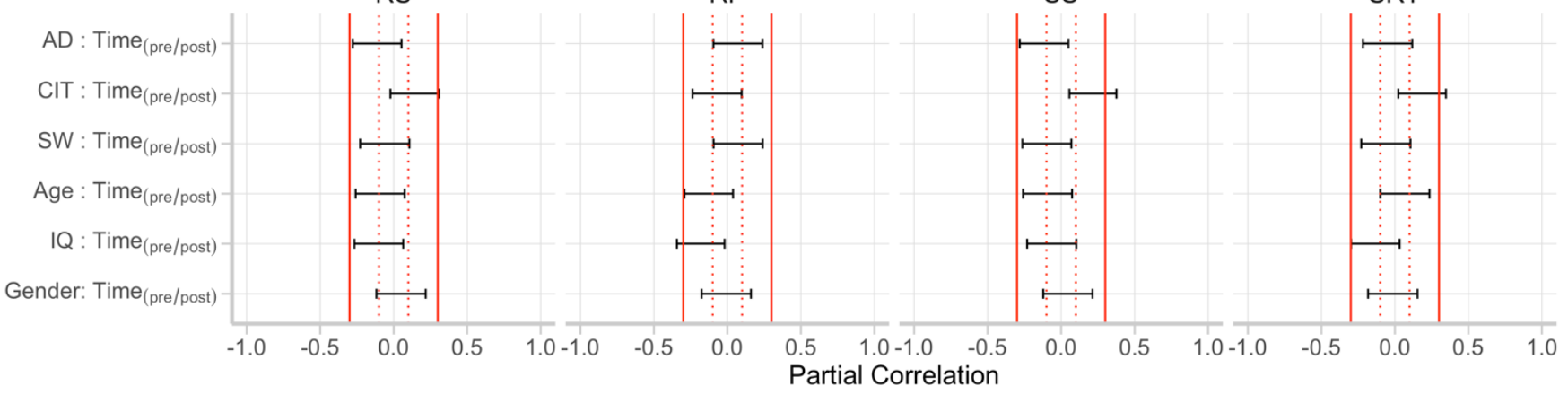

Supplementary Figure 7. Equivalence testing for models longitudinal changes in survey-based self-regulation. We computed a paired difference for the dependent variable of interest (e.g., EMC post onset COVID-19-EMC pre onset COVID-19) of each model and calculated its partial correlation with the regressors included in the model (e.g., AD, CIT, SW, Age, IQ, Gender). The plot reflects the partial correlation obtained and the associated $90 \%$ CI, computed using a standard Fisher's Z transformation based CI. The results are effectively a test of equivalence for the interactions included in the mixed models (Material and Methods) reported in Supplementary Table 5, hence the labels on the y axis. Dotted and continuous line correspond to a small . (i.e., - -0.1, 0.1) and medium (i.e., -0.3, 0.3) cut off respectively. When the $90 \%$ CI was included within the boundaries for the medium cut off (i.e., -0.3, 0.3 ), the effect was deemed smaller than the smallest effect of interest, hence equivalent to a null result. AD, Anxious-Depression; CIT, Compulsive behavior and Intrusive Thoughts; SW, Social Withdrawal. AGR, Agreeableness; EMC, Emotional Control; ERT, Ethical Risk-Taking; GDM, Goal-Directed/Mindfulness; RS, Reward Sensitivity; RP, Risk Perception; SS, Sensation Seeking; SRT, Social Risk-Taking;

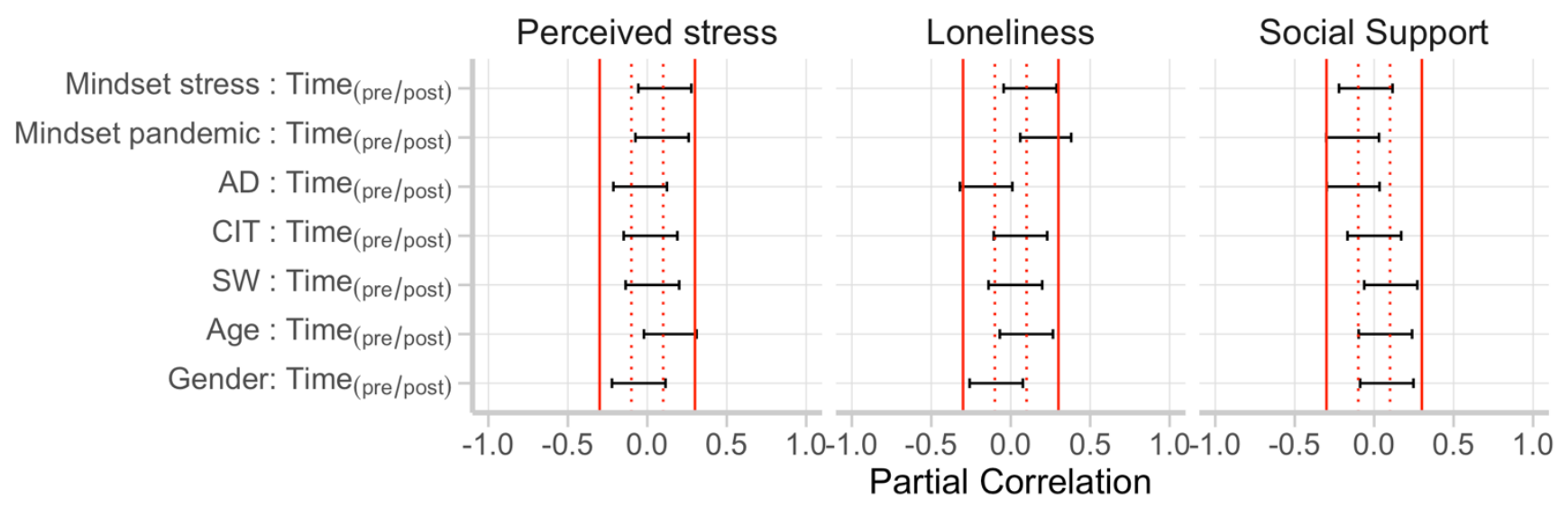

Supplementary Figure 8. Equivalence testing for models examining trajectories of well-being related to the pandemic onset. We computed a paired difference for the dependent variable of interest (e.g., Perceived stress post onset CoviD-19-Perceived stress pre onset CoVID-19) of each model and calculated its partial correlation with the regressors included in the model (e.g., mindset stress, mindset pandemic, AD, CIT, SW, Age, Gender). The plot reflects the partial correlation obtained and the associated $90 \%$ CI, computed using a standard Fisher's Z transformation based CI. The results are effectively a test of equivalence for the interactions included in the mixed models (Material and Methods) reported in Supplementary Table 3, hence the labels on the y axis. Dotted and continuous line correspond to a small . (i.e., -0.1, 0.1) and medium (i.e., -0.3, 0.3) cut off respectively. When the 90\% CI was included within the boundaries for the medium cut off (i.e., -0.3, 0.3), the effect was deemed smaller than the smallest effect of interest, hence equivalent to a null result. AD, Anxious-Depression; CIT, Compulsive behavior and Intrusive Thoughts; SW, Social Withdrawal. 
A

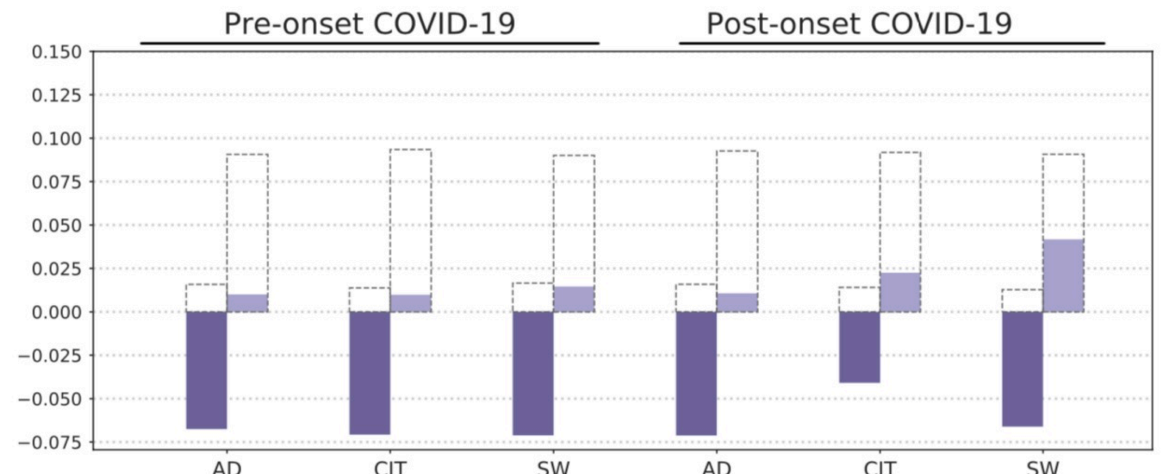

Cross-validated prediction

Insample prediction

95\% shuffled prediction

B

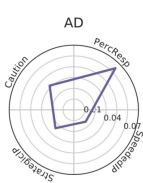

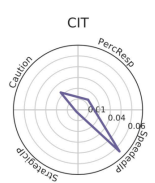

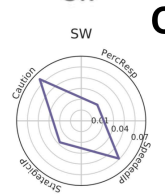

C

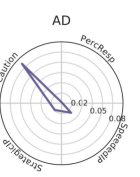

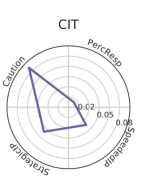

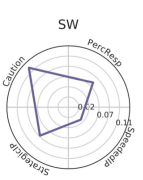

Supplementary Figure 9. Prediction of psychiatric symptoms dimension using task factor-scores. (A) Predictions where selfregulation factors scores of the period preceding (pre, prospective) or following (post, cross-sectional) the onset of COVID-19 were used to predict psychiatric symptoms assessed during the emerging of the COVID-19 pandemic. In the bottom row, fingerprints using factor scores of the period preceding (B) or following $(C)$ the onset of the COVID-10 pandemic are displayed. Dark and light bars indicate $R^{2}$ cross-validated and insample prediction respectively. Dashed gray boxes indicate $95 \%$ of null distribution, estimated from 2500 shuffles of the target outcome. Fingerprints displayed as polar plots indicate the standardized $\beta$ for each factor. Perc/Resp, Perception/Response; IP, Information Processing; AD, Anxious-Depression; CIT, Compulsive behavior and Intrusive Thoughts; SW, Social Withdrawal.

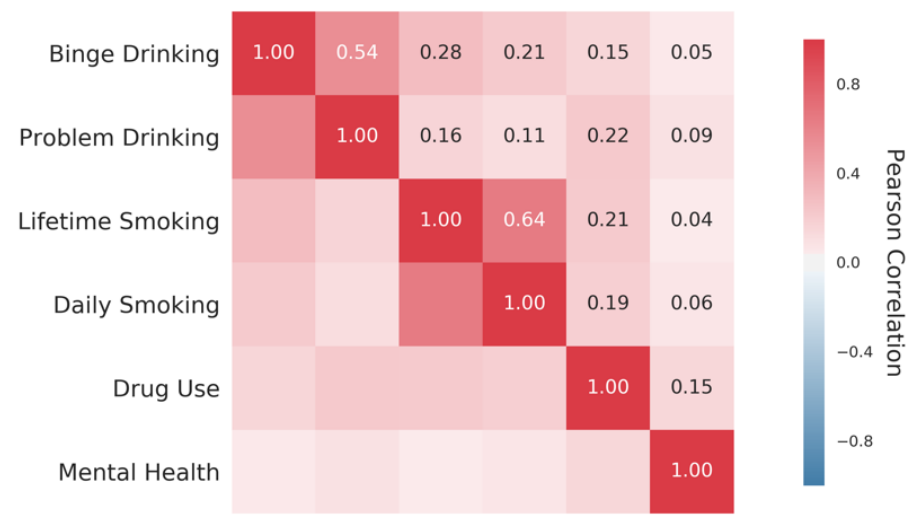

Supplementary Figure 10. Correlation of factor scores from Exploratory Factor Analysis models on the training dataset for health risk behavior measures. Pearson correlation amongst factors is displayed. 
A

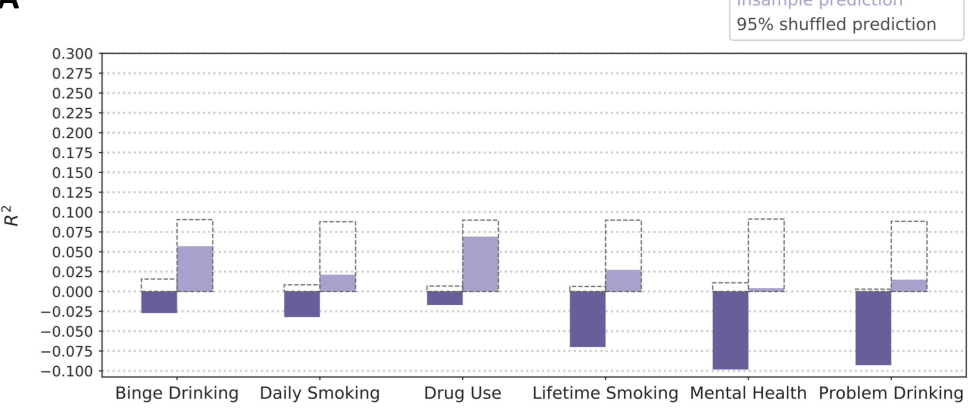

C

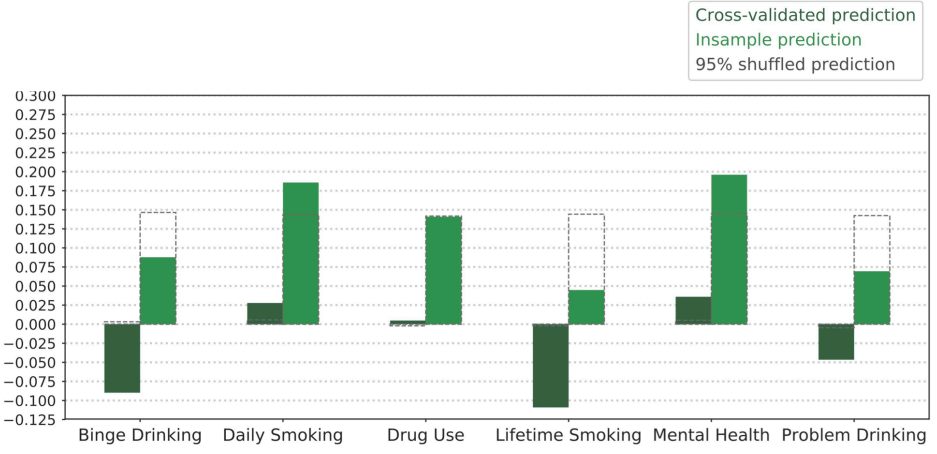

B
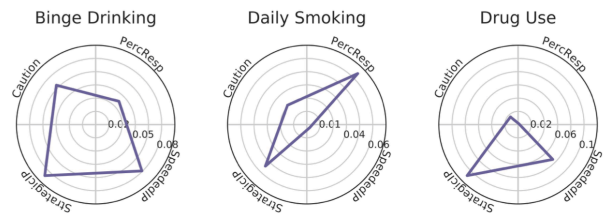

Lifetime Smoking
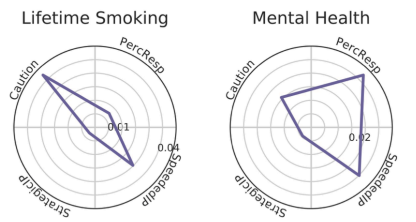

Problem Drinking

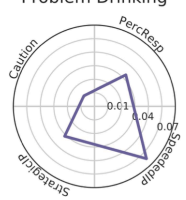

D
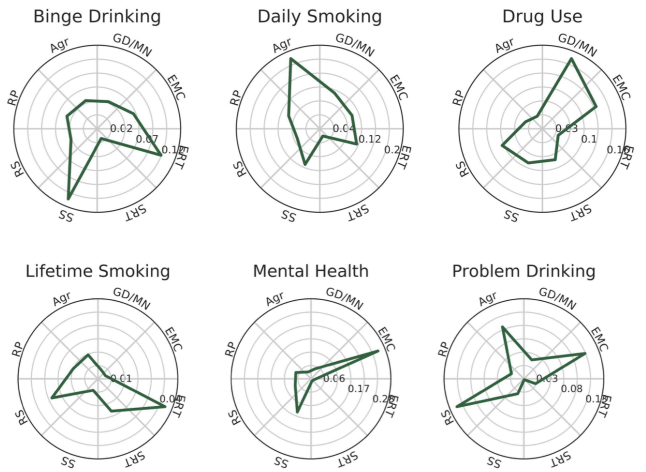

Supplementary Figure 11. Prediction of change in health risk behaviors. (A) Tasks- and (C) survey-related self-regulation factors scores of the period preceding the onset of COVID-19 were used to predict change in health risk behaviors. Fingerprint corresponding to (B) tasks and (D) survey factor scores. Dark and light bars indicate $R^{2}$ cross-validated and insample prediction respectively. Dashed gray boxes indicate $95 \%$ of null distribution, estimated from 2500 shuffles of the target outcome. Fingerprints displayed as polar plots indicate the standardized $\beta$ for each factor. The y-axes are scaled for each fingerprint to highlight the distribution of associations - no inference can be drawn comparing individual factor magnitudes across outcomes. EMC, Emotional Control; GD/MND, Goal-Directed/Mindfulness; Agr, Agreeableness; RP, Risk Perception; RS, Reward Sensitivity; SS, Sensation Seeking; SRT, Social-Risk Taking; ERT, Ethical Risk-Taking. 
Supplementary Table 1. Demographic characteristics of subjects included in the training and testing datasets for selfregulation

\begin{tabular}{|c|c|c|c|c|}
\hline & & $\begin{array}{c}\text { Training } \\
\text { dataset } \\
(\mathrm{N}=386) \\
\end{array}$ & $\begin{array}{c}\text { Pre-onset } \\
\text { COVID-19 } \\
(\mathrm{N}=102) \\
\end{array}$ & $\begin{array}{c}\text { Post-onset } \\
\text { COVID-19 } \\
(\mathrm{N}=102) \\
\end{array}$ \\
\hline Age & $\begin{array}{l}\text { Mean } \\
\text { (SD) }\end{array}$ & $\begin{array}{l}32.46 \\
(7.51)\end{array}$ & $\begin{array}{l}36.61 \\
(7.86)\end{array}$ & $\begin{array}{l}40.26 \\
(7.80)\end{array}$ \\
\hline \multirow[t]{3}{*}{ Gender* } & Female & $194(50.26 \%)$ & $50(49.02 \%)$ & $49(48.04 \%)$ \\
\hline & Male & $192(49.74 \%)$ & $52(50.98 \%)$ & $52(50.98 \%)$ \\
\hline & Non-binary/ Third gender & & & $1(0.98 \%)$ \\
\hline \multirow[t]{2}{*}{ Hispanic/Latino } & No & $359(93.01 \%)$ & $94(92.16 \%)$ & $94(92.16 \%)$ \\
\hline & Yes & $27(6.99 \%)$ & $8(7.84 \%)$ & $8(7.84 \%)$ \\
\hline \multirow[t]{6}{*}{ Highest Education } & Advanced Graduate work or Ph.D & $9(2.33 \%)$ & $4(3.92 \%)$ & $3(2.94 \%)$ \\
\hline & Bachelor's Degree & $147(38.08 \%)$ & $38(37.25 \%)$ & $44(43.14 \%)$ \\
\hline & High School/GED & $52(13.47 \%)$ & $16(15.69 \%)$ & $14(13.73 \%)$ \\
\hline & Master's Degree & $15(3.89 \%)$ & $6(5.88 \%)$ & $7(6.86 \%)$ \\
\hline & Some College & $160(41.45 \%)$ & $38(37.25 \%)$ & $34(33.33 \%)$ \\
\hline & Did Not Complete High School & $3(0.78 \%)$ & & \\
\hline \multirow{3}{*}{$\begin{array}{l}\text { Relationship } \\
\text { Status }\end{array}$} & Committed Relationship & $96(24.87 \%)$ & $24(23.53 \%)$ & $19(18.63 \%)$ \\
\hline & Married & $124(32.12 \%)$ & $35(34.31 \%)$ & $38(37.25 \%)$ \\
\hline & Single & $166(43.01 \%)$ & $43(42.16 \%)$ & $45(44.12 \%)$ \\
\hline \multirow[t]{4}{*}{ Divorce Count } & 0 & $339(87.82 \%)$ & $88(86.27 \%)$ & $87(85.29 \%)$ \\
\hline & 1 & $40(10.36 \%)$ & $11(10.78 \%)$ & $13(12.75 \%)$ \\
\hline & 2 & $6(1.55 \%)$ & $3(2.94 \%)$ & $2(1.96 \%)$ \\
\hline & 3 & $1(0.26 \%)$ & & \\
\hline \multirow{11}{*}{$\begin{array}{l}\text { Psychiatric } \\
\text { disorder }\end{array}$} & Attention Deficit Hyperactivity Disorder & $14(3.63 \%)$ & $3(2.94 \%)$ & $6(5.88 \%)$ \\
\hline & Alcohol Dependency & $3(0.78 \%)$ & $3(2.94 \%)$ & $3(2.94 \%)$ \\
\hline & Anorexia Nervosa & $6(1.55 \%)$ & $1(0.98 \%)$ & $1(0.98 \%)$ \\
\hline & Anxiety Disorder & $66(17.10 \%)$ & $16(15.69 \%)$ & $22(21.57 \%)$ \\
\hline & Borderline Personality Disorder & $1(0.26 \%)$ & & $1(0.98 \%)$ \\
\hline & Depression & $32(8.29 \%)$ & $7(6.86 \%)$ & $4(3.92 \%)$ \\
\hline & Drug Dependency & $3(0.78 \%)$ & $1(0.98 \%)$ & $1(0.98 \%)$ \\
\hline & Manic-Depressive (Bipolar) illness & $2(0.52 \%)$ & $1(0.98 \%)$ & \\
\hline & Obsessive Compulsive Disorder & $3(0.78 \%)$ & & $1(0.98 \%)$ \\
\hline & Other & $8(2.07 \%)$ & $3(2.94 \%)$ & $1(0.98 \%)$ \\
\hline & None & $248(64.25 \%)$ & $67(65.69 \%)$ & $62(60.78 \%)$ \\
\hline \multirow{2}{*}{$\begin{array}{l}\text { Neurological } \\
\text { disorder }\end{array}$} & Yes & $5(1.30 \%)$ & $2(1.96 \%)$ & $2(1.96 \%)$ \\
\hline & No & $381(98.70 \%)$ & $100(98.04 \%)$ & $100(98.04 \%)$ \\
\hline
\end{tabular}

${ }^{*}$ The question about gender was modified when collecting data after the onset of COVID-19, to account for non-binary or third gender; SD, Standard Deviation. Unless otherwise specified, number of subjects and associated percentage for the given category are shown in the table.

Supplementary Table 2. Summary of model fit measures for each Exploratory Factor Analysis on the training datasets

\begin{tabular}{lccccc}
\hline & N Subjects & N Factors & $\mathbf{R}^{\mathbf{2}}$ & RMSEA & RMSR \\
\hline $\begin{array}{l}\text { EFA on tasks of self- } \\
\text { regulation }\end{array}$ & 386 & 4 & .21 & .060 & .060 \\
\hline $\begin{array}{l}\text { EFA on surveys of self- } \\
\text { regulation }\end{array}$ & 386 & 8 & .51 & .064 & .039 \\
\hline $\begin{array}{l}\text { EFA on self-reported } \\
\text { psychiatric symptoms }\end{array}$ & 497 & 3 & .27 & .044 & .058 \\
\hline $\begin{array}{l}\text { EFA on the Corona } \\
\text { Health and Impact Survey }\end{array}$ & 2868 & 10 & .48 & .029 & .014 \\
\hline
\end{tabular}

EFA, Exploratory Factor Analysis; BIC, Bayesian Information Criterion; RMSEA, Root Mean Square Error of Approximation; $R$ $M S R$, Root Mean Square of the Residuals. The RMSR is and empirical value and it is comparable to the RMSEA, which is based $u$ pon normal theory and the non-central $\chi^{2}$. A RMSEA <.08 is indicative of a good fit (Browne \& Cudeck, 1992). 
Supplementary Table 3. Results from linear mixed models examining longitudinal changes in task-related measures of self-regulation

\begin{tabular}{|c|c|c|c|c|c|c|c|c|c|c|c|c|}
\hline & \multicolumn{3}{|c|}{ Caution } & \multicolumn{3}{|c|}{ Perception/ Response } & \multicolumn{3}{|c|}{ Speeded IP } & \multicolumn{3}{|c|}{ Strategic IP } \\
\hline & $\stackrel{\beta}{\beta}$ & $\begin{array}{c}t \\
\text { value }\end{array}$ & $\begin{array}{c}p \text { value } \\
{[95 \% \mathrm{Cl}]}\end{array}$ & $\stackrel{\beta}{\beta}$ & $\begin{array}{c}t \\
\text { value }\end{array}$ & $\begin{array}{c}p \text { value } \\
{[95 \% \mathrm{Cl}]}\end{array}$ & $\stackrel{\beta}{\beta}$ & $\begin{array}{c}t \\
\text { value }\end{array}$ & $\begin{array}{c}p \text { value } \\
{[95 \% \mathrm{Cl}]}\end{array}$ & $\stackrel{\beta}{\beta}$ & $\begin{array}{c}t \\
\text { value }\end{array}$ & $\begin{array}{c}p \text { value } \\
{[95 \% \mathrm{Cl}]}\end{array}$ \\
\hline Intercept & $\begin{array}{l}-.05 \\
(.09)\end{array}$ & -.59 & $\begin{array}{c}.56 \\
{[-.23, .12]}\end{array}$ & $\begin{array}{l}-.05 \\
(.08)\end{array}$ & -.66 & $\begin{array}{c}.51 \\
{[-.20, .10]}\end{array}$ & $\begin{array}{l}-.03 \\
(.07)\end{array}$ & -.34 & $\begin{array}{c}.73 \\
{[-.17, .12]}\end{array}$ & $\begin{array}{l}.02 \\
(.07)\end{array}$ & .34 & $\begin{array}{c}.73 \\
{[-.10, .15]}\end{array}$ \\
\hline$A D$ & $\begin{array}{l}.25 \\
(.12)\end{array}$ & 1.99 & $\begin{array}{c}.05 \\
{[.01, .48]}\end{array}$ & $\begin{array}{l}-.02 \\
(.11)\end{array}$ & -.2 & $\begin{array}{c}.84 \\
{[-.23, .19]}\end{array}$ & $\begin{array}{l}.03 \\
(.1)\end{array}$ & .31 & $\begin{array}{c}.76 \\
{[-.16, .22]}\end{array}$ & $\begin{array}{l}.07 \\
(.09)\end{array}$ & .81 & $\begin{array}{c}.42 \\
{[-.10, .25]}\end{array}$ \\
\hline CIT & $\begin{array}{l}-.12 \\
(.11)\end{array}$ & -1.1 & $\begin{array}{c}.27 \\
{[-.34, .09]}\end{array}$ & $\begin{array}{c}.06 \\
(.10)\end{array}$ & .63 & $\begin{array}{c}.53 \\
{[-.13, .25]}\end{array}$ & $\begin{array}{l}-.16 \\
(.09)\end{array}$ & -1.71 & $\begin{array}{c}.09 \\
{[-.33, .02]}\end{array}$ & $\begin{array}{l}-.17 \\
(.08)\end{array}$ & -2.08 & $\begin{array}{c}.04 \\
{[-.33, .01]}\end{array}$ \\
\hline SW & $\begin{array}{l}-.19 \\
(.12)\end{array}$ & -1.61 & $\begin{array}{c}.11 \\
{[-.42, .04]}\end{array}$ & $\begin{array}{l}-.06 \\
(.10)\end{array}$ & -.6 & $\begin{array}{c}.54 \\
{[-.26, .14]}\end{array}$ & $\begin{array}{l}.09 \\
(.1)\end{array}$ & .98 & $\begin{array}{c}.33 \\
{[-.09, .28]}\end{array}$ & $\begin{array}{l}.1 \\
(.09)\end{array}$ & 1.11 & $\begin{array}{c}.27 \\
{[-.07, .27]}\end{array}$ \\
\hline Age & $\begin{array}{l}.24 \\
(.09)\end{array}$ & 2.53 & $\begin{array}{c}.01^{*} \\
{[.06, .42]}\end{array}$ & $\begin{array}{l}.14 \\
(.08)\end{array}$ & 1.6 & $\begin{array}{c}.11 \\
{[-.03, .29]}\end{array}$ & $\begin{array}{l}.13 \\
(.08)\end{array}$ & 1.69 & $\begin{array}{c}.01 \\
{[-.02, .28]}\end{array}$ & $\begin{array}{l}-.24 \\
(.07)\end{array}$ & -3.38 & $\begin{array}{c}<.001^{* * *} \\
{[-.37,-.10]}\end{array}$ \\
\hline IQ & $\begin{array}{l}.05 \\
(.09)\end{array}$ & .58 & $\begin{array}{c}.56 \\
{[-.12, .23]}\end{array}$ & $\begin{array}{l}-.11 \\
(.08)\end{array}$ & -1.32 & $\begin{array}{c}.19 \\
{[-.26, .05]}\end{array}$ & $\begin{array}{l}.33 \\
(.08)\end{array}$ & 4.5 & $\begin{array}{l}<.001^{* * *} \\
{[.19, .48]}\end{array}$ & $\begin{array}{l}.56 \\
(.07)\end{array}$ & 8.21 & $\begin{array}{l}<.001^{* * *} \\
{[.43, .69]}\end{array}$ \\
\hline Gender & $\begin{array}{l}-.08 \\
(.09)\end{array}$ & -.91 & {$[-.26, .09]$} & $\begin{array}{c}0 \\
(.08)\end{array}$ & -.05 & $\begin{array}{c}.96 \\
{[-.16, .15]}\end{array}$ & $\begin{array}{l}.02 \\
(.08)\end{array}$ & .3 & $\begin{array}{c}.77 \\
{[-.12, .17]}\end{array}$ & $\begin{array}{l}-.14 \\
(.07)\end{array}$ & -2.03 & $\begin{array}{c}.05 \\
{[-.27,-.01]}\end{array}$ \\
\hline $\begin{array}{l}\text { Time } \\
\text { pre/post }\end{array}$ & $\begin{array}{l}.01 \\
(.07)\end{array}$ & .11 & $\begin{array}{c}.91 \\
{[-.12, .13]}\end{array}$ & $\begin{array}{l}-.03 \\
(.09)\end{array}$ & -.3 & $\begin{array}{c}.77 \\
{[-.20, .14]}\end{array}$ & $\begin{array}{l}.01 \\
(.06)\end{array}$ & .12 & $\begin{array}{c}.91 \\
{[-.11, .13]}\end{array}$ & $\begin{array}{l}-.02 \\
(.06)\end{array}$ & -.29 & $\begin{array}{c}.77 \\
{[-.13, .10]}\end{array}$ \\
\hline $\begin{array}{l}\text { AD: } \\
\text { Time } \\
\text { pre/post }\end{array}$ & $\begin{array}{c}.23 \\
(.09)\end{array}$ & 2.53 & $\begin{array}{c}.01^{*} \\
{[.06, .40]}\end{array}$ & $\begin{array}{c}.27 \\
(.12)\end{array}$ & 2.24 & $\begin{array}{c}.03 \\
{[.04, .50]}\end{array}$ & $\begin{array}{c}.06 \\
(.09)\end{array}$ & .66 & $\begin{array}{c}.51 \\
{[-.11, .22]}\end{array}$ & $\begin{array}{l}-.04 \\
(.08)\end{array}$ & -.44 & $\begin{array}{c}.66 \\
{[-.19, .12]}\end{array}$ \\
\hline $\begin{array}{l}\text { CIT: } \\
\text { Time } \\
\text { pre/post }\end{array}$ & $\begin{array}{l}-.12 \\
(.08)\end{array}$ & -1.46 & $\begin{array}{c}.15 \\
{[-.27, .04]}\end{array}$ & $\begin{array}{c}0 \\
(.11)\end{array}$ & -.02 & $\begin{array}{c}.99 \\
{[-.21, .21]}\end{array}$ & $\begin{array}{l}-.02 \\
(.08)\end{array}$ & -.23 & {$[-.82$} & $\begin{array}{l}-.13 \\
(.07)\end{array}$ & -1.77 & 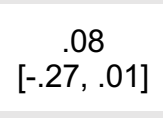 \\
\hline $\begin{array}{l}\text { SW: } \\
\text { Time } \\
\text { pre/post }\end{array}$ & $\begin{array}{l}-.16 \\
(.09)\end{array}$ & -1.87 & {$[-.33, .00]$} & $\begin{array}{c}-.3 \\
(.12)\end{array}$ & -2.52 & $\begin{array}{c}.01^{*} \\
{[-.52, .07]}\end{array}$ & $\begin{array}{l}-.04 \\
(.08)\end{array}$ & -.52 & {$\left[\begin{array}{c}.61 \\
{[-.20, .12]}\end{array}\right.$} & $\begin{array}{l}.15 \\
(.08)\end{array}$ & 1.96 & $\begin{array}{c}.05 \\
{[.00, .30]}\end{array}$ \\
\hline $\begin{array}{l}\text { Age: } \\
\text { Time } \\
\text { pre/post }\end{array}$ & $\begin{array}{l}.15 \\
(.07)\end{array}$ & 2.18 & $\begin{array}{c}.03 \\
{[.02, .28]}\end{array}$ & $\begin{array}{c}.18 \\
(.09)\end{array}$ & 2.02 & $\begin{array}{c}.05 \\
{[.01, .36]}\end{array}$ & $\begin{array}{c}.07 \\
(.07)\end{array}$ & .98 & $\begin{array}{c}.33 \\
{[-.06, .19]}\end{array}$ & $\begin{array}{c}.05 \\
(.06)\end{array}$ & .89 & $\begin{array}{c}.37 \\
{[-.06, .17]}\end{array}$ \\
\hline $\begin{array}{l}\text { IQ: } \\
\text { Time } \\
\text { pre/post }\end{array}$ & $\begin{array}{c}.02 \\
(.07)\end{array}$ & .27 & $\begin{array}{c}.79 \\
{[-.11, .15]}\end{array}$ & $\begin{array}{l}-.12 \\
(.09)\end{array}$ & -1.24 & $\begin{array}{c}.22 \\
{[-.28, .06]}\end{array}$ & $\begin{array}{c}.02 \\
(.06)\end{array}$ & .31 & $\begin{array}{c}.75 \\
{[-.10, .14]}\end{array}$ & $\begin{array}{l}-.06 \\
(.06)\end{array}$ & -1.04 & $\begin{array}{c}.31 \\
{[-.18, .05]}\end{array}$ \\
\hline $\begin{array}{l}\text { Gender: } \\
\text { Time } \\
\text { pre/post }\end{array}$ & $\begin{array}{l}-.16 \\
(.07)\end{array}$ & -2.36 & $\begin{array}{c}.02 \\
{[-.29,-.03]}\end{array}$ & $\begin{array}{l}.06 \\
(.09)\end{array}$ & .69 & $\begin{array}{c}.49 \\
{[-.11, .23]}\end{array}$ & $\begin{array}{l}-.06 \\
(.06)\end{array}$ & -1.02 & $\begin{array}{c}.31 \\
{[-.19, .06]}\end{array}$ & $\begin{array}{l}-.12 \\
(.06)\end{array}$ & -1.94 & $\begin{array}{c}.05 \\
{[-.23,-.00]}\end{array}$ \\
\hline
\end{tabular}

IP, Information Processing; AD, Anxious-Depression; CIT, Compulsive behavior and Intrusive Thought; SW, Social Withdrawal; $S E$, Standard Error. Uncorrected p values are shown in the table. The main text reports in addition p values FDR-corrected FDRcorrected over the number of dependent variables $(N=4)$, asterisks denote FDR-corrected significance *p<.05, ** $p<.01$, $* * * p<.001$ 
Supplementary Table 4. Results from linear mixed models examining longitudinal changes in survey-related measures of self-regulation

\begin{tabular}{|c|c|c|c|c|c|c|c|c|c|c|c|c|}
\hline & \multicolumn{3}{|c|}{ Agreeableness } & \multicolumn{3}{|c|}{ Emotional Control } & \multicolumn{3}{|c|}{ Ethical Risk-Taking } & \multicolumn{3}{|c|}{$\begin{array}{l}\text { Goal-directed } \\
\text { /Mindfulness }\end{array}$} \\
\hline & $\begin{array}{c}\beta \\
\text { (SE) }\end{array}$ & $\begin{array}{c}\mathbf{t} \\
\text { value }\end{array}$ & $p$ value & $\begin{array}{c}\beta \\
(\mathrm{SE})\end{array}$ & $\begin{array}{c}\mathbf{t} \\
\text { value }\end{array}$ & $p$ value & $\begin{array}{c}\beta \\
(\mathrm{SE})\end{array}$ & $\begin{array}{c}\mathbf{t} \\
\text { value }\end{array}$ & $p$ value & $\begin{array}{l}\beta \\
(\mathrm{SE})\end{array}$ & $\begin{array}{c}\mathbf{t} \\
\text { value }\end{array}$ & p value \\
\hline Intercept & $\begin{array}{l}-.03 \\
(.08)\end{array}$ & -.35 & $\begin{array}{c}.73 \\
{[-.18, .12]}\end{array}$ & $\begin{array}{l}-.01 \\
(.05)\end{array}$ & -.18 & $\begin{array}{c}.86 \\
{[-.10, .09]}\end{array}$ & $\begin{array}{c}.03 \\
(.08)\end{array}$ & .42 & $\begin{array}{c}.66 \\
{[-.12, .18]}\end{array}$ & $\begin{array}{l}-.03 \\
(.07)\end{array}$ & -.47 & $\begin{array}{c}.64 \\
{[-.16, .09]}\end{array}$ \\
\hline$A D$ & $\begin{array}{l}-.5 \\
(.11)\end{array}$ & -4.69 & $\begin{array}{c}<.001^{* * *} \\
{[-.71,-.30]}\end{array}$ & $\begin{array}{c}-.43 \\
(.07)\end{array}$ & -6.39 & $\begin{array}{c}<.001^{* * *} \\
{[-.56,-.30]}\end{array}$ & $\begin{array}{c}.04 \\
(.11)\end{array}$ & .33 & $\begin{array}{c}.74 \\
{[-.17, .24]}\end{array}$ & $\begin{array}{c}-.76 \\
(.09)\end{array}$ & -8.43 & $\begin{array}{c}<.001^{* * *} \\
{[-.93,-.58]}\end{array}$ \\
\hline CIT & $\begin{array}{c}.08 \\
(.10)\end{array}$ & .85 & $\begin{array}{c}.40 \\
{[-.10, .27]}\end{array}$ & $\begin{array}{c}-.24 \\
(.06)\end{array}$ & -3.97 & $\begin{array}{c}<.001^{* * *} \\
{[-.36,-.13]}\end{array}$ & $\begin{array}{c}.29 \\
(.10)\end{array}$ & 2.96 & $\begin{array}{l}<.001^{* * *} \\
{[.10, .47]}\end{array}$ & $\begin{array}{c}.01 \\
(.08)\end{array}$ & .13 & $\frac{.9}{[-.14, .17]}$ \\
\hline SW & $\begin{array}{c}.20 \\
(.10)\end{array}$ & 1.91 & $\begin{array}{c}.06 \\
{[.00, .39]}\end{array}$ & $\begin{array}{c}-.41 \\
(.06)\end{array}$ & -6.3 & $\begin{array}{c}<.001^{* * *} \\
{[-.53,-.29]}\end{array}$ & $\begin{array}{c}.03 \\
(.10)\end{array}$ & .26 & $\begin{array}{c}.80 \\
{[-.17, .22]}\end{array}$ & $\begin{array}{l}.13 \\
(.09)\end{array}$ & 1.56 & {$\left[\begin{array}{c}.12 \\
{[-.03, .30]}\end{array}\right.$} \\
\hline Age & $\begin{array}{l}-.03 \\
(.08)\end{array}$ & -.37 & $\begin{array}{c}.71 \\
{[-.19, .13]}\end{array}$ & $\begin{array}{c}.02 \\
(.05)\end{array}$ & .36 & $\begin{array}{c}.72 \\
{[-.08, .12]}\end{array}$ & $\begin{array}{c}-.2 \\
(.08)\end{array}$ & -2.47 & {$[-.02$} & $\begin{array}{c}.08 \\
(.07)\end{array}$ & 1.18 & $\begin{array}{c}.24 \\
{[-.05, .21]}\end{array}$ \\
\hline IQ & $\begin{array}{l}-.08 \\
(.08)\end{array}$ & -.94 & $\begin{array}{c}.35 \\
{[-.23, .08]}\end{array}$ & $\begin{array}{l}-.05 \\
(.05)\end{array}$ & -1.00 & $\begin{array}{c}.32 \\
{[-.15, .05]}\end{array}$ & $\begin{array}{c}.13 \\
(.08)\end{array}$ & 1.68 & {$[-.02, .29]$} & $\begin{array}{l}-.13 \\
(.07)\end{array}$ & -1.98 & $\begin{array}{c}.05 \\
{[-.26,-.01]}\end{array}$ \\
\hline Gender & $\begin{array}{c}.11 \\
(.08)\end{array}$ & 1.38 & $\begin{array}{c}.17 \\
{[-.04, .26]}\end{array}$ & $\begin{array}{c}-.13 \\
(.05)\end{array}$ & -2.59 & $\begin{array}{c}.01^{*} \\
{[-.23,-.03]}\end{array}$ & $\begin{array}{c}-.23 \\
(.08)\end{array}$ & -2.91 & $\begin{array}{c}<.001^{* * *} \\
{[-.39,-.08]}\end{array}$ & $\begin{array}{l}-.02 \\
(.07)\end{array}$ & -.32 & $\begin{array}{c}.75 \\
{[-.15, .11]}\end{array}$ \\
\hline $\begin{array}{l}\text { Time } \\
\text { pre/post }\end{array}$ & $\begin{array}{l}-.02 \\
(.06)\end{array}$ & -.34 & $\begin{array}{c}.74 \\
{[-.13, .09]}\end{array}$ & $\begin{array}{c}.01 \\
(.05)\end{array}$ & .14 & $\begin{array}{c}.89 \\
{[-.08, .09]}\end{array}$ & $\begin{array}{l}-.02 \\
(.06)\end{array}$ & -.26 & $\begin{array}{c}.79 \\
{[-.13, .10]}\end{array}$ & $\begin{array}{l}-.01 \\
(.04)\end{array}$ & -.26 & {$\left[\begin{array}{c}.8 \\
{[-.09, .07]}\end{array}\right.$} \\
\hline $\begin{array}{l}\text { AD: } \\
\text { Time } \\
\text { pre/post }\end{array}$ & $\begin{array}{l}-.10 \\
(.08)\end{array}$ & -1.27 & $\begin{array}{c}.21 \\
{[-.25, .05]}\end{array}$ & $\begin{array}{l}-.03 \\
(.06)\end{array}$ & -.49 & $\begin{array}{c}.63 \\
{[-.15, .09]}\end{array}$ & $\begin{array}{l}.06 \\
(.08)\end{array}$ & .77 & $\begin{array}{c}.44 \\
{[-.10, .22]}\end{array}$ & $\begin{array}{l}-.08 \\
(.05)\end{array}$ & -1.54 & $\begin{array}{c}.13 \\
{[-.19, .02]}\end{array}$ \\
\hline $\begin{array}{l}\text { CIT: } \\
\text { Time } \\
\text { pre/post }\end{array}$ & $\begin{array}{l}.03 \\
(.07)\end{array}$ & .41 & $\begin{array}{c}.69 \\
{[-.11, .17]}\end{array}$ & $\begin{array}{c}.03 \\
(.06)\end{array}$ & .53 & $\begin{array}{c}.59 \\
{[-.08, .14]}\end{array}$ & $\begin{array}{c}-.04 \\
(.07)\end{array}$ & -.5 & $\begin{array}{c}.62 \\
{[-.18, .11]}\end{array}$ & $\begin{array}{l}-.06 \\
(.05)\end{array}$ & -1.14 & $\begin{array}{c}.26 \\
{[-.15, .04]}\end{array}$ \\
\hline $\begin{array}{l}\text { SW: } \\
\text { Time } \\
\text { pre/post }\end{array}$ & $\begin{array}{l}.08 \\
(.08)\end{array}$ & 1.01 & $\begin{array}{c}.31 \\
{[-.07, .23]}\end{array}$ & $\begin{array}{l}-.06 \\
(.06)\end{array}$ & -.93 & $\begin{array}{c}.36 \\
{[-.17, .06]}\end{array}$ & $\begin{array}{l}.05 \\
(.08)\end{array}$ & .63 & $\begin{array}{c}.53 \\
{[-.10, .20]}\end{array}$ & $\begin{array}{l}-.03 \\
(.05)\end{array}$ & -.50 & $\begin{array}{c}.62 \\
{[-.13, .07]}\end{array}$ \\
\hline $\begin{array}{l}\text { Age: } \\
\text { Time }\end{array}$ & $\begin{array}{c}.10 \\
(.06)\end{array}$ & 1.61 & $\begin{array}{c}.11 \\
{[-.02, .21]}\end{array}$ & $\begin{array}{l}-.01 \\
(.05)\end{array}$ & -.16 & $\begin{array}{c}.87 \\
{[-.10, .08]}\end{array}$ & $\begin{array}{c}.11 \\
(.06)\end{array}$ & 1.77 & $\begin{array}{c}.08 \\
{[-.01, .23]}\end{array}$ & $\begin{array}{c}.04 \\
(.04)\end{array}$ & .92 & $\begin{array}{c}.36 \\
{[-.04, .12]}\end{array}$ \\
\hline $\begin{array}{l}\text { IQ: } \\
\text { Time } \\
\text { pre/post }\end{array}$ & $\begin{array}{l}.14 \\
(.06)\end{array}$ & 2.29 & $\begin{array}{c}.02 \\
{[.02, .25]}\end{array}$ & $\begin{array}{c}.03 \\
(.05)\end{array}$ & .7 & $\begin{array}{c}.49 \\
{[-.06, .12]}\end{array}$ & $\begin{array}{l}-.1 \\
(.06)\end{array}$ & -1.69 & $\begin{array}{c}.09 \\
{[-.22, .01]}\end{array}$ & $\begin{array}{c}.02 \\
(.04)\end{array}$ & .54 & $\begin{array}{c}.59 \\
{[-.06, .10]}\end{array}$ \\
\hline $\begin{array}{l}\text { Gender: } \\
\text { Time } \\
\text { pre/post }\end{array}$ & $\begin{array}{l}.07 \\
(.06)\end{array}$ & 1.21 & $\begin{array}{c}.23 \\
{[-.04, .19]}\end{array}$ & $\begin{array}{l}.03 \\
(.05)\end{array}$ & .56 & $\begin{array}{c}.56 \\
{[-.06, .12]}\end{array}$ & $\begin{array}{l}-.04 \\
(.06)\end{array}$ & -.59 & $\begin{array}{c}.56 \\
{[-.15, .08]}\end{array}$ & $\begin{array}{l}.06 \\
(.04)\end{array}$ & 1.37 & $\begin{array}{c}.18 \\
{[-.02, .13]}\end{array}$ \\
\hline
\end{tabular}




\begin{tabular}{|c|c|c|c|c|c|c|c|c|c|c|c|c|}
\hline & \multicolumn{3}{|c|}{ Reward Sensitivity } & \multicolumn{3}{|c|}{ Risk Perception } & \multicolumn{3}{|c|}{ Sensation Seeking } & \multicolumn{3}{|c|}{ Social Risk Taking } \\
\hline & $\begin{array}{c}\beta \\
\text { (SE) }\end{array}$ & $\begin{array}{c}\mathbf{t} \\
\text { value }\end{array}$ & $p$ value & $\begin{array}{c}\beta \\
\text { (SE) }\end{array}$ & $\begin{array}{c}\mathbf{t} \\
\text { value }\end{array}$ & $p$ value & $\begin{array}{c}\beta \\
\text { (SE) }\end{array}$ & $\begin{array}{c}\mathbf{t} \\
\text { value }\end{array}$ & $p$ value & $\begin{array}{c}\beta \\
\text { (SE) }\end{array}$ & $\begin{array}{c}\mathbf{t} \\
\text { value }\end{array}$ & $p$ value \\
\hline Intercept & $\begin{array}{l}.01 \\
(.07)\end{array}$ & .13 & $\begin{array}{c}.89 \\
{[-.13, .15]}\end{array}$ & $\begin{array}{l}-.07 \\
(.08)\end{array}$ & -.81 & $\begin{array}{c}.42 \\
{[-.23, .09]}\end{array}$ & $\begin{array}{l}.01 \\
(.09)\end{array}$ & .16 & $\begin{array}{c}.88 \\
{[-.15, .18]}\end{array}$ & $\begin{array}{c}.04 \\
(.08)\end{array}$ & .47 & $\begin{array}{c}.64 \\
{[-.11, .19]}\end{array}$ \\
\hline$A D$ & $\begin{array}{l}.05 \\
(.10)\end{array}$ & .53 & $\begin{array}{c}.60 \\
{[-.14, .24]}\end{array}$ & $\begin{array}{l}-.34 \\
(.12)\end{array}$ & -2.95 & $\begin{array}{c}<.001^{* * *} \\
{[-.56,-.12]}\end{array}$ & $\begin{array}{l}.14 \\
(.12)\end{array}$ & 1.21 & $\begin{array}{c}.23 \\
{[-.08, .37]}\end{array}$ & $\begin{array}{l}-.15 \\
(.11)\end{array}$ & -1.39 & {$[-. .17, .06]$} \\
\hline CIT & $\begin{array}{c}.45 \\
(.09)\end{array}$ & 4.94 & $\begin{array}{l}<.001^{* * *} \\
{[.27, .62]}\end{array}$ & $\begin{array}{l}.16 \\
(.10)\end{array}$ & 1.49 & {$[-.04, .36]$} & $\begin{array}{c}.32 \\
(.11)\end{array}$ & 2.96 & $\begin{array}{c}<.001^{* * *} \\
{[.11, .53]}\end{array}$ & $\begin{array}{c}.52 \\
(.10)\end{array}$ & 5.38 & $\begin{array}{c}<.001^{* * *} \\
{[.34, .71]}\end{array}$ \\
\hline SW & $\begin{array}{l}-.61 \\
(.10)\end{array}$ & -6.38 & $\begin{array}{c}<.001^{\star * *} \\
{[-.79,-.43]}\end{array}$ & $\begin{array}{c}.2 \\
(.11)\end{array}$ & 1.81 & $\begin{array}{c}.07 \\
{[-.01, .41]}\end{array}$ & $\begin{array}{l}-.43 \\
(.11)\end{array}$ & -3.76 & $\begin{array}{c}<.001^{* * *} \\
{[-.65,-.21]}\end{array}$ & $\begin{array}{l}-.41 \\
(.10)\end{array}$ & -4.01 & $\begin{array}{c}<.001^{* * *} \\
{[-.61,-.22]}\end{array}$ \\
\hline Age & $\begin{array}{c}0 \\
(.08)\end{array}$ & .01 & {$[-.1$} & $\begin{array}{c}.03 \\
(.09)\end{array}$ & .34 & $\begin{array}{c}.74 \\
{[-.14, .20]}\end{array}$ & $\begin{array}{c}.01 \\
(.09)\end{array}$ & .1 & {$[-.92$} & $\begin{array}{c}.04 \\
(.08)\end{array}$ & .43 & $\begin{array}{c}.67 \\
{[-.12, .19]}\end{array}$ \\
\hline IQ & $\begin{array}{l}-.15 \\
(.07)\end{array}$ & -1.98 & $\begin{array}{c}.05 \\
{[-.29,-.01]}\end{array}$ & $\begin{array}{l}-.13 \\
(.09)\end{array}$ & -1.52 & $\begin{array}{c}.13 \\
{[-.29, .03]}\end{array}$ & $\begin{array}{c}.1 \\
(.09)\end{array}$ & 1.15 & $\begin{array}{c}.25 \\
{[-.07, .27]}\end{array}$ & $\begin{array}{l}-.03 \\
(.08)\end{array}$ & -.40 & $\begin{array}{c}.69 \\
{[-.19, .12]}\end{array}$ \\
\hline Gender & $\begin{array}{l}-.13 \\
(.07)\end{array}$ & -1.78 & $\begin{array}{c}.08 \\
{[-.28, .01]}\end{array}$ & $\begin{array}{l}.12 \\
(.09)\end{array}$ & 1.34 & $\begin{array}{c}.18 \\
{[-.05, .28]}\end{array}$ & $\begin{array}{l}-.25 \\
(.09)\end{array}$ & -2.77 & $\begin{array}{c}.01^{*} \\
{[-.42,-.08]}\end{array}$ & $\begin{array}{c}.09 \\
(.08)\end{array}$ & 1.16 & $\begin{array}{c}.25 \\
{[-.06, .25]}\end{array}$ \\
\hline $\begin{array}{l}\text { Time } \\
\text { pre/post }\end{array}$ & $\begin{array}{l}.01 \\
(.06)\end{array}$ & .10 & $\begin{array}{c}.92 \\
{[-.10, .11]}\end{array}$ & $\begin{array}{l}-.01 \\
(.06)\end{array}$ & -.2 & $\begin{array}{c}.85 \\
{[-.14, .11]}\end{array}$ & $\begin{array}{c}0 \\
(.05)\end{array}$ & .05 & $\begin{array}{c}.96 \\
{[-.10, .11]}\end{array}$ & $\begin{array}{c}0 \\
(.06)\end{array}$ & -.08 & $\begin{array}{c}.94 \\
{[-.12, .11]}\end{array}$ \\
\hline $\begin{array}{l}\text { AD: } \\
\text { Time } \\
\text { pre/post }\end{array}$ & $\begin{array}{l}-.09 \\
(.08)\end{array}$ & -1.13 & $\begin{array}{c}.26 \\
{[-.23, .06]}\end{array}$ & $\begin{array}{c}.06 \\
(.09)\end{array}$ & .74 & $\begin{array}{c}.46 \\
{[-.10, .23]}\end{array}$ & $\begin{array}{l}-.09 \\
(.07)\end{array}$ & -1.18 & $\begin{array}{c}.24 \\
{[-.23, .06]}\end{array}$ & $\begin{array}{l}-.04 \\
(.08)\end{array}$ & -.49 & $\begin{array}{c}.62 \\
{[-.20, .12]}\end{array}$ \\
\hline $\begin{array}{l}\text { CIT: } \\
\text { Time } \\
\text { pre/post }\end{array}$ & $\begin{array}{c}.1 \\
(.07)\end{array}$ & 1.43 & $\begin{array}{c}.15 \\
{[-.03, .23]}\end{array}$ & $\begin{array}{l}-.06 \\
(.08)\end{array}$ & -.7 & $\begin{array}{c}.49 \\
{[-.21, .10]}\end{array}$ & $\begin{array}{c}.15 \\
(.07)\end{array}$ & 2.22 & $\begin{array}{c}.03 \\
{[.02, .28]}\end{array}$ & $\begin{array}{l}.14 \\
(.08)\end{array}$ & 1.89 & $\begin{array}{c}.06 \\
{[.00, .29]}\end{array}$ \\
\hline $\begin{array}{l}\text { SW: } \\
\text { Time } \\
\text { pre/post }\end{array}$ & $\begin{array}{l}-.04 \\
(.07)\end{array}$ & -.61 & $\begin{array}{c}.55 \\
{[-.18, .10]}\end{array}$ & $\begin{array}{c}.06 \\
(.08)\end{array}$ & .73 & $\begin{array}{c}.47 \\
{[-.10, .22]}\end{array}$ & $\begin{array}{l}-.07 \\
(.07)\end{array}$ & -.98 & $\begin{array}{c}.33 \\
{[-.21, .07]}\end{array}$ & $\begin{array}{l}-.05 \\
(.08)\end{array}$ & -.62 & $\begin{array}{c}.53 \\
{[-.21, .10]}\end{array}$ \\
\hline $\begin{array}{l}\text { Age: } \\
\text { Time }\end{array}$ & $\begin{array}{l}-.05 \\
(.06)\end{array}$ & -.94 & {$[-.17, .06]$} & $\begin{array}{l}-.09 \\
(.07)\end{array}$ & -1.28 & {$[-.21, .04]$} & $\begin{array}{l}-.05 \\
(.06)\end{array}$ & -.92 & $\begin{array}{c}.36 \\
{[-.16, .06]}\end{array}$ & $\begin{array}{c}.04 \\
(.06)\end{array}$ & .68 & $\begin{array}{c}.49 \\
{[-.08, .17]}\end{array}$ \\
\hline $\begin{array}{l}\text { IQ: } \\
\text { Time } \\
\text { pre/post }\end{array}$ & $\begin{array}{l}-.06 \\
(.06)\end{array}$ & -1.02 & $\begin{array}{c}.31 \\
{[-.17, .05]}\end{array}$ & $\begin{array}{l}-.12 \\
(.07)\end{array}$ & -1.85 & $\begin{array}{c}.07 \\
{[-.25, .00]}\end{array}$ & $\begin{array}{l}-.04 \\
(.06)\end{array}$ & -.64 & $\begin{array}{c}.52 \\
{[-.14, .07]}\end{array}$ & $\begin{array}{l}-.09 \\
(.06)\end{array}$ & -1.35 & $\begin{array}{c}.18 \\
{[-.21, .04]}\end{array}$ \\
\hline $\begin{array}{l}\text { Gender: } \\
\text { Time } \\
\text { pre/post }\end{array}$ & $\begin{array}{c}.03 \\
(.06)\end{array}$ & .49 & $\begin{array}{c}.62 \\
{[-.08, .14]}\end{array}$ & $\begin{array}{l}-.00 \\
(.07)\end{array}$ & -.08 & $\begin{array}{c}.94 \\
{[-.13, .12]}\end{array}$ & $\begin{array}{c}.03 \\
(.06)\end{array}$ & .47 & $\begin{array}{c}.64 \\
{[-.08, .13]}\end{array}$ & $\begin{array}{l}-.01 \\
(.06)\end{array}$ & -.14 & $\begin{array}{c}.89 \\
{[-.13, .11]}\end{array}$ \\
\hline
\end{tabular}


Supplementary Table 5. Results from linear mixed models examining the trajectories of wellbeing related to the pandemic onset

\begin{tabular}{|c|c|c|c|c|c|c|c|c|c|}
\hline & \multicolumn{3}{|c|}{ Perceived stress } & \multicolumn{3}{|c|}{ Loneliness } & \multicolumn{3}{|c|}{ Social support } \\
\hline & $\begin{array}{c}\beta \\
(\mathrm{SE}) \\
\end{array}$ & $\begin{array}{c}\mathbf{t} \\
\text { value }\end{array}$ & $\begin{array}{c}p \text { value } \\
{[95 \% \mathrm{Cl}]}\end{array}$ & $\begin{array}{c}\beta \\
(\mathrm{SE}) \\
\end{array}$ & $\begin{array}{c}\mathbf{t} \\
\text { value } \\
\end{array}$ & $\begin{array}{c}p \text { value } \\
{[95 \% \mathrm{Cl}]}\end{array}$ & $\begin{array}{c}\beta \\
(\mathrm{SE}) \\
\end{array}$ & $\begin{array}{c}\mathbf{t} \\
\text { value } \\
\end{array}$ & $\begin{array}{c}p \text { value } \\
{[95 \% \mathrm{Cl}]}\end{array}$ \\
\hline Intercept & $\begin{array}{l}-.01 \\
(.05)\end{array}$ & -.12 & $\begin{array}{c}.90 \\
{[-.10, .09]}\end{array}$ & $\begin{array}{l}.01 \\
(.07)\end{array}$ & .08 & $\begin{array}{c}.94 \\
{[-.13, .14]}\end{array}$ & $\begin{array}{l}-.03 \\
(.08)\end{array}$ & -.41 & $\begin{array}{c}.68 \\
{[-.18, .11]}\end{array}$ \\
\hline Mindset stress & $\begin{array}{l}.06 \\
(.05)\end{array}$ & 1.08 & $\begin{array}{c}.28 \\
{[-.04, .16]}\end{array}$ & $\begin{array}{l}-.14 \\
(.08)\end{array}$ & -1.83 & $\begin{array}{c}.07 \\
{[-.28, .01]}\end{array}$ & $\begin{array}{l}.12 \\
(.08)\end{array}$ & 1.47 & $\begin{array}{c}.14 \\
{[-.04, .28]}\end{array}$ \\
\hline Mindset pandemic & $\begin{array}{l}-.03 \\
(.05)\end{array}$ & -.61 & $\begin{array}{c}.54 \\
{[-.14, .07]}\end{array}$ & $\begin{array}{c}.06 \\
(.08)\end{array}$ & .77 & $\begin{array}{c}.44 \\
{[-.09, .20]}\end{array}$ & $\begin{array}{c}.1 \\
(.08)\end{array}$ & 1.28 & $\begin{array}{c}.20 \\
{[-.05, .26]}\end{array}$ \\
\hline$A D$ & $\begin{array}{c}.52 \\
(.07)\end{array}$ & 7.37 & $\begin{array}{l}<.001^{* * *} \\
{[.38, .65]}\end{array}$ & $\begin{array}{l}.30 \\
(.10)\end{array}$ & 3.03 & $\begin{array}{l}<.001^{* * *} \\
{[.11, .48]}\end{array}$ & $\begin{array}{l}-.52 \\
(.11)\end{array}$ & -4.89 & $\begin{array}{c}<.001^{* * *} \\
{[-.72,-.32]}\end{array}$ \\
\hline CIT & $\begin{array}{c}.26 \\
(.06)\end{array}$ & 4.04 & $\begin{array}{l}<.001^{* * *} \\
{[.14, .38]}\end{array}$ & $\begin{array}{l}.18 \\
(.09)\end{array}$ & 2.05 & $\begin{array}{c}.04 \\
{[.01, .35]}\end{array}$ & $\begin{array}{l}-.02 \\
(.10)\end{array}$ & -.23 & $\begin{array}{c}.82 \\
{[-.20, .16]}\end{array}$ \\
\hline SW & $\begin{array}{c}.2 \\
(.07)\end{array}$ & 2.99 & $\begin{array}{l}<.001^{* * *} \\
{[.07, .33]}\end{array}$ & $\begin{array}{l}.18 \\
(.09)\end{array}$ & 1.96 & $\begin{array}{c}.05 \\
{[.01, .36]}\end{array}$ & $\begin{array}{l}-.16 \\
(.10)\end{array}$ & -1.56 & {$\left[\begin{array}{c}.12 \\
{[-.35, .03]}\end{array}\right.$} \\
\hline Age & $\begin{array}{l}.06 \\
(.05)\end{array}$ & 1.07 & $\begin{array}{c}.29 \\
{[-.04, .16]}\end{array}$ & $\begin{array}{l}.05 \\
(.07)\end{array}$ & .71 & $\begin{array}{c}.48 \\
{[-.09, .19]}\end{array}$ & $\begin{array}{l}.01 \\
(.08)\end{array}$ & .18 & $\begin{array}{c}.86 \\
{[-.14, .17]}\end{array}$ \\
\hline Gender & $\begin{array}{l}.01 \\
(.05)\end{array}$ & .10 & {$[-.09, .10]$} & $\begin{array}{l}-.12 \\
(.07)\end{array}$ & -1.69 & $\begin{array}{c}.09 \\
{[-.26, .02]}\end{array}$ & $\begin{array}{l}.08 \\
(.08)\end{array}$ & 1.04 & {$[-. .30$} \\
\hline Time pre/post & $\begin{array}{l}-.02 \\
(.07)\end{array}$ & -.25 & $\begin{array}{c}.80 \\
{[-.15, .12]}\end{array}$ & $\begin{array}{l}-.01 \\
(.09)\end{array}$ & -.12 & {$[-.18, .15]$} & $\begin{array}{l}-.01 \\
(.04)\end{array}$ & -.19 & $\begin{array}{c}.85 \\
{[-.08, .07]}\end{array}$ \\
\hline $\begin{array}{l}\text { Mindset stress: } \\
\text { Time pre/post }\end{array}$ & $\begin{array}{l}.08 \\
(.08)\end{array}$ & 1.11 & $\begin{array}{c}.27 \\
{[-.06, .23]}\end{array}$ & $\begin{array}{l}.11 \\
(.09)\end{array}$ & 1.22 & $\begin{array}{c}.22 \\
{[-.06, .29]}\end{array}$ & $\begin{array}{l}-.02 \\
(.04)\end{array}$ & -.53 & $\begin{array}{c}.60 \\
{[-.10, .06]}\end{array}$ \\
\hline $\begin{array}{l}\text { Mindset pandemic: } \\
\text { Time pre/post }\end{array}$ & $\begin{array}{l}.07 \\
(.07)\end{array}$ & .93 & {$[-.07, .21]$} & $\begin{array}{l}.21 \\
(.09)\end{array}$ & 2.25 & $\begin{array}{c}.03 \\
{[.03, .38]}\end{array}$ & $\begin{array}{l}-.06 \\
(.04)\end{array}$ & -1.36 & $\begin{array}{c}.18 \\
{[-.14, .02]}\end{array}$ \\
\hline $\begin{array}{l}\text { AD: } \\
\text { Time pre/post }\end{array}$ & $\begin{array}{l}-.04 \\
(.1)\end{array}$ & -.45 & $\begin{array}{c}.65 \\
{[-.23, .14]}\end{array}$ & $\begin{array}{l}-.19 \\
(.12)\end{array}$ & -1.56 & {$[-.42, .04]$} & $\begin{array}{l}-.07 \\
(.05)\end{array}$ & -1.33 & $\begin{array}{c}.19 \\
{[-.18, .03]}\end{array}$ \\
\hline $\begin{array}{l}\text { CIT: } \\
\text { Time pre/post }^{-}\end{array}$ & $\begin{array}{l}.02 \\
(.09)\end{array}$ & .2 & $\begin{array}{c}.84 \\
{[-.15, .18]}\end{array}$ & $\begin{array}{l}.07 \\
(.11)\end{array}$ & .61 & $\begin{array}{c}.54 \\
{[-.14, .27]}\end{array}$ & $\begin{array}{c}0 \\
(.05)\end{array}$ & .01 & $\begin{array}{c}.99 \\
{[-.09, .09]}\end{array}$ \\
\hline $\begin{array}{l}\text { SW: } \\
\text { Time pre/post }\end{array}$ & $\begin{array}{l}.03 \\
(.09)\end{array}$ & .32 & $\begin{array}{c}.75 \\
{[-.15, .20]}\end{array}$ & $\begin{array}{l}.03 \\
(.11)\end{array}$ & .29 & $\begin{array}{c}.77 \\
{[-.18, .25]}\end{array}$ & $\begin{array}{l}.05 \\
(.05)\end{array}$ & 1.05 & $\begin{array}{c}.30 \\
{[-.04, .15]}\end{array}$ \\
\hline $\begin{array}{l}\text { Age: } \\
\text { Time pre/post }\end{array}$ & $\begin{array}{l}.11 \\
(.07)\end{array}$ & 1.45 & {$[-.15$} & $\begin{array}{c}.09 \\
(.09)\end{array}$ & .99 & {$[-.33$} & $\begin{array}{l}.03 \\
(.04)\end{array}$ & .70 & $\begin{array}{c}.48 \\
{[-.05, .11]}\end{array}$ \\
\hline $\begin{array}{l}\text { Gender: } \\
\text { Time pre/post }\end{array}$ & $\begin{array}{l}-.04 \\
(.07)\end{array}$ & -.54 & $\begin{array}{c}.59 \\
{[-.17, .10]}\end{array}$ & $\begin{array}{l}-.08 \\
(.09)\end{array}$ & -.91 & $\begin{array}{c}.36 \\
{[-.25, .09]}\end{array}$ & $\begin{array}{l}.03 \\
(.04)\end{array}$ & .80 & $\begin{array}{c}.43 \\
{[-.04, .11]}\end{array}$ \\
\hline
\end{tabular}

AD, Anxious-Depression; CIT, Compulsive behavior and Intrusive Thought; SW, Social Withdrawal; SE, Standard Error. Uncorrected $p$ values are shown in the table. The main text reports p values FDR-corrected over the number of dependent variables $(N=3)$, asterisks denote FDR-corrected significance $* p<.05, * * p<.01, * * * p<.001$ 
Supplementary Table 6. Results from linear models examining the subjective impact of the pandemic onset

\begin{tabular}{|c|c|c|c|c|c|c|c|c|c|c|c|c|}
\hline & \multicolumn{3}{|c|}{ COVID-19 worries } & \multicolumn{3}{|c|}{ Changes relationship } & \multicolumn{3}{|c|}{ Economic concern } & \multicolumn{3}{|c|}{ General anxiety } \\
\hline & $\stackrel{\beta}{\beta}$ & $\begin{array}{c}\mathbf{t} \\
\text { value }\end{array}$ & $\begin{array}{c}\text { p value } \\
{[95 \% \mathrm{Cl}]}\end{array}$ & $\stackrel{\beta}{\beta}$ & $\begin{array}{c}t \\
\text { value }\end{array}$ & $\begin{array}{c}\text { p value } \\
{[95 \% \mathrm{Cl}]}\end{array}$ & $\begin{array}{c}\beta \\
\text { (SE) }\end{array}$ & $\begin{array}{c}\mathbf{t} \\
\text { value }\end{array}$ & $\begin{array}{c}\text { p value } \\
{[95 \% \mathrm{Cl}]}\end{array}$ & $\stackrel{\beta}{\beta}$ & $\begin{array}{c}t \\
\text { value }\end{array}$ & $\begin{array}{c}\text { p value } \\
{[95 \% \mathrm{Cl}]}\end{array}$ \\
\hline Intercept & $\begin{array}{l}-.01 \\
(.07)\end{array}$ & -.19 & $\begin{array}{c}.85 \\
{[-.14, .12]}\end{array}$ & $\begin{array}{c}00 \\
(.06)\end{array}$ & -.06 & $\begin{array}{c}.95 \\
{[-.13, .12]}\end{array}$ & $\begin{array}{l}-.02 \\
(.06)\end{array}$ & -.28 & $\begin{array}{c}.78 \\
{[-.14, .11]}\end{array}$ & $\begin{array}{c}.03 \\
(.06)\end{array}$ & .48 & $\begin{array}{c}.63 \\
{[-.09, .15]}\end{array}$ \\
\hline $\begin{array}{l}\text { Mindset } \\
\text { stress }\end{array}$ & $\begin{array}{l}-.13 \\
(.07)\end{array}$ & -1.82 & {$[-.27, .01]$} & $\begin{array}{l}.20 \\
(.07)\end{array}$ & 3.07 & $\begin{array}{l}<.001^{\star * *} \\
{[.07, .33]}\end{array}$ & $\begin{array}{l}.08 \\
(.07)\end{array}$ & 1.18 & $\begin{array}{c}.24 \\
{[-.05, .22]}\end{array}$ & $\begin{array}{l}-.07 \\
(.06)\end{array}$ & -1.1 & $\begin{array}{c}.27 \\
{[-.20, .06]}\end{array}$ \\
\hline $\begin{array}{l}\text { Mindset } \\
\text { pandemic }\end{array}$ & $\begin{array}{l}.21 \\
(.07)\end{array}$ & 3.01 & $\begin{array}{c}.001^{* * *} \\
{[.07, .35]}\end{array}$ & $\begin{array}{c}.03 \\
(.07)\end{array}$ & .44 & $\begin{array}{c}.66 \\
{[-.10, .16]}\end{array}$ & $\begin{array}{l}-.06 \\
(.07)\end{array}$ & -.87 & $\begin{array}{c}.39 \\
{[-.19, .08]}\end{array}$ & $\begin{array}{l}.07 \\
(.06)\end{array}$ & 1.1 & $\begin{array}{c}.27 \\
{[-.06, .20]}\end{array}$ \\
\hline$A D$ & $\begin{array}{l}-.21 \\
(.09)\end{array}$ & -2.28 & $\begin{array}{c}.02 \\
{[-.39,-} \\
.03]\end{array}$ & $\begin{array}{l}-.29 \\
(.08)\end{array}$ & -3.42 & $\begin{array}{c}<.001^{* * *} \\
{[-.46,-.12]}\end{array}$ & $\begin{array}{c}.16 \\
(.09)\end{array}$ & 1.81 & $\begin{array}{c}.07 \\
{[-.01, .34]}\end{array}$ & $\begin{array}{c}.09 \\
(.08)\end{array}$ & 1.12 & $\begin{array}{c}.26 \\
{[-.07, .26]}\end{array}$ \\
\hline CIT & $\begin{array}{c}.45 \\
(.08)\end{array}$ & 5.52 & $\begin{array}{l}<.001^{* * *} \\
{[.29, .62]}\end{array}$ & $\begin{array}{l}-.09 \\
(.08)\end{array}$ & -1.17 & $\begin{array}{c}.25 \\
{[-.24, .06]}\end{array}$ & $\begin{array}{l}.19 \\
(.08)\end{array}$ & 2.42 & $\begin{array}{c}.02^{*} \\
{[.04, .35]}\end{array}$ & $\begin{array}{c}.28 \\
(.07)\end{array}$ & 3.72 & $\begin{array}{c}<.001^{* * *} \\
{[.13, .42]}\end{array}$ \\
\hline SW & $\begin{array}{l}.06 \\
(.09)\end{array}$ & .75 & $\begin{array}{c}.46 \\
{[-.11, .24]}\end{array}$ & $\begin{array}{l}-.05 \\
(.08)\end{array}$ & -.62 & {$[-.21, .11]$} & $\begin{array}{l}-.03 \\
(.08)\end{array}$ & -.35 & $\begin{array}{c}.73 \\
{[-.20, .14]}\end{array}$ & $\begin{array}{c}.28 \\
(.08)\end{array}$ & 3.61 & $\begin{array}{c}<.001^{* * *} \\
{[.13, .44]}\end{array}$ \\
\hline Age & $\begin{array}{l}.00 \\
(.07)\end{array}$ & .04 & $\begin{array}{c}.97 \\
{[-.13, .14]}\end{array}$ & $\begin{array}{l}.09 \\
(.06)\end{array}$ & 1.35 & {$[-.04, .21]$} & $\begin{array}{l}-.06 \\
(.07)\end{array}$ & -.87 & $\begin{array}{c}.39 \\
{[-.19, .07]}\end{array}$ & $\begin{array}{l}.08 \\
(.06)\end{array}$ & 1.27 & $\begin{array}{c}.21 \\
{[-.04, .20]}\end{array}$ \\
\hline \multirow[t]{3}{*}{ Gender } & $\begin{array}{l}.00 \\
(.07)\end{array}$ & .00 & {$\left[\begin{array}{c}1 \\
{[-.13} \\
.13\end{array}\right]$} & $\begin{array}{l}.16 \\
(.06)\end{array}$ & 2.6 & $\begin{array}{c}.01 \\
{[.04, .29]}\end{array}$ & $\begin{array}{l}.00 \\
(.07)\end{array}$ & -.07 & $\begin{array}{c}.94 \\
{[-.13, .12]}\end{array}$ & $\begin{array}{l}.06 \\
(.06)\end{array}$ & .9 & {$\left[\begin{array}{c}.37 \\
{[-.07, .18]}\end{array}\right.$} \\
\hline & \multicolumn{3}{|c|}{ Media usage } & \multicolumn{3}{|c|}{ Negative mood } & \multicolumn{3}{|c|}{ Physical exercise } & \multicolumn{3}{|c|}{ Sleep hours } \\
\hline & $\begin{array}{c}\beta \\
\text { (SE) }\end{array}$ & $\begin{array}{c}t \\
\text { value }\end{array}$ & $\begin{array}{c}\text { p value } \\
{[95 \% \mathrm{Cl}]}\end{array}$ & $\stackrel{\beta}{\beta}$ & $\begin{array}{c}\mathbf{t} \\
\text { value }\end{array}$ & $\begin{array}{c}\text { p value } \\
{[95 \% \mathrm{Cl}]}\end{array}$ & $\begin{array}{c}\beta \\
\text { (SE) }\end{array}$ & $\begin{array}{c}\mathbf{t} \\
\text { value }\end{array}$ & $\begin{array}{c}\text { p value } \\
{[95 \% \mathrm{Cl}]}\end{array}$ & $\underset{\text { (SE) }}{\beta}$ & $\begin{array}{c}t \\
\text { value }\end{array}$ & $\begin{array}{c}\text { p value } \\
{[95 \% \mathrm{Cl}]}\end{array}$ \\
\hline Intercept & $\begin{array}{l}.01 \\
(.06)\end{array}$ & 11 & $\begin{array}{c}.91 \\
{[-.11, .13]}\end{array}$ & $\begin{array}{c}.01 \\
(.03)\end{array}$ & .22 & $\begin{array}{c}.82 \\
{[.06, .08]}\end{array}$ & $\begin{array}{l}.03 \\
(.07)\end{array}$ & .49 & $\begin{array}{c}.62 \\
{[-.10, .16]}\end{array}$ & $\begin{array}{l}-.01 \\
(.07)\end{array}$ & -.09 & $\begin{array}{c}.93 \\
{[-.14, .13]}\end{array}$ \\
\hline $\begin{array}{l}\text { Mindset } \\
\text { stress }\end{array}$ & $\begin{array}{c}.02 \\
(.07)\end{array}$ & .32 & $\begin{array}{c}.75 \\
{[-.11, .15]}\end{array}$ & $\begin{array}{l}-.08 \\
(.04)\end{array}$ & -2.23 & $\begin{array}{c}.03 \\
{[-.16,-.01]}\end{array}$ & $\begin{array}{c}.07 \\
(.07)\end{array}$ & 1.02 & $\begin{array}{c}.31 \\
{[-.07, .21]}\end{array}$ & $\begin{array}{l}-.07 \\
(.07)\end{array}$ & -.92 & $\begin{array}{c}.36 \\
{[-.21, .08]}\end{array}$ \\
\hline $\begin{array}{l}\text { Mindset } \\
\text { pandemic }\end{array}$ & $\begin{array}{l}.13 \\
(.06)\end{array}$ & 2.07 & $\begin{array}{c}.04 \\
{[.01, .26]}\end{array}$ & $\begin{array}{l}-.04 \\
(.04)\end{array}$ & -1.11 & $\begin{array}{c}.27 \\
{[-.12, .03]}\end{array}$ & $\begin{array}{l}-.04 \\
(.07)\end{array}$ & 62 & $\begin{array}{c}.54 \\
{[-.18, .10]}\end{array}$ & $\begin{array}{l}-.30 \\
(.07)\end{array}$ & -4.17 & $\begin{array}{c}<.001^{* * *} \\
{[-.44,-.16]}\end{array}$ \\
\hline$A D$ & $\begin{array}{l}.08 \\
(.08)\end{array}$ & .93 & $\begin{array}{c}.35 \\
{[-.09, .25]}\end{array}$ & $\begin{array}{c}.31 \\
(.05)\end{array}$ & 6.49 & $\begin{array}{c}<.001^{* * *} \\
{[.22, .41]}\end{array}$ & $\begin{array}{l}-.19 \\
(.09)\end{array}$ & -2.06 & $\begin{array}{c}.04 \\
{[-.37,-.01]}\end{array}$ & $\begin{array}{c}.03 \\
(.09)\end{array}$ & .33 & $\begin{array}{c}.74 \\
{[-.15, .22]}\end{array}$ \\
\hline CIT & $\begin{array}{c}.20 \\
(.08)\end{array}$ & 2.58 & $\begin{array}{c}.01^{*} \\
{[.05, .35]}\end{array}$ & $\begin{array}{c}.49 \\
(.044)\end{array}$ & 11.11 & $\begin{array}{l}<.001^{* * *} \\
{[.40, .57]}\end{array}$ & $\begin{array}{c}.18 \\
(.08)\end{array}$ & 2.16 & $\begin{array}{c}.03^{*} \\
{[.02, .34]}\end{array}$ & $\begin{array}{l}-.10 \\
(.08)\end{array}$ & -1.19 & $\begin{array}{c}.24 \\
{[-.27, .07]}\end{array}$ \\
\hline SW & $\begin{array}{c}.06 \\
(.08)\end{array}$ & .76 & $\begin{array}{c}.45 \\
{[-.10, .22]}\end{array}$ & $\begin{array}{c}.24 \\
(.05)\end{array}$ & 5.17 & $\begin{array}{l}<.001^{* * *} \\
{[.15, .33]}\end{array}$ & $\begin{array}{l}-.13 \\
(.09)\end{array}$ & -1.47 & $\begin{array}{c}.14 \\
{[-.30, .04]}\end{array}$ & $\begin{array}{l}-.10 \\
(.09)\end{array}$ & -1.11 & $\begin{array}{c}.27 \\
{[-.28, .08]}\end{array}$ \\
\hline Age & $\begin{array}{c}.10 \\
(.06)\end{array}$ & 1.62 & $\begin{array}{c}.11 \\
{[-.02, .23]}\end{array}$ & $\begin{array}{l}-.01 \\
(.04)\end{array}$ & -.21 & $\begin{array}{c}.83 \\
{[-.08, .06]}\end{array}$ & $\begin{array}{c}.09 \\
(.07)\end{array}$ & 1.36 & $\begin{array}{c}.17 \\
{[-.04, .23]}\end{array}$ & $\begin{array}{c}.00 \\
(.07)\end{array}$ & .04 & $\begin{array}{c}.97 \\
{[-.14, .14]}\end{array}$ \\
\hline Gender & $\begin{array}{l}-.06 \\
(.06)\end{array}$ & -.94 & $\begin{array}{c}.35 \\
{[-.18, .06]}\end{array}$ & $\begin{array}{c}.07 \\
(.04)\end{array}$ & 1.94 & $\begin{array}{c}.05 \\
{[.00, .14]}\end{array}$ & $\begin{array}{c}.03 \\
(.07)\end{array}$ & .44 & $\begin{array}{c}.66 \\
{[-.10, .16]}\end{array}$ & $\begin{array}{c}.00 \\
(.07)\end{array}$ & -.05 & $\begin{array}{c}.96 \\
{[-.14, .13]}\end{array}$ \\
\hline
\end{tabular}




\begin{tabular}{|c|c|c|c|c|c|c|}
\hline & \multicolumn{3}{|c|}{ Sleep time } & \multicolumn{3}{|c|}{ Stress life changes } \\
\hline & $\begin{array}{c}\beta \\
\text { (SE) }\end{array}$ & $\begin{array}{c}\mathbf{t} \\
\text { value }\end{array}$ & $\begin{array}{c}\text { p value } \\
{[95 \% \mathrm{Cl}]}\end{array}$ & $\begin{array}{c}\beta \\
\text { (SE) }\end{array}$ & $\begin{array}{c}\mathbf{t} \\
\text { value }\end{array}$ & $\begin{array}{c}\text { p value } \\
{[95 \% \mathrm{Cl}]}\end{array}$ \\
\hline Intercept & $\begin{array}{c}.03 \\
(.07)\end{array}$ & .4 & $\begin{array}{c}.69 \\
{[-.11, .16]}\end{array}$ & $\begin{array}{l}-.04 \\
(.06)\end{array}$ & -.73 & $\stackrel{.47}{[-.15, .07]}$ \\
\hline $\begin{array}{l}\text { Mindset } \\
\text { stress }\end{array}$ & $\begin{array}{l}-.05 \\
(.07)\end{array}$ & -.74 & $\begin{array}{c}.46 \\
{[-.20, .09]}\end{array}$ & $\begin{array}{l}.02 \\
(.06)\end{array}$ & .36 & $\begin{array}{c}.72 \\
{[-.10, .14]}\end{array}$ \\
\hline $\begin{array}{l}\text { Mindset } \\
\text { pandemic }\end{array}$ & $\begin{array}{c}.04 \\
(.07)\end{array}$ & .61 & $\begin{array}{c}.55 \\
{[-.10, .19]}\end{array}$ & $\begin{array}{l}.05 \\
(.06)\end{array}$ & .87 & $\begin{array}{c}.39 \\
{[-.07, .17]}\end{array}$ \\
\hline$A D$ & $\begin{array}{c}.20 \\
(.09)\end{array}$ & 2.13 & $\begin{array}{c}.03 \\
{[.02, .39]}\end{array}$ & $\begin{array}{l}-.04 \\
(.08)\end{array}$ & -.57 & $\begin{array}{c}.57 \\
{[-.20, .11]}\end{array}$ \\
\hline $\mathrm{CIT}$ & $\begin{array}{c}.14 \\
(.09)\end{array}$ & 1.68 & $\begin{array}{c}.09 \\
{[-.03, .31]}\end{array}$ & $\begin{array}{l}.36 \\
(.07)\end{array}$ & 5.04 & $\begin{array}{c}<.001^{* * *} \\
{[.22, .50]}\end{array}$ \\
\hline SW & $\begin{array}{l}-.08 \\
(.09)\end{array}$ & -.89 & {$\left[\begin{array}{c}.37 \\
{[-.26, .10]}\end{array}\right.$} & $\begin{array}{l}.08 \\
(.07)\end{array}$ & 1.05 & {$[-.07, .23]$} \\
\hline Age & $\begin{array}{l}.11 \\
(.07)\end{array}$ & 1.49 & {$[-.14$} & $\begin{array}{l}.12 \\
(.06)\end{array}$ & 2.13 & $\begin{array}{c}.03 \\
{[.01, .24]}\end{array}$ \\
\hline Gender & $\begin{array}{l}-.13 \\
(.07)\end{array}$ & -1.82 & $\begin{array}{c}.07 \\
{[-.27, .01]}\end{array}$ & $\begin{array}{l}-.07 \\
(.06)\end{array}$ & -1.25 & $\begin{array}{c}.21 \\
{[-.19, .04]}\end{array}$ \\
\hline
\end{tabular}

AD, Anxious-Depression; CIT, Compulsive behavior and Intrusive Thought; SW, Social Withdrawal; SE, Standard Error. Uncorrected $p$ values are shown in the table. The main text reports $p$ values FDR-corrected over the number of dependent variables $(N=10)$, asterisks denote FDR-corrected significance $* p<.05, * * p<.01, * * * p<.001$ 
Supplementary Table 7. Prospective predictions. Ridge regression using pre-onset COVID-19 factor scores to predict individual psychiatric symptoms.

\begin{tabular}{|c|c|c|c|c|c|c|c|c|c|c|}
\hline & & Apathy & Schizotypy & $\begin{array}{c}\text { Social } \\
\text { Anxiety }\end{array}$ & $\begin{array}{l}\text { Eating } \\
\text { Disorder }\end{array}$ & $\begin{array}{l}\text { Alcohol } \\
\text { disorder }\end{array}$ & Anxiety & Depression & Impulsivity & OCD \\
\hline \multirow{2}{*}{$\begin{array}{l}\text { Tasks Factor } \\
\text { Scores }\end{array}$} & $\mathrm{R}^{2}$ & $\begin{array}{c}-0.6 \\
(0.01)\end{array}$ & $\begin{array}{l}-0.05 \\
(0.02)\end{array}$ & $\begin{array}{l}-0.09 \\
(0.01)\end{array}$ & $\begin{array}{l}-0.05 \\
(0.02)\end{array}$ & $\begin{array}{l}-0.07 \\
(0.02)\end{array}$ & $\begin{array}{l}-0.08 \\
(0.0)\end{array}$ & $\begin{array}{l}-0.07 \\
(0.01)\end{array}$ & $\begin{array}{l}-0.09 \\
(0.0)\end{array}$ & $\begin{array}{r}-0.11 \\
(0.0)\end{array}$ \\
\hline & MAE & $\begin{array}{c}0.84 \\
(0.82)\end{array}$ & $\begin{array}{c}0.8 \\
(0.77)\end{array}$ & $\begin{array}{c}0.86 \\
(0.82)\end{array}$ & $\begin{array}{c}0.8 \\
(0.77)\end{array}$ & $\begin{array}{c}0.87 \\
(0.84)\end{array}$ & $\begin{array}{c}0.85 \\
(0.82)\end{array}$ & $\begin{array}{c}0.9 \\
(0.87)\end{array}$ & $\begin{array}{c}0.78 \\
(0.76)\end{array}$ & $\begin{array}{l}0.85 \\
(0.8)\end{array}$ \\
\hline \multirow{2}{*}{$\begin{array}{l}\text { Survey Factor } \\
\text { Scores }\end{array}$} & $\mathrm{R}^{2}$ & $\begin{array}{l}0.33 \\
(0.4)\end{array}$ & $\begin{array}{c}0.35 \\
(0.45)\end{array}$ & $\begin{array}{c}0.34 \\
(0.44)\end{array}$ & $\begin{array}{c}0.12 \\
(0.24)\end{array}$ & $\begin{array}{l}-0.09 \\
(0.07)\end{array}$ & $\begin{array}{c}0.54 \\
(0.61)\end{array}$ & $\begin{array}{c}0.31 \\
(0.42)\end{array}$ & $\begin{array}{c}0.48 \\
(0.57)\end{array}$ & $\begin{array}{c}0.26 \\
(0.38)\end{array}$ \\
\hline & MAE & $\begin{array}{c}0.65 \\
(0.61)\end{array}$ & $\begin{array}{c}0.58 \\
(0.53)\end{array}$ & $\begin{array}{l}0.65 \\
(0.6)\end{array}$ & $\begin{array}{c}0.71 \\
(0.67)\end{array}$ & $\begin{array}{c}0.88 \\
(0.82)\end{array}$ & $\begin{array}{c}0.52 \\
(0.49)\end{array}$ & $\begin{array}{c}0.69 \\
(0.63)\end{array}$ & $\begin{array}{c}0.56 \\
(0.51)\end{array}$ & $\begin{array}{c}0.7 \\
(0.64)\end{array}$ \\
\hline
\end{tabular}

Insample score is displayed in parenthesis

Supplementary Table 8. Prospective predictions. Ridge regression using pre-onset COVID-19 factor scores to predict transdiagnostic dimensions of psychiatry.

\begin{tabular}{|c|c|c|c|c|}
\hline & & $A D$ & CIT & SW \\
\hline \multirow{2}{*}{$\begin{array}{l}\text { Tasks Factor } \\
\text { Scores }\end{array}$} & $\mathrm{R}^{2}$ & $\begin{array}{l}-0.07 \\
(0.01)\end{array}$ & $\begin{array}{l}-0.07 \\
(0.01)\end{array}$ & $\begin{array}{l}-0.07 \\
(0.01)\end{array}$ \\
\hline & MAE & $\begin{array}{l}0.83 \\
(0.8)\end{array}$ & $\begin{array}{l}0.73 \\
(0.7)\end{array}$ & $\begin{array}{c}0.84 \\
(0.81)\end{array}$ \\
\hline \multirow{2}{*}{$\begin{array}{l}\text { Survey Factor } \\
\text { Scores }\end{array}$} & $\mathrm{R}^{2}$ & $\begin{array}{c}0.48 \\
(0.55)\end{array}$ & $\begin{array}{l}0.39 \\
(0.52)\end{array}$ & $\begin{array}{c}0.41 \\
(0.52)\end{array}$ \\
\hline & MAE & $\begin{array}{c}0.56 \\
(0.52)\end{array}$ & $\begin{array}{c}0.52 \\
(0.46)\end{array}$ & $\begin{array}{c}0.58 \\
(0.53)\end{array}$ \\
\hline
\end{tabular}

Insample score is displayed in parenthesis; AD, Anxious-Depression; CIT, Compulsive behavior and Intrusive Thoughts. 
Supplementary Table 9. Cross-sectional predictions. Ridge regression using post-onset COVID-19 factor scores to predict individual psychiatric symptoms.

\begin{tabular}{|c|c|c|c|c|c|c|c|c|c|c|}
\hline & & Apathy & Schizotypy & $\begin{array}{c}\text { Social } \\
\text { Anxiety }\end{array}$ & $\begin{array}{c}\text { Eating } \\
\text { Disorder }\end{array}$ & $\begin{array}{c}\text { Alcohol } \\
\text { disorder }\end{array}$ & Anxiety & Depression & Impulsivity & OCD \\
\hline \multirow{2}{*}{$\begin{array}{c}\text { Tasks Factor } \\
\text { Scores }\end{array}$} & $\mathrm{R}^{2}$ & $\begin{array}{c}-0.06 \\
(0.02)\end{array}$ & $\begin{array}{c}-0.05 \\
(0.01)\end{array}$ & $\begin{array}{c}-0.05 \\
(0.03)\end{array}$ & $\begin{array}{c}-0.02 \\
(0.06)\end{array}$ & $\begin{array}{c}-0.04 \\
(0.03)\end{array}$ & $\begin{array}{c}-0.07 \\
(0.01)\end{array}$ & $\begin{array}{c}-0.06 \\
(0.01)\end{array}$ & $\begin{array}{c}-0.09 \\
(0.0)\end{array}$ & $\begin{array}{c}-0.11 \\
(0.01)\end{array}$ \\
\cline { 2 - 10 } & $\mathrm{MAE}$ & $\begin{array}{c}0.85 \\
(0.82)\end{array}$ & $\begin{array}{c}0.79 \\
(0.77)\end{array}$ & $\begin{array}{c}0.83 \\
(0.79)\end{array}$ & $\begin{array}{c}0.79 \\
(0.75)\end{array}$ & $\begin{array}{c}0.86 \\
(0.83)\end{array}$ & $\begin{array}{c}0.85 \\
(0.82)\end{array}$ & $\begin{array}{c}0.9 \\
(0.87)\end{array}$ & $\begin{array}{c}0.8 \\
(0.76)\end{array}$ & $\begin{array}{c}0.84 \\
(0.8)\end{array}$ \\
\hline \multirow{2}{*}{$\begin{array}{c}\text { Survey Factor } \\
\text { Scores }\end{array}$} & $\mathrm{R}$ & $\begin{array}{c}0.42 \\
(0.51)\end{array}$ & $\begin{array}{c}0.48 \\
(0.55)\end{array}$ & $\begin{array}{c}0.41 \\
(0.5)\end{array}$ & $\begin{array}{c}0.07 \\
(0.23)\end{array}$ & $\begin{array}{c}-0.13 \\
(0.04)\end{array}$ & $\begin{array}{c}0.64 \\
(0.7)\end{array}$ & $\begin{array}{c}0.45 \\
(0.53)\end{array}$ & $\begin{array}{c}0.52 \\
(0.61)\end{array}$ & $\begin{array}{c}0.3 \\
(0.4)\end{array}$ \\
\cline { 2 - 11 } & $\mathrm{MAE}$ & $\begin{array}{c}0.59 \\
(0.55)\end{array}$ & $\begin{array}{c}0.51 \\
(0.48)\end{array}$ & $\begin{array}{c}0.6 \\
(0.56)\end{array}$ & $\begin{array}{c}0.74 \\
(0.68)\end{array}$ & $\begin{array}{c}0.9 \\
(0.83)\end{array}$ & $\begin{array}{c}0.45 \\
(0.41)\end{array}$ & $\begin{array}{c}0.59 \\
(0.55)\end{array}$ & $\begin{array}{c}0.52 \\
(0.47)\end{array}$ & $\begin{array}{c}0.66 \\
(0.61)\end{array}$ \\
\hline
\end{tabular}

Insample score in parenthesis

Supplementary Table 10. Cross-sectional predictions. Ridge regression using post-onset COVID-19 factor scores to predict to predict transdiagnostic dimensions of psychiatry

\begin{tabular}{|c|c|c|c|c|}
\hline & & $A D$ & CIT & SW \\
\hline \multirow{2}{*}{$\begin{array}{l}\text { Tasks Factor } \\
\text { Scores }\end{array}$} & $R^{2}$ & $\begin{array}{l}-0.07 \\
(0.01)\end{array}$ & $\begin{array}{l}-0.04 \\
(0.02)\end{array}$ & $\begin{array}{l}-0.07 \\
(0.04)\end{array}$ \\
\hline & MAE & $\begin{array}{l}0.83 \\
(0.8)\end{array}$ & $\begin{array}{c}0.71 \\
(0.69)\end{array}$ & $\begin{array}{l}0.83 \\
(0.79)\end{array}$ \\
\hline \multirow{2}{*}{$\begin{array}{l}\text { Survey Factor } \\
\text { Scores }\end{array}$} & $\mathrm{R}^{2}$ & $\begin{array}{c}0.6 \\
(0.66)\end{array}$ & $\begin{array}{c}0.49 \\
(0.57)\end{array}$ & $\begin{array}{l}0.52 \\
(0.6)\end{array}$ \\
\hline & MAE & $\begin{array}{c}0.43 \\
(0.46)\end{array}$ & $\begin{array}{c}0.45 \\
(0.49)\end{array}$ & $\begin{array}{c}0.49 \\
(0.54)\end{array}$ \\
\hline
\end{tabular}

Insample score is displayed in parenthesis; AD, Anxious-Depression; CIT, Compulsive behavior and Intrusive Thoughts. 
Supplementary Table 11. List of cognitive tasks for self-regulation and derived variables

\begin{tabular}{|c|c|}
\hline Task & Derived variables used for Exploratory Factor Analysis \\
\hline Adaptive N-Back & $\begin{array}{ll}\text { - } & \text { DDM Parameters }{ }^{1} \\
\text { - } & \text { Drift Rate as a function of load } \\
\text { - } & \text { Average load } \\
\end{array}$ \\
\hline Angling Risk Task & \begin{tabular}{|l} 
Two Conditions (Keep, Release): \\
- Adjusted Clicks \\
- Coefficient of Variation (release condition) \\
- Score
\end{tabular} \\
\hline Attention Network Task & $\begin{array}{ll}\text { - } & \text { DDM Parameters } \\
\text { - } & \text { Alerting Effect } \\
\text { - } & \text { Orienting Effect } \\
\text { - } & \text { Conflict Effect }\end{array}$ \\
\hline Bickel Titrator & - $\quad$ Discount Rate for three payout magnitudes \\
\hline Choice Reaction Task & - DDM Parameters $^{1}$ \\
\hline Cognitive Reflection Task & $\begin{array}{l}\text { - } \text { Correct Proportion } \\
\text { - Intuitive Proportion }\end{array}$ \\
\hline Columbia Card Task Cold/Hot & $\begin{array}{l}\text { - } \text { Average \# of cards chosen } \\
\text { - Gain Sensitivity } \\
\text { - Loss Sensitivity } \\
\text { - } \text { \# Loss Cards Sensitivity } \\
\text { - Level of Information Use } \\
\end{array}$ \\
\hline Dietary Decision Task & $\begin{array}{ll} & \text { Health Sensitivity } \\
\text { - } & \text { Taste Sensitivity } \\
\end{array}$ \\
\hline Digit Span & $\begin{array}{l}\text { - } \text { Forward Span } \\
\text { - } \text { Reverse Span } \\
\end{array}$ \\
\hline Directed Forgetting & $\begin{array}{ll} & \text { DDM Parameters }{ }^{1} \\
\text { - } & \text { Proactive Interference } \\
\end{array}$ \\
\hline Discount Titrator & - Percent Patient \\
\hline Dot Pattern Expectancy & $\begin{array}{ll}\text { - } & \text { DDM Parameters } 1 \\
\text { - } & \text { AY-BY } \\
\text { - } & \text { BX-BY } \\
\text { - } & \text { D-prime } \\
\text { Bias }\end{array}$ \\
\hline Go-NoGo & $\begin{array}{ll}\text { - } & \text { D-prime } \\
\text { - } & \text { Bias } \\
\end{array}$ \\
\hline Hierarchical Learning Task & - Total Score \\
\hline Holt \& Laury & $\begin{array}{ll}\text { - } & \text { Percent Patient } \\
\text { - } & \text { Beta (inverse softmax temperature) } \\
\text { - Risk Aversion (value function curvature) } \\
\text { - } \text { \# Safe Choices }\end{array}$ \\
\hline Information Sampling Task & $\begin{array}{l}\text { Two conditions (Decreasing Win, Fixed Win): } \\
\text { - Probability Correct at choice } \\
\text { - Motivation }\end{array}$ \\
\hline Keep Track Task & - Score \\
\hline Kirby & $\begin{array}{l}\text { - } \text { Discount Rate for three payout magnitudes } \\
\text { - Percent Patient Choices } \\
\text { - Percent Patient Choices for three payout magnitudes }\end{array}$ \\
\hline Local-Global Task & $\begin{array}{ll}\text { - } & \text { DDM Parameters }{ }^{1} \\
\text { - } & \text { Switch Cost } \\
\text { - } & \text { Conflict Effect } \\
\text { - } & \text { Global Bias } \\
\end{array}$ \\
\hline Motor Selective Stop Signal & $\begin{array}{ll}\text { - } & \text { DDM Parameters } 1 \\
\text { - } & \text { SSRT } \\
\text { - } & \text { Reactive Control } \\
\text { - } & \text { Selective Proactive Control } \\
\text { - } & \text { Proactive Control } \\
\end{array}$ \\
\hline Probabilistic Selection Task & $\begin{array}{ll}\text { - } & \text { Positive Learning Bias } \\
\text { - Value Sensitivity }\end{array}$ \\
\hline Psychological Refractory Period Task & - Slope of PRP function \\
\hline Raven's Progressive Matrices & - Score \\
\hline Recent Probes & $\begin{array}{ll}- & \text { DDM Parameters } \\
\text { - } & \text { Proactive Interference }\end{array}$ \\
\hline
\end{tabular}




\begin{tabular}{|c|c|}
\hline Shape Matching Task & $\begin{array}{ll} & \text { DDM Parameters } \\
\text { - } & \text { Stimulus Interference }\end{array}$ \\
\hline Shift Task & $\begin{array}{cl} & \text { Accuracy } \\
- & \text { Learning Rate } \\
\text { Model parameters: } \\
\text { - } \\
\text { Beta (inverse softmax temperature) } \\
\text { - } & \text { Rttentional Decay learning rate } \\
\end{array}$ \\
\hline Simon Task & $\begin{array}{ll}\text { - } & \text { DDM Parameters } \\
\text { - } & \text { Simon Effect } \\
\end{array}$ \\
\hline Simple Reaction Time & Average Reaction Time \\
\hline Spatial Span & $\begin{array}{ll}\text { - } & \text { Forward Span } \\
\text { - } & \text { Reverse Span }\end{array}$ \\
\hline Stimulus Selective Stop Signal & $\begin{array}{ll} & \text { DDM Parameters } \\
\text { - } & \text { SSRT } \\
\text { - } & \text { Reactive Control } \\
\end{array}$ \\
\hline Stop Signal & $\begin{array}{ll} & \text { DDM Parameters } \\
- & \text { SSRT (low stop signal probability condition) } \\
- & \text { SSRT (high stop signal probability condition) } \\
- & \text { Proactive SSRT speeding } \\
- & \text { Proactive Slowing } \\
\end{array}$ \\
\hline Stroop & $\begin{array}{ll}- & \text { DDM Parameters } \\
\text { - } & \text { Stroop Effect } \\
\end{array}$ \\
\hline Cue/Task-Switch & $\begin{array}{ll}- & \text { DDM Parameters } \\
\text { - } & \text { Stimulus Switch Cost } \\
\text { - } & \text { Task Switch Cost } \\
\end{array}$ \\
\hline Tower of London & $\begin{array}{ll} & \text { Average Move Time } \\
- & \text { \# Extra Moves } \\
\text { - } & \text { \# Optimal Solutions } \\
\text { - } & \text { Planning Time } \\
\end{array}$ \\
\hline Two-step Decision & $\begin{array}{ll}- & \text { Model-Based Index } \\
- & \text { Model-Free Index } \\
- & \text { Perseverance } \\
\end{array}$ \\
\hline Writing Task & $\begin{array}{cl}\text { Sentiment } & \text { Analysis: } \\
\text { • } & \text { Positive Probability } \\
\text { - } & \text { Negative Probability }\end{array}$ \\
\hline
\end{tabular}

${ }^{1}$ DDM Parameters include drift rate, threshold and non-decision time 
Supplementary Table 12. List of surveys for self-regulation and derived variables

\begin{tabular}{|c|c|}
\hline Self-Report Surveys & Derived variables used for Exploratory Factor Analysis \\
\hline BIS-BAS & $\begin{array}{ll}- & \text { BAS Drive } \\
- & \text { BAS Fun-Seeking } \\
- & \text { BAS Reward-Responsiveness } \\
- & \text { BIS }\end{array}$ \\
\hline Brief Self-Control Scale & Self-Control \\
\hline Dickman's Impulsivity Inventory & Functional \\
\hline DOSPERT (EB/RP/RT) & $\begin{array}{ll}- & \text { Ethical } \\
- & \text { Financial } \\
- & \text { Health/Safety } \\
- & \text { Recreational } \\
& \text { Social } \\
\end{array}$ \\
\hline Three-Factor Eating Questionnaire (R18) & $\begin{array}{ll}- & \text { Cognitive Restraint } \\
- & \text { Emotional Eating } \\
- & \text { Uncontrolled Eating }\end{array}$ \\
\hline Emotion Regulation Questionnaire & $\begin{array}{ll}\text { - } & \text { Reappraisal } \\
\text { - } & \text { Suppression } \\
\end{array}$ \\
\hline Five Facet Mindfulness Questionnaire & $\begin{array}{ll}- & \text { Acts with Awareness } \\
\text { - } & \text { Describe } \\
\text { - } & \text { Non judgment } \\
\text { - } & \text { Non reactive } \\
\text { - } & \text { Observe } \\
\end{array}$ \\
\hline Future Time Perspective & Future Time Perspective \\
\hline Grit Scale & Grit \\
\hline Impulsive-Venturesome Survey & $\begin{array}{ll}\text { - } & \text { Venturesomeness } \\
\text { - } & \text { Impulsiveness }\end{array}$ \\
\hline Mindful Attention Awareness Scale & Mindfulness \\
\hline Multidimensional Personality Questionnaire (Control subscale) & Control \\
\hline Selection Optimization Compensation & $\begin{array}{ll}- & \text { Elective Selection } \\
\text { - } & \text { Loss-based Selection } \\
\text { - } & \text { Compensation } \\
\text { - } & \text { Optimization }\end{array}$ \\
\hline Sensation Seeking Survey & $\begin{array}{ll}- & \text { Boredom Susceptibility } \\
\text { - } & \text { Disinhibition } \\
\text { - } & \text { Experience Seeking } \\
\text { - } & \text { Thrill/Adventure Seeking } \\
\end{array}$ \\
\hline Short Self-Regulation Survey & Control \\
\hline Ten Item Personality Questionnaire & $\begin{array}{ll}- & \text { Agreeableness } \\
- & \text { Conscientiousness } \\
- & \text { Emotional Stability } \\
\text { - } & \text { Extraversion } \\
\text { - } & \text { Openness } \\
\end{array}$ \\
\hline Theories of Willpower & Endorse Limited Resource \\
\hline Time Perspective Survey & $\begin{array}{ll}- & \text { Past Positive } \\
\text { - } & \text { Past Negative } \\
\text { - } & \text { Present Hedonistic } \\
\text { - } & \text { Present Fatalistic } \\
\text { - } & \text { Future } \\
\end{array}$ \\
\hline UPPS+P & $\begin{array}{ll}\text { - } & \text { Lack of Perseverance } \\
- & \text { Lack of Premeditation } \\
\text { - } & \text { Negative urgency } \\
\text { - } & \text { Positive urgency } \\
\text { - } & \text { Sensation seeking }\end{array}$ \\
\hline
\end{tabular}


Supplementary Table 13. List of surveys and items used to derive measures of health risk behavior

\begin{tabular}{|c|c|}
\hline List o & surveys and items used to derive measures of health risk behavior \\
\hline- & Weight \\
\hline- & Education level \\
\hline- & Relationship status \\
\hline- & Divorce count \\
\hline- & Years in relationship \\
\hline- & Number of relationships \\
\hline- & Number of children) \\
\hline- & Household income \\
\hline- & Retirement account \\
\hline- & Rent or Own a house \\
\hline- & Traffic tickets \\
\hline- & Traffic accidents \\
\hline- & Past or current problems with gambling \\
\hline- & Caffeine intake \\
\hline- & Legal troubles \\
\hline- & $\begin{array}{l}\text { Alchol, smoking and drug questionnaire (Questions for alcohol, smoking and drugs were taken from the Alcohol Use } \\
\text { Disorder Identification Test, Cannabis Use Disorder Identification test, and the Drug Abuse Screening test, respectively) }\end{array}$ \\
\hline- & $\begin{array}{l}\text { Kessler psychological distress scale } \\
\text { (items referred to being nervous, hopeless, restless, depressed, feeling worthless, feeling that everything is an effort }\end{array}$ \\
\hline
\end{tabular}

\section{References}

Crum, A. J., Salovey, P., \& Achor, S. (2013). Rethinking stress: the role of mindsets in determining the stress response. Journal of personality and social psychology, 104(4), 716-733.

Eisenberg, I. W., Bissett, P. G., Enkavi, A. Z., Li, J., MacKinnon, D. P., Marsch, L. A., et al. (2019). Uncovering the structure of self-regulation through data-driven ontology discovery. Nature communications, 10(1), 2319.

Katahira, K. (2016). How hierarchical models improve point estimates of model parameters at the individual level. Journal of mathematical psychology, 73, 37-58.

Ratcliff, R., \& Childers, R. (2015). Individual Differences and Fitting Methods for the Two-Choice Diffusion Model of Decision Making. Decision, 2015.

Rouault, M., Seow, T., Gillan, C. M., \& Fleming, S. M. (2018). Psychiatric Symptom Dimensions Are Associated With Dissociable Shifts in Metacognition but Not Task Performance. Biological psychiatry, Translating Biology to Treatment in Schizophrenia, 84(6), 443-451.

Wiecki, T. V., Sofer, I., \& Frank, M. J. (2013). HDDM: Hierarchical Bayesian estimation of the DriftDiffusion Model in Python. Frontiers in neuroinformatics, 7. Frontiers. 